\title{
"I LIKE MY CLASS AND MY CLASS LIKES ME!" \\ LINKS BETWEEN CHILDREN'S PERCEPTIONS OF THEIR CLASSROOM \\ ENVIRONMENT AND SOCIO-EMOTIONAL ADJUSTMENT
}

\author{
A thesis submitted to \\ the Faculty of Graduate Studies and Research \\ in Partial Fulfillment of the requirements for the degree
}

\section{DOCTOR OF PHILOSOPHY}

by

Adrienne J. DeBow

Department of Psychology

Carleton University

Ottawa, Ontario, Canada

December 2008

(C) copyright, 2008 Adrienne J. DeBow 


$\begin{array}{ll}\begin{array}{l}\text { Library and } \\ \text { Archives Canada }\end{array} & \begin{array}{l}\text { Bibliothèque et } \\ \text { Archives Canada }\end{array} \\ \begin{array}{l}\text { Published Heritage } \\ \text { Branch }\end{array} & \begin{array}{l}\text { Direction du } \\ \text { Patrimoine de l'édition }\end{array} \\ \begin{array}{l}\text { 395 Wellington Street } \\ \text { Ottawa ON K1A 0N4 } \\ \text { Canada }\end{array} & \begin{array}{l}\text { 395, rue Wellington } \\ \text { Ottawa ON K1A 0N4 } \\ \text { Canada }\end{array}\end{array}$

Your file Votre référence ISBN: 978-0-494-47459-4 Our file Notre référence ISBN: 978-0-494-47459-4

NOTICE:

The author has granted a nonexclusive license allowing Library and Archives Canada to reproduce, publish, archive, preserve, conserve, communicate to the public by telecommunication or on the Internet, loan, distribute and sell theses worldwide, for commercial or noncommercial purposes, in microform, paper, electronic and/or any other formats.

The author retains copyright ownership and moral rights in this thesis. Neither the thesis nor substantial extracts from it may be printed or otherwise reproduced without the author's permission.
AVIS:

L'auteur a accordé une licence non exclusive permettant à la Bibliothèque et Archives Canada de reproduire, publier, archiver, sauvegarder, conserver, transmettre au public par télécommunication ou par l'Internet, prêter, distribuer et vendre des thèses partout dans le monde, à des fins commerciales ou autres, sur support microforme, papier, électronique et/ou autres formats.

L'auteur conserve la propriété du droit d'auteur et des droits moraux qui protège cette thèse. $\mathrm{Ni}$ la thèse ni des extraits substantiels de celle-ci ne doivent être imprimés ou autrement reproduits sans son autorisation.
In compliance with the Canadian Privacy Act some supporting forms may have been removed from this thesis.

While these forms may be included in the document page count, their removal does not represent any loss of content from the thesis.
Conformément à la loi canadienne sur la protection de la vie privée, quelques formulaires secondaires ont été enlevés de cette thèse.

Bien que ces formulaires aient inclus dans la pagination, il n'y aura aucun contenu manquant.

\section{Canada}




\begin{abstract}
There is a long tradition of research indicating that children who exhibit shy and aggressive behaviors at school are at risk for social, emotional, and academic difficulties. However, closer inspection of the adjustment of these "high risk" children reveals substantial heterogeneity in their adjustment. Missing from most attempts to explain children's multi-dimensional social adjustment is consideration of the school environment. Yet, modern models of development emphasize that development is a product of dynamic interactions between multiple levels within the child and their environment. Thus, a first step in raising empirical research efforts to match the sophistication of developmental theory is examining the extent to which the relation between individual child behavioral vulnerabilities and adjustment outcomes may be moderated by the quality of classroom environments children encounter as they progress through school. Guided by a child-by-environment model, the current dissertation research focused on the role of classrooms factors (i.e., self-reported classroom perceptions) as moderators of the multi-dimensional social adjustment of behaviourally "at risk" (e.g., shy \& aggressive) children. The current research expanded upon the previous classroom perception literature to explore the nature of the associations between classroom perceptions and socio-emotional functioning. In two separate studies, the association between classroom perceptions and socio-emotional functioning was explored. In studies 1 and 2, participants were $N=328$ and $N=297$ children in Grades 3 to 5 , who completed self-report measures of classroom perception and indices of socioemotional functioning (i.e., loneliness, peer victimization). Examination of the factor structure and psychometric properties indicated a 3-factor structure of classroom
\end{abstract}


perceptions including teacher characteristics, student characteristics, and personal characteristics. Results from both studies suggest that classroom perceptions were significantly related to socio-emotional functioning overall. Further, results provided some preliminary evidence for the moderating role of classroom perceptions among shy and aggressive children. Findings in the current dissertation research are particularly meaningful as they provide preliminary evidence for the significant role of classroom perceptions in the prediction of socio-emotional functioning for elementary school children. 


\section{Acknowledgements}

First and foremost, I would like to thank my supervisor Dr. Robert Coplan for all of his guidance and assistance in completing this doctoral dissertation. Dr. Coplan provides endless opportunities to each of his students whether it be teaching, research, conferences, or publishing. With this extra commitment to his students, Dr. Coplan encourages each of us to achieve our best. I would also like to offer my sincere gratitude to my husband, Lucas Matheson, for all of his unconditional support through this process. Lucas is always the first to celebrate with my successes and my strongest supporter when challenges arise. I would also like to thank my parents, Gerald and Shirley DeBow, for all of their help throughout my studies. In particular, I would like to thank my Mom for all her help with data collection. I would also like to acknowledge my lab-mates, with a special thanks to Kimberley Arbeau. Kim has been a very patient friend, counselor, and stats consultant to me over the last four years.

I would like to acknowledge Wendy Fox, and all of the principals, teachers, and parents at the Lethbridge School Board District 51 in Lethbridge, Alberta. I am a graduate from this school board, and it was an honour to have the opportunity to conduct this research in my former elementary school. I would also like to also offer my sincere thanks to all of the children that participated in this research. The time and attention that each of the students paid to completing the questionnaires is greatly appreciated.

Due to the focus on early school experiences, I would like to dedicate my dissertation to my nephew, Noah DeBow. Noah currently attends Grade 4 at General Stewart Elementary School and has been instrumental in guiding this research by sharing his thoughts, ideas, feelings, friendships, and experiences at school. 


\section{Table of Contents}

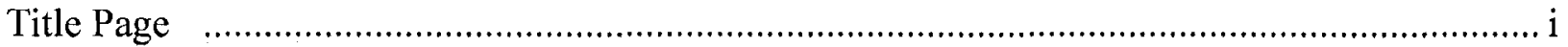

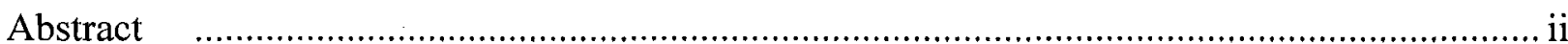

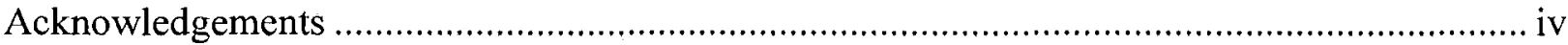

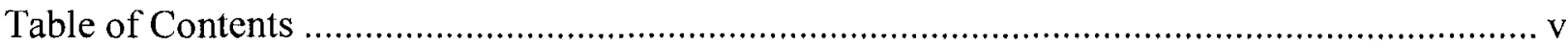

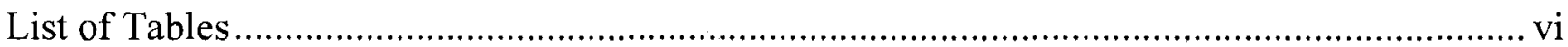

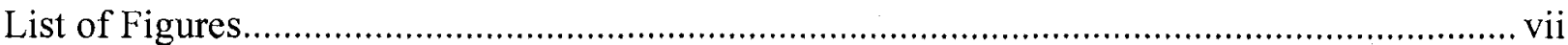

List of Appendices,........................................................................................................... viii

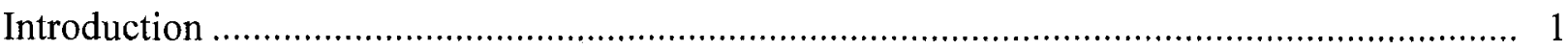

Study 1

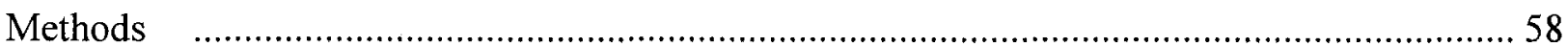

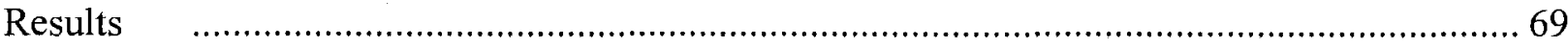

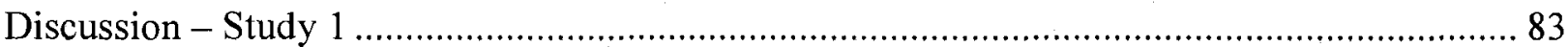

Study 2

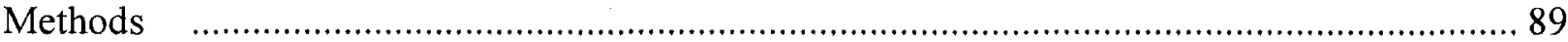

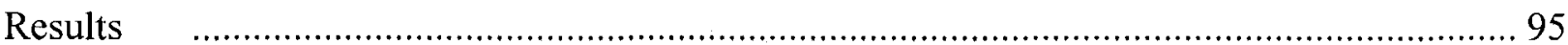

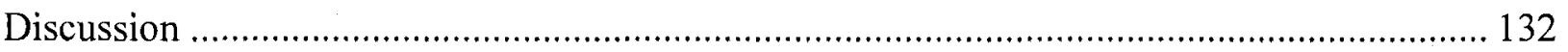

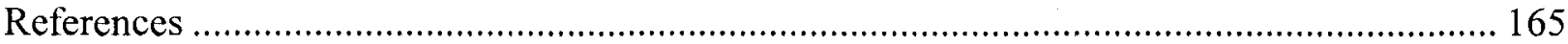

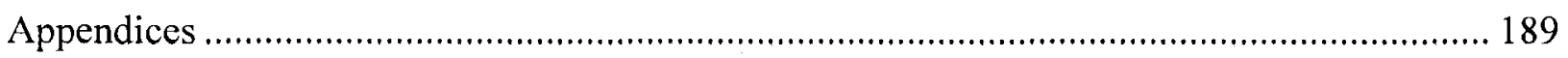




\section{List of Tables}

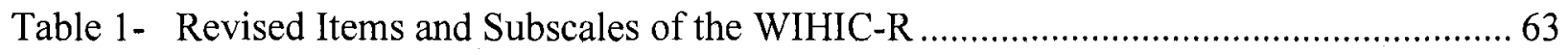

Table 2 - Table of Means, $S D$, and Range for the WIHIC-R Items....................................6 65

Table 3 - Means, SD, and Range for All Study Variables................................................. 71

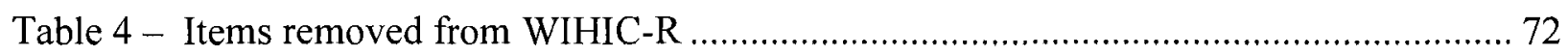

Table 5 - Factor Loadings on WIHIC-R Items......................................................... 74

Table 6 - Intercorrelations between all Study Variables ................................................... 77

Table 7 - Hierarchical Regression Analyses predicting Social Adjustment outcomes from Gender and Subscale Perception Scores................................................ 80

Table 8 - Intercorrelations between Subscale Perception scores, Behavioural Characteristics, \& Outcome Variables ....................................................... 101

Table 9 - Means, $S D$, and Range for All Study Variables ............................................. 102

Table 10 - Hierarchical Regression Analyses predicting Social Adjustment outcomes from Gender and Subscale Perception Scores................................................. 107

Table 11 - Hierarchical Regression Analyses predicting Perception Scores from Behavioural Characteristics..................................................................... 116

Table 12 - Hierarchical Regression Analyses predicting Self-Concept- Peers from Perception Scores and Behavioural Characteristics. 


\section{List of Figures}

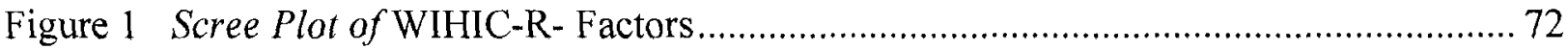

Figure 2 Confirmatory Factor Analysis - Factor Structure .............................................. 98

Figure 3 Shyness x Perception Interaction Predicting Depressive Symptoms..................... 122

Figure 4 Aggression x Perception Interaction Predicting School Avoidance ....................... 124 


\section{List of Appendices}

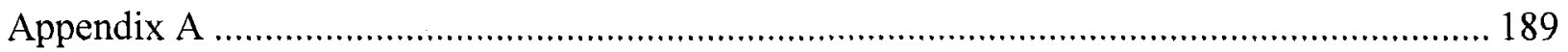

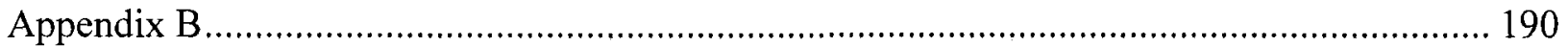

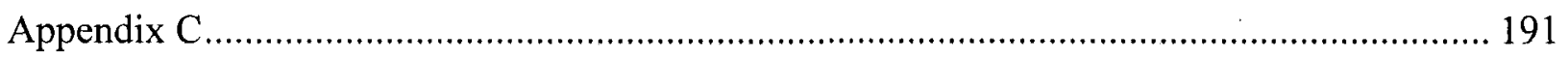

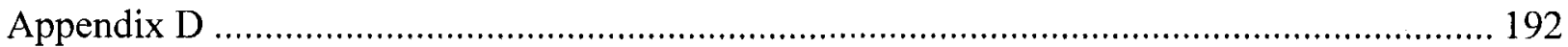

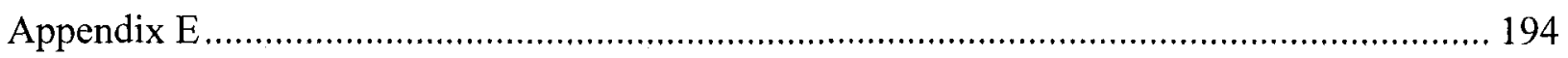

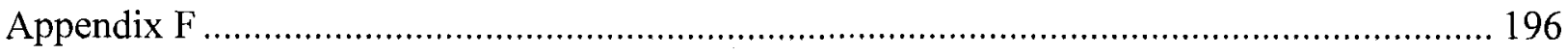

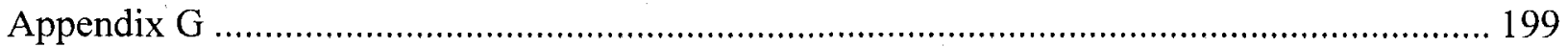

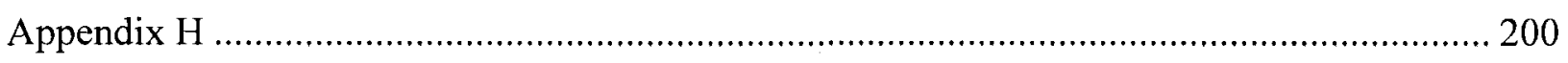

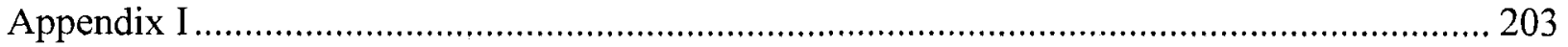

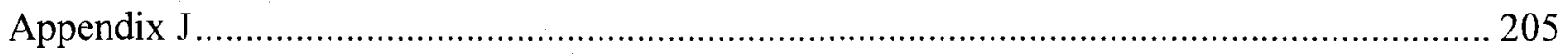

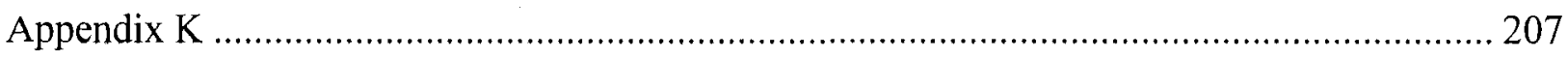

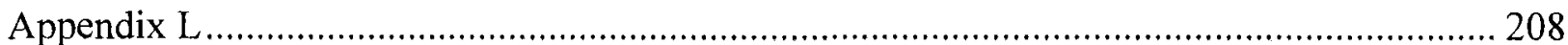


"I like My Class and My Class Likes Me!" Links between Children's Perceptions of their Classroom Environment and Socio-Emotional Adjustment

Our mission is to empower students with the knowledge, skills, and attributes to succeed as caring, responsible, and effective Canadian citizens. Lethbridge School District No 51.,Alberta, Canada (www.lethsd.ab.ca).

Traditionally, the primary purpose of educational institutions has been to provide children with academic knowledge allowing them to go on to become contributing adults in the workforce. However, the role of the school has changed dramatically over the years. The school board mission statement presented above clearly indicates that its role is no longer limited to only providing students with a formal academic education. Inherent in this statement is a responsibility to also provide children with the tools that allow them to successfully function in their social world as well. Schools have become a place where children learn to interact, socialize, communicate, and compromise with their peers.

The changing role of the school reflects a similar shift that has occurred in the field of developmental psychology and educational research. Historically, developmental researchers have focused on child-characteristics or traits as the primary predictor to later adjustment outcomes (Gazelle, 2006; Parker \& Asher, 1987; Rubin, Bukowski, \& Parker, 2006). However, within the last few decades, developmental research has broadened to include the social context as a meaningful environmental variable contributing to the development of social and academic outcomes for young children (e.g., Gazelle \& Rudolph, 2004; Urdan \& Schoenfelder, 2006). Children spend a large majority of their time at school and with their friends. Therefore, researchers can focus on the dynamics within these social contexts in order to assess the differential effects of various experiences on the trajectory of both positive and negative adjustment outcomes. For 
example, a substantial amount of research has been focused on school-related variables including teacher-child relationships (e.g., Kon- tos \& Wilcox-Herzog, 1997; Kostelnik, Stein, \& Whiren, 1988; La Paro, Pianta, \& Stuhlman, 2004; Pianta, 1999), friendships (e.g., Brendgen, Bowen, Rondeau, \& Vitaro, 1999; Hartup, 1998; Miell \& MacDonald, 2000; Zajac \& Hartup, 1997), and bullying (e.g., Buhs and Ladd, 2001; Juvonen, Nishina, \& Graham, 2000; Kochenderfer \& Ladd 1996; Schwartz, Gorman, Nakamoto, \& Toblin, 2005).

Consistent with the research exploring school experiences on adjustment outcomes, a more recent body of research focusing on the overall functioning of the class has begun to emerge. This more comprehensive approach to the predictive role of the school context includes the interactions between all of the variables listed above. Classroom environment is referred to as the "global classroom atmosphere and the degree to which the classroom as a whole functions smoothly and harmoniously and is characterized by interactions with a positive tone or, conversely, by frequent disruption, conflict, and disorganization" (Gazelle, 2006, p. 1180). Empirical links between overall classroom environment and academic outcomes (e.g., reading and language abilities) and social adjustment outcomes (e.g., aggressive behaviours) have been consistently demonstrated (Boivin, Dodge, \& Coie, 1995; Stormshak, Bierman, Bruschi, Dodge, \& Coie, 1999; Werthamer-Larsson, Kellam, \& Wheeler, 1991; Wright, Giammarino, \& Parad, 1986). Many classroom environment studies employ observational methods in order to obtain an overall measure of the classroom environment. Although observations are clearly useful in obtaining an objective measure of global classroom functioning, the question remains as to how the individual children themselves perceive their classroom experiences. 
Further, does the way in which a child perceives their classroom experience predict later adjustment outcomes? Drawing upon a social-cognitive perspective, the primary goal of the proposed dissertation research was to explore relations between children's perceptions of classroom environment and socio-emotional adjustment outcomes.

The current classroom perception literature is also lacking in the investigation of behavioural subgroups of children. For example, it is widely reported in the socialcognitive literature that aggressive and shy children interpret their social environments differently than less-aggressive and less shy children (Dodge \& Price, 1994; Rubin \& Krasor, 1986). Aggressive children are more likely to attribute hostility to social situations whereas shy children are more likely to interpret their experiences in a more fearful manner. Moreover, aggressive and shy children are at an increased risk of experiencing adjustment difficulties. It is therefore argued that classroom environment may play a particularly important role for children already at risk for psychosocial maladjustment, (Gazelle, 2006). Thus, a secondary goal of this dissertation research was to explore the moderating role of perceptions of classroom environment in the adjustment of shy and aggressive children.

\section{Theoretical Models of Social Adjustment}

Heterogeneity in the trajectories of adjustment difficulties has led to the investigation of potential influences of early childhood experiences. It has been consistently found that certain behavioural characteristics place children at a higher risk of experiencing adjustment difficulties (Gazelle; 2006; Parker \& Asher, 1987; Rubin et al., 2006). For example, aggressive, shy, and hyperactive children are more likely to experience peer rejection, victimization, loneliness, and depressive symptoms (e.g., Coie, 
Dodge, Kupersmidt, 1990; Gazelle, 2006; Gazelle \& Ladd, 2003; Hymel, Rubin, Rowden, \& LeMare, 1990; Morison \& Masten, 1991; Rubin, Chen, McDougall, Bowker, et al., 1995; Rubin, Coplan, \& Bowker, 2009. Rubin \& Mills, 1998). However, upon further investigation it is also found that not all of these children experience difficulties (Cillessen, Van Ijzendoorn, Van Lieshout, \& Hartup, 1992; Gazelle, 2006; Gazelle \& Ladd, 2003; Gazelle \& Rudolph, 2004). Thus, some "at-risk" children are able to somehow avoid experiencing these difficulties, which in turn suggests that there may be additional contributing factors. Therefore, a meaningful question that should be addressed in the literature is why do some "at-risk" children experience difficulties whereas others do not?

In order to answer this question, investigators have assessed numerous early childhood factors that act as potential protective factors to peer adversity and academic success in early and middle childhood (e.g., Early, Bryant, Pianta, Clifford, Burchinal et al., 2006; Gazelle \& Rudolph, 2004). Protective factors can be described as variables that may buffer individuals from negative outcomes (Birch \& Ladd, 1997). For example, friendship quality (Rubin, Wojslawowicz, Rose-Krasnor, Booth-LaForce, \& Burgess, 2006), teacher-child relationships (Howes, 2000; Pianta, 1999; Urdan \& Shoenfelder, 2006), family factors (Coplan, Arbeau, \& Armer, 2008; Rubin, Burgess, \& Hastings, 2002; Rubin, Cheah, \& Fox, 2001), and levels of social skills (Coie, Dodge, \& Coppotelli, 1982; Dodge, Coie, \& Brakke, 1982; Rubin \& Daniels-Bierness, 1983) have been linked to the heterogeneity in adjustment outcomes. A portion of the current study explored the role of classroom perception among subgroups of children including those 
characterized as aggressive or shy. A review of some of the theoretical frameworks within which social adjustment has been assessed will now be presented.

Social Skills Model. Historically, research exploring child individual differences has assessed the relation between specific child characteristics and outcomes such as peer adversity and academic achievement (Coie, Dodge, \& Kupersmidt, 1990; Newcomb, Bukowski, \& Pattee, 1993; Parker \& Asher, 1987). Levels of aggression, social skills deficits, and social interaction styles are often used as child-characteristic variables linked to adjustment difficulties (e.g., Coplan \& Armer, 2007; Perren, von Wyl, Stadelmann, Burgin, von Klitzing, 2006). For example, a large portion of the research in the area of peer relations has focused on the association between children's levels of aggression as predicting adjustment difficulty at school (Battistich, Solomon, Kim, Watson, \& Schaps, 1995; Coie, Dodge, \& Kupersmidt, 1995; Dishion, Spracklen, Andrews, \& Patterson, 1996). Overall, aggressive children are more likely to be rejected by their peers than non-aggressive children (Boivin, Dodge, \& Coie, 1995; Coie, Dodge, \& Kupersmidt, 1990). In addition to aggression, social-skills deficits and interaction styles are also often assessed as child characteristics or traits that may lead to adversity and subsequently adjustment difficulties in early childhood (Coie et al., 1982).

The social-skills model (Boivin et al., 1995; Stormshak, Bierman, Bruschi, Dodge, \& Coie, 1999) has been widely implemented as a framework under which individual differences have been assessed. This model suggests that child factors (e.g., social skills) are the primary predictors of the level of adjustment and adversity among the peer group (Ladd \& Mize, 1983). For example, it is predicted within the frameworks of the social skills model that behavioural deficiencies lead to lower levels of peer 
preference, whereas behavioural competencies enhance peer preference among a group. Therefore, it would be assumed that a child with poor social skills (e.g., inattentive behaviours) would experience difficulties across contexts (Stormshak et al., 1999). In other words, it is not the environment that is leading to the difficulties rather it is a stable underlying characteristic, such as a social skills deficit, that is resulting in peer adversity. A substantial amount of empirical literature exists to support the social skills model. Associations have been demonstrated between social skills deficits and peer adversity from early childhood through to adolescence (e.g., Gazelle, 2006; Gazelle \& Rudolph, 2004; Gazelle \& Ladd 2003; Hymel, Rubin, Rowden, \& LeMare, 1990; Ladd \& Burgess, 1999; Rodkin, Farmer, Pearl, \& Van-Acker, 2006). Findings suggest that children with poor social skills are more likely to be rejected and have more difficulty interacting in the peer group than children with good social skills (Boivin, et al., 1995; Rubin \& Daniels-Bierness, 1983; Coie, Dodge, \& Coppotelli, 1982; Dodge, Coie, \& Brakke, 1982). In addition, a child with poor social skills is more likely to experience peer rejection in both familiar peer groups and unfamiliar peer groups (Gazelle, Putallaz, Li, Grimes, Kupersmidt, \& Coie, 2005) suggesting the peer rejection is not associated with the context rather it is associated with the deficit in the child's social skills. These findings highlight the relation between a child characteristic and peer adversity even while controlling for social context.

Identifying links between child characteristics (e.g., aggression or social skills) is important as it allows sound program development designed to modify problem behaviours that are linked to adjustment difficulties. There are, however, limitations to this approach. Although some of the variance in adjustment outcomes is accounted for by 
child-specific characteristics, a portion remains unexplained (Stormshak et al., 1999). In other words, although child-characteristics such as those just listed offer some insight into the variance of behavioural outcomes, these factors do not completely explain why differences exist. Indeed, peer outcomes within at risk groups vary significantly; suggesting that there are additional contributing factors beyond child characteristics only. For example, shy ${ }^{1}$ children are socially anxious and often play alone when among familiar playmates (Gazelle, 2006). It has been consistently reported that shy children are at an increased risk of experiencing difficulty in the peer group (e.g., Gazelle et al., 2005; Hymel, et al., 1990; Rubin, et al., 1995; Rubin et al., 2009). However, not all of these children experience problems (Gazelle \& Ladd, 2003). Some shy children seem to avoid peer adversity whereas others do not. These diverse outcomes would suggest that there are perhaps other meaningful variables in addition to a child characteristic, perhaps in the child's social environment, that are contributing to these differences (Gazelle, 2006; Gazelle \& Ladd, 2004).

The current studies assessed the environmental context of the classroom, as an additional predictor of variability in individual differences associated with peer adversity. The person-group similarity theory (described below) incorporates environmental factors, in addition to personal characteristics, for a more comprehensive approach to assessing peer adversity.

Person-Group Similarity Theory. As a result of the limited scope of the social skills model, researchers have broadened their approach to include environmental factors

\footnotetext{
${ }^{1}$ In her research, Gazelle (e.g., 2006) refers to shy, anxious and socially-withdrawn children as "Anxious Solitary". Given the conceptual similarity, and to avoid the confusing use of different terminology, the term "shy" will be used throughout this dissertation
} 
that may explain some of this undetermined variance (Boyce, Frank, Jenson, Kessler, Nelson, Steinberg, and the Mac Arthur Network on Psychopathology and Development, 1998; Howes, 2000; Pianta, Lopez-Hernandez, \& Ferguson, 1997). This approach to research on individual differences stems from findings that suggest that environmental factors play a moderating role in the relationship between peer adversity and adjustment difficulties (Gazelle, 2006). The person-group similarity theory (Boivin, Dodge, \& Coie, 1995; Stormshak et al., 1999) suggests that acceptability and status within a group will vary based on group norms.

For example, Boivin et al. (1995) explored the relation between behavioural correlates of status within a group of boys and the context of the peer group. Aggression measures including reactive aggression (hostile acts displayed in response to a perceived threat or provocation), proactive aggression (non-provoked aversive means of influencing another with the intent to harm and dominate), and rough-and-tumble play were obtained through observations of groups of boys in first and third grade. Subjects were placed in groups which met for 45 minutes during a period of five days. Social preference was determined via sociometric nominations which were obtained by a research assistant following each play group. Based on observations of the play sessions, the group levels of aggression differed significantly. It was found that highly aggressive members were more likely to maintain a positive status in an aggressive group versus a non-aggressive group. Similarly, it was also determined that aggressive boys that were members of a non-aggressive group were more likely to be rejected by their peer group and maintain lower status. These findings suggest that the reaction of the peer group to a 
typically undesirable trait such as aggression will depend upon the social climate of the group.

Continuing to use the example of aggression as a child characteristic that is associated with adjustment difficulties, it is useful to examine the interaction between this child characteristic and outcomes when an environmental variable is also entered into the equation. For example, it is widely reported that aggression is a relatively stable trait through early and middle childhood (Chang, 2003; Kellam, Ling, Merisca, Brown, Hendricks, \& Ialongo, 2000). However, this stability may change when an environmental factor, such as classroom environment, is considered. Kellam, Ling, Merisca, Brown, and Ialongo (1998) investigated the trajectory of aggressive behaviours from the first to sixth grade and also obtained a measure of mean level aggression in the first grade classroom. Findings suggested that aggressive children who were enrolled in highly aggressive first grade classrooms were more likely to continue to be rated as highly aggressive in the sixth grade. However, highly aggressive children in the first grade who were enrolled in a non-aggressive first grade classroom were not as likely to continue to be rated as highly aggressive in the sixth grade. This finding suggests that the trajectory of aggressive behaviours may be moderated by an environmental characteristic such as classroom environment and provides evidence of the importance of including environmental factors in the assessment of peer adversity outcomes.

This is an important point when proposing the use of classroom environment as a predictor variable of social adjustment and peer adversity. The current study assessed the impacts of child characteristics (i.e., shyness and aggression) within the contexts of their classroom environment. By including both child characteristics and environmental 
characteristics, classroom environment can be assessed as a potential moderator of these relationships (Gazelle, 2006).

Role of social context. Social contexts are conceptualized as any type of environment in which humans are required to interact with one another in a social setting (Urdan \& Shoenfelder, 2006). As one can imagine, we are exposed to endless amounts of social contexts throughout our lifetime. In addition to many others, social contexts can include our families, groups of friends, the workplace, and more importantly for the purposes of this study, the classroom or school. Naturally, it is important to study the effects of these various contextual experiences in order to identify potential outcomes that may arise. For example, a child that is raised in a metropolis has a distinctive school experience from a child raised on a farm in a rural area. In terms of the school environment these two children may be exposed to different school policies, class sizes, and teacher level of education. These diverse experiences lead to interesting and important questions regarding individual differences and behavioural outcomes resulting from the unique environmental contexts. The present study incorporated the classroom as a social context that is hypothesized to account for some of the unexplained variance associated with social adjustment outcomes including feelings of loneliness, peer victimization, and school avoidance.

\section{Classroom Environment}

In order to consider the contribution of environmental factors towards the development of peer adversity and adjustment difficulties, investigators must obtain information across different social contexts (Boivin et al., 1995). An example of a social context that is relevant for the present study is classroom environment. Classroom 
environment can be defined as "the global classroom atmosphere and the degree to which the classroom as a whole functions smoothly and harmoniously and is characterized by interactions with a positive tone or, conversely, by frequent disruption, conflict, and disorganization" (Gazelle, 2006, p. 1180). More specifically, classroom environment involves interactions at multiple levels including teacher-child interactions, child-teacherinteractions, child-child interactions, as well as the overall mood in the classroom (Gazelle, 2006; Pianta, Howes, Burchinal Bryant, Clifford, \& Early et al., 2005; Urdan \& Schoenfelder, 2006). Howes (2000) refers to a similar construct entitled socio-emotional classroom climate. These two terms are conceptually similar and are often used interchangeably in the literature. Classroom environment can be understood as falling upon a continuum from positive to negative (Howes, 2000). A positive classroom climate consists of a generally prosocial environment, in which there is little disruptive behaviour, and positive and close-knit interactions between the students and the teacher (Gazelle, 2006). Towards the other end of the continuum, negative classrooms consist of a hostile environment in which disruptive behaviour often occurs, a conflictual relationship between the students and the teacher is apparent, and there is very little occurrence of constructive prosocial peer interaction (Gazelle, 2006). Although the current dissertation focused on the effects of perceived classroom environment, a large amount of literature supports the association between observed classroom environment and adjustment outcomes. Therefore, in order to thoroughly assess perceived classroom environment, it is first important to highlight the influences of observed environmental characteristics in the classroom. As such, the following section explores research related 
to classroom environment as a social context and its role on the trajectory of academic success and social adjustment.

\section{Theoretical Background}

Children are increasingly spending a large majority of their time in the classroom or school context (Meyer, Wardrop, \& Hastings, 1993). Historically, research in the area of school and classroom environment has focused on the relationship between specific child and teacher characteristics within the classroom rather than the global atmosphere of the classroom (e.g., Howes, 2000; Meyer, Wardrop \& Hastings, 1993; NICHD, 2000a, $2000 \mathrm{~b}, 2000 \mathrm{c}, 2000 \mathrm{~d})$. For example, child characteristics such as retention abilities have been linked with academic outcomes (Graue, 1993). In contrast to child characteristics and teacher characteristics, research has also placed emphasis on broad school characteristics, such as the implementation of global school policy (La Paro, \& Pianta, 2000). It is surprising that until relatively recently, the atmosphere of the actual classroom as a global measure was not assessed as a potential predictor of peer adversity or academic achievement. However, in recent years, significant links between observed classroom environment and behavioural outcomes such as peer rejection/acceptance or victimization (Gazelle, 2006), aggression or shyness (Gazelle, 2006; Pianta, La Paro, Payne, Cox, \& Bradley, 2002; Stormshak, et al., 1999) and academic achievement (Burchinal, Peisner-Feinberg, Pianta, \& Howes, 2002; Pianta et al., 2005) have been investigated.

In order to assess classroom environment, various studies have employed observations, teacher reports, peer reports, and self report data in more than one classroom situation (Coie et al., 1990; Newcomb, Bukowski, \& Pattee, 1993). This has 
allowed researchers to explore the similarities and differences of multiple classroom contexts and subsequently assess child behaviours and peer relations within each (Burchinal, Peisner-Feinberg, Pianta, \& Howes, 2002; Gazelle, 2006; Howes, 2000; Urdan \& Schoenfelder, 2006).

Studies that include environmental factors highlight the usefulness of measuring both child-characteristics and environmental characteristics. Although it is widely reported in the literature that classroom environment does in fact predict several adjustment outcomes, some research is also available that challenges these findings. Interestingly, among behavioural subgroups, evidence exists both supporting and challenging the hypothesis that classroom environment plays a moderating role in the trajectory of adjustment difficulties (Coie et al., 1999; Newcomb, Bukowski, \& Pattee, 1993; Stormshak et al., 1999). For example, Stormshak et al., (1999) reported that rejected children were likely to remain rejected even when they changed classroom contexts. This finding suggests that perhaps a child characteristic, such as aggression or hyperactivity, is leading to the rejection regardless of the classroom environment. Therefore, these particular findings provide support for the hypothesis that a child factor is contributing to the peer adversity and not the social context (Coie et al., 1990; Newcomb, Bukowski, \& Pattee, 1993). However, to the contrary it has also been found that $50 \%$ of rejected children show improved peer relationships when placed in a different classroom context (Bukowski \& Newcomb, 1984, Coie \& Kupersmidt, 1983). Therefore, it is clear that evidence exists supporting the contributing role of both child factors and classroom factors in the development of adjustment outcomes. This leads to the hypothesis that perhaps the interaction between a child's characteristics and the 
uniqueness of environmental factors becomes more important when assessed within a social context.

Several studies have assessed the effect of the classroom environment on behaviorural outcomes (Burchinal et al., 2002; Jackson, Barth, Powell, \& Lochman, 2006; Gazelle, 2006; Howes, 2000; Pianta, et al., 2005; Pianta, et al., 2002; Urdan \& Schoenfelder, 2006). To explore additional contributing factors, some researchers have adopted a child-by-environment model, using the classroom as an environmental characteristic in the prediction of peer adversity.

For example, several studies have explored the interaction between aggressive children, social contexts, and adjustment outcomes (Boivin et al., 1995).

In order to assess the relation between classroom environment and adjustment difficulties, various researchers have explored the trajectory of difficulties for children that are at an increased risk of experiencing peer adversity. Gazelle (2006) predicted that shy (i.e., anxious solitary) children in the first grade would experience less peer adversity, peer victimization, and depressive symptoms in a positive classroom environment rather than in a negative classroom environment. Findings suggested that shy children in a positive first grade classroom were significantly less likely to be rejected by their peers, more likely to be accepted by their peers (particularly boys), and less likely to be victimized (particularly girls) than shy children in a negative classroom environment. Findings also suggested that a positive classroom environment may act as a protective factor for shy children (Gazelle, 2006; Gazelle \& Ladd, 2004; Stormshak et al., 1999). Within the framework of the person-group similarity theory, it would be hypothesized 
that shy children would be at an increased risk of peer adversity in classrooms where shy behaviours are perceived as abnormal.

Research results suggest that although child characteristics (e.g., social skills) do account for a portion of the variance associated with peer adversity in the classroom, there remains a significant amount of unexplained variance (e.g., Cillessen, et al., 1992; French, 1990; Gazelle et al., 2005). As a result of this limitation in the classroom environment literature, a shift in the research has occurred moving from specific child characteristics to a child-by-environment model (Gazelle \& Rudolph, 2004; Magnusson, 1988). Within the framework of a child-by-environment model, development occurs as a result of the interaction between child characteristics and environmental characteristics (Gazelle \& Rudolph, 2004). Although we know that child characteristics play an important role in the potential for peer adversity, it may be useful to include the classroom environment as an additional variable to assist in explaining some of the undetermined variance associated with peer adversity (Cairns, Elder, \& Costello, 1996; Magnusson, 1988; Sameroff, 1993).

It is also important to explore the relation between global classroom environment and peer adversity as it has been demonstrated that classrooms do vary significantly from one another (NICHD ECCRN, 2003; Meyers, et al., 1993). Based on extensive observations (full day for 9 days) over two consecutive years, Meyers et al. (1993) reported a wide range of differences in kindergarten classrooms. In addition, this particular study identified a positive association between classroom environment and achievement over the course of the kindergarten year. Results from numerous other studies supported this finding, providing further evidence of a relation between positive 
preschool settings and positive school outcomes (Barnett et al., 1998; Lazar, Darlington, Murray, Royce, \& Snipper, 1982, Campbell \& Ramey, 1994; Ramey \& Ramey, 1999; Schweinhart, Weikart, \& Larner, 1986). Observed differences across classroom settings allow researchers to explore the association between differences in classroom climate (e.g., positive or negative) and the outcomes for both children within the normal range of various behavioural characteristics as well as special populations (e.g., shy or aggressive groups). Within the framework of a child-by-environment model, researchers are now able to assess various questions that include classroom environment as a predictor variable to behavioural outcomes. For example, are shy children that are placed in a negative classroom environment at even more of an increased risk of peer adversity than their shy peers in a positive classroom? Will aggressive children display higher or lower levels of aggression in a classroom with a negative environment than if they were in a classroom with a positive climate?

Literature highlighting the importance of including an environmental characteristic has now been presented. A substantial amount of support exists that emphasizes the importance of including additional environmental characteristics when exploring individual differences in outcomes. A review of the empirical work that explores the association between classroom quality and academic success and social adjustment follows.

Outcomes Linked with Classroom Environment: What the Research Says

A conceptual framework indicating the importance of studying classroom environment has now been presented. It is important at this point to review some of the empirical findings that highlight the association between classroom quality and 
adjustment difficulties. Before a review of empirical findings is presented, a general limitation in the classroom environment literature must first be addressed. Most of the empirical research in the area of classroom quality focuses on kindergarten and prekindergarten classrooms, while neglecting upper-elementary school populations (e.g., Burchinal et al., 2002; Howes, 2000; Mashburn, Hamre, Downer, \& Pianta, 2006; Meyer et al., 1993; Pianta et al., 2002). These studies often link the quality of early childhood settings with both short and long term adjustment difficulties for young children. Although research among early childhood populations is clearly important in order to promote empirically based development of early prevention and intervention programs (e.g., Bryant, Clifford, \& Peisner, 1991), it can be argued that the need for research in older populations is of equal importance.

The present studies focused on classroom quality as an environmental characteristic in upper-elementary school classrooms. This particular age group has been relatively neglected in the previous classroom environment literature. In fact, there are only a handful of studies that assess the relation between classroom environment variables and short/long term behavioural outcomes in elementary to upper-elementary school populations (e.g., Entwisle \& Hayduk, 1982; Gazelle, 2006; Burchinal, Howes, \& Kontos, 2002; Peisner-Feinberg, Burchinal, Clifford, Culkin, Howes, Kagan, et al., 2001; Trickett \& Moos, 1974; Urdan \& Midgley, 2003). It should be noted that among the studies that do exist using an upper-elementary school population, almost all of them assess aspects of classroom environment rather than the overall global quality.

Rationale for including an upper-elementary school sample. There are two primary reasons why an upper-elementary school sample (children in grades three to five) 
was used in the current research. First, upper-elementary school children spend the large majority of their day in a single classroom, with one main teacher, as compared to kindergarten and pre-kindergarten children that usually attend school for half days or only two or three days a week (Meyer et al., 1993). Similarly, older children and adolescents are continuously changing classrooms and teachers throughout the day which also poses measurement difficulties when assessing classroom environment. An upperelementary school sample has a more consistent classroom experience which makes them ideal for assessing global classroom environment.

The second reason for employing older children in the current study is because of the central focus on child perceptions of classroom experiences. In order to validly assess this construct, children must have developed the appropriate cognitive skills allowing them to accurately make this type of self-report (Woolley, 2004). Younger children are likely not as skilled in providing self-reports about their perceptions of their classroom experiences. For example, Piaget's concrete operations stage of cognitive development occurs approximately between the ages of six and twelve years (as cited in Woolley, 2004). During the concrete operational stage, children develop the ability to form mental representations of their social experiences. Once this ability has developed, children then have the opportunity to manipulate these representations and draw conclusions about their social environment. In the present studies, children were asked to report not only their perceptions of their classroom experiences but also their perceptions of themselves in terms of their peer relationships and their abilities in school. Therefore, it was of particular importance in the current investigation that children were old enough to not only read the items on the questionnaire, but also have the cognitive ability to draw from 
their social environment and make conclusions based on their perceptions and interpretations of these experiences.

Finally, it is apparent that a gap clearly exists in the classroom environment literature in terms of the assessment of an upper-elementary school sample. For this reason, it is useful to assess the role of classroom environment in a population that has been understudied.

Overview of empirical work. Although global classroom quality within any age group has only recently received a great deal of research attention, several investigators have begun to focus their attention on the role of this association in the trajectory of adjustment difficulties (e.g., Boivin, et al., 1995; Gazelle, 2006, Gazelle \& Ladd, 2003; Gazelle \& Rudolph, 2004; Hamre \& Pianta, 2001; Howes, 2000; Mashburn et al., 2006; Peisner-Feinberg \& Burchinal, 1997; Peisner-Feinberg et al., 2001; Pianta, et al., 2002; Roeser, Midgley, \& Urdan, 1996; Stipek, Givvin, Salmon, \& MacGyvers, 1998). For example, classroom quality variables have been consistently linked with social and behavioural outcomes such as aggression (Boivin, et al., 1995), shy and anxious behaviours (e.g., Gazelle, 2006, Gazelle \& Ladd, 2003; Gazelle \& Rudolph, 2004), and social competence (e.g., Hamre \& Pianta, 2001; Mashburn et al., 2006; Pianta et al., 2002) as well as academic outcomes including early language, cognition, reading skills, and mathematics abilities (e.g., Howes, 2000; Mashburn et al., 2006; Peisner-Feinberg \& Burchinal, 1997; Peisner-Feinberg et al., 2001; Pianta et al., 2002; Roeser, et al., 1996; Stipek, et al., 1998).

Although the current study focused on an upper-elementary school population, it is still useful to discuss some of the links that have been identified between early 
classroom experiences and adjustment difficulties in preschool and kindergarten classrooms. It is also important to note that a large number of studies assessing classroom environment variables do not assess the global quality of the classroom (Birch \& Ladd, 1997; Howes \& Smith, 1995a, 1995b; Pianta, Steinberg, \& Rollins, 1995). Rather, many studies include factors that are embedded within the global classroom quality. For example, teacher-child relationships are often used as a measure of certain components of classroom environment. Teacher-child relationships have been linked with academic difficulties for children as young as pre-kindergarten (e.g., Pianta et al., 2002; Burchinal et al., 2002; Hamre \& Pianta, 2001). Teacher ratings of the level of closeness with individual children have also been linked with academic outcomes from preschool through to the eighth grade (Hamre \& Pianta, 2001). Although teacher perceptions of teacher-child relationships are not a global measure of classroom environment, it is nonetheless an important contributor to the emotional and instructional tone of the class and as such some of these findings will also be reviewed.

Evidence supports a link between classroom environment and academic outcomes, including reading and mathematic abilities (NICHD ECCRN, 2000), in addition to social-emotional outcomes including variables such as social competence and anxiety (Howes, 2000). An exploration of the links between classroom environment and outcomes follows.

Reading abilities. Pianta et al. (2002) established a relation between the observed overall quality of kindergarten classrooms and subsequent reading competence. Findings suggest that children demonstrated better reading abilities in positive kindergarten classroom environments than in negative environments. Positive classrooms consisted of 
a positive emotional tone, effective classroom management, evaluative feedback, and positive instructional quality. This association remained even when family characteristics (e.g., family income and maternal education) were controlled for suggesting the significant and unique contribution of the observed classroom environment on reading ability in a kindergarten population.

Language abilities. Observed overall classroom quality has also been linked with early language abilities (Peisner-Feinberg et al., 2001). Based on longitudinal observations beginning in preschool and continuing through to the second grade, a moderate association between language abilities and classroom practices has been identified (Peisner-Feinberg et al., 2001). Classroom practices (e.g., instructional method) are also associated with reading ability, sociability, cognitive, and attention skills in preschool. These findings remained significant even while child characteristics were controlled for, again suggesting the significant and unique contribution of classroom environment factors on reading and language abilities in the early school years.

Links between global classroom quality and academic outcomes have been demonstrated in samples as young as children attending daycare (McCartney, 1984). For example, McCartney (1984) observed several daycare quality variables and assessed their association with children's intellectual and language development. Findings suggest that the overall quality strongly predicted language development (using multiple methods of language assessment). These findings provide further support for the predictive role of the quality of classrooms on outcomes at a very early age.

Mathematics. Based on observations of the classroom climate in an early childhood sample, links have been consistently demonstrated between a negative 
environment and difficulties with mathematics (Peisner-Feinberg, et al., 2001; Pianta et al., 2002). For example, Turner, Midgley, Meyer, Gheen, Anderman, \& Kang, et at., (2002) assessed the effect of sixth grade student's perceptions of the goal structure (e.g., mastery goal structure and performance goal structure) and instructional discourse (e.g., supportive versus non-supportive) in their classroom on their reported use of avoidant strategies in mathematics. Between-classroom comparisons yielded significant differences between the levels of reported use of avoidant strategies suggesting that an environmental component in the classrooms were significantly contributing to these differences. Interestingly, a significant association between perceived classroom goal structures and use of avoidant strategies in math was not found to be significant. However, an association was found between self-reported use of avoidant strategies and observed teaching methods. Children reported significantly less avoidant strategies in classrooms that were perceived to emphasize factors such as learning, understanding, effort and enjoyment.

Although perceived classroom goal structure did not predict avoidant strategies, it is important to note that the perception of the teacher's instructional method was significant. This finding is useful for the present study as it highlights the role of perception in academic outcomes. The fact that the perceived classroom goal structure was not found significant emphasizes the importance of using an all encompassing measure of classroom environment. By doing so, all of the pieces of information that occur within a classroom are accounted for and measurable.

Social competence. Social skills competencies have also been consistently linked to global classroom environment (e.g., Battistich, et al., 1995; Dishion et al., 1996; 
Howes, 2000). Research results have demonstrated that children enrolled in a more positive classroom environment demonstrate better social skills and competencies in the short- and long-term than children in a negative classroom environment. For example, Howes (2000) observed the emotional climate in a preschool classroom and used this classroom variable to predict social competence with peers two years later. Based on observations of the socio-emotional climate of the classroom, Howes (2000) found that classrooms that were high in problem behaviours also had lower levels of child-teacher closeness in preschool. This relation remains significant even when controlling for child characteristics (e.g., gender, age, grades) suggesting that classroom environment, as early as preschool, is a good predictor of future social competence. These findings suggest that second grade social competence (based on peer ratings) can be predicted by the social emotional climate of their preschool classroom meaning that early classroom variables do in fact contribute to social competence over time even while controlling for child characteristics.

Similarly, early global classroom climate and classroom environment variables (e.g., teacher child relationships) have also been linked with levels of social competence. Pianta et al. (2002) observed three classroom composite variables including; instructional climate, child-centered climate, and level of teacher positivity. A significant association between a higher child-to-adult ratio, and lower teacher positivity and lower instructional climate was found. Not surprisingly, this finding suggests that teachers with a large number of students without additional assistance have a more difficult time maintaining positivity and a positive instructional climate. In addition, higher observed quality of the global composites (e.g., teacher positivity and instructional climate) positively related to 
teacher rated child competence and observed 'on task' behaviour suggesting that the student-to-teacher ratio has an indirect effect on the presence of social competence in the class. This association remained even when controlling for family income and maternal education. It should be noted that this result may be do to the fact that the teachers with more students and less assistance may be tired and stretched for resources because of the added strain of having more students, which may inadvertently lead to a bias in their reporting of the presence of socially competent students in the class.

Meyer et al. (1993) assessed the effects of teacher and classroom characteristics on social competencies in pre-kindergarten classrooms. Classroom characteristics consisted of variables such as student-to-teacher ratios or half/full day programs. In terms of teacher rated social competence, it was found that children in classrooms with lower student-teacher ratios were rated as more socially competent than children in classrooms with higher student-to-teacher ratios. Teachers reported more problem behaviours in full day classes versus half day classes. It is important to note that a substantial amount of the variance associated with ratings of children's social competencies were in effect due to differences among the raters themselves.

Adjustment difficulties have also been linked with classroom environment variables such as the overall achievement level of the class and the overall behavioural level of the class. Werthamer-Larsson, Kellam, \& Wheeler (1991) conducted a longitudinal investigation assessing the effects of two components of a first grade classroom environment (Achieving Environment and Behavioural Environment) on behavioural and academic outcomes such as shyness, aggression, and concentration problems. Teachers completed the Teacher Observation of Classroom Adaptation- 
Revised (Kellam, Branch, Agrawal, Ensminger, 1975) which targets teacher beliefs about each child on aggression, shyness, and level of concentration. In order to determine a classroom achievement score, each child's scores on basic kindergarten skills (concept formation, language, reading, and mathematics) was averaged in order to obtain a general achievement score for each child. A ratio was then calculated which compared the number of 'high achievers' and 'low achievers'. When the ratio of was greatly skewed in terms of a larger numbers of 'high achievers', the class would be labeled as 'high achieving'.

The classroom behaviour environment was determined in a similar manner, although conduct scores were used in the calculations rather than achievement scores. Children in 'low achieving' classroom were more likely to demonstrate higher rates of shy behaviours, aggressive behaviours, and concentration problems as compared to children in 'high achieving classrooms'. In terms of the behavioural environment, children that were placed in 'poor behaving' classrooms were more likely to demonstrate higher levels of shy behaviours. These findings also remained when child characteristics were controlled for suggesting that the environmental characteristics are predicting the behavioural outcomes. In addition, these authors assessed the relation between the 'behavioural environment' of the classroom while controlling for the 'achievement environment'. Findings suggest that children in poor-behaving classrooms will continue to demonstrate higher levels of shy behaviours regardless of the level of achievement in the class.

Measuring Classroom Environment 


\section{Classroom Perceptions}

In order to provide a fair assessment of classroom environment, measurement methods must be carefully considered to ensure that the global atmosphere of the class is actually being represented. Essentially, it is the quality of the classroom environment that is being assessed. The quality of the classroom environment includes social, emotional, physical, and instructional elements of interactions between the teachers and the students (Pianta et al., 2005). The meaningful factors associated with quality can vary significantly depending upon variables such as the age group, the demographics, and the number of students in the class. As a result, researchers must choose measures that are both age appropriate and situation specific. Several observational measures (e.g., Classroom Assessment Scoring System; La Paro, Pianta, \& Stuhlman, 2004; Early Childhood Environment Rating Scale- Revised; Harms, Clifford, \& Cryer, 1998) and teacher report measures (Pianta, 1994) exist each of which offer an assessment of unique factors associated with classroom environment. A brief description of some of these measures is now presented.

Teacher ratings of classroom environment. Several teacher measures are available that target teacher's perceptions of the quality of their relationship with their students (e.g., Harms, Clifford, \& Cryer, 1998; Pianta, 1994; Stormshak et al., 1999; WertahmerLarsson, Kellam, \& Wheeler, 1991). For the present purposes, only a brief discussion of some findings associated with teacher-child relationships are described. The degree of closeness and conflict between teachers and students has been consistently linked with academic and social adjustment difficulties (e.g., Pianta, 1999; Howes, 1999). As such, it is important in the current investigation to review the role of teacher child-relationships as they are clearly a contributor to the functioning and overall atmosphere of the 
classroom. Teacher data is also used as an assessment tool of child behaviours within an educational context and there are several benefits to this approach (Mashburn et al., 2006). Based on their daily interactions with their students, teachers have the opportunity to draw from extensive observations that occur within the classroom context (Kenny \& Cheakaluk, 1993). Also, teachers have numerous students at one time which offers them more information by which to compare behavioural competencies among their students. Teacher ratings of child competencies and teacher-child relationships are cost effective and feasible and therefore are often used as the primary means of information for program development and implementation in the school systems.

Although teacher- rated reports offer valuable information regarding specific aspects of teacher-child relationships and child competencies, there are limitations to using this type of measurement when assessing global classroom environment (Mashburn et al., 2006). For example, when teacher reports are used as an overall rating of the quality of the classroom environment, important contributing factors (e.g., interactions between children, physical attributes of the classroom) are being neglected.

A broader limitation relates to the narrow scope of using teacher-child relationships as a measure of classroom experiences. It is argued that teacher reports are limited in their ability to provide an all encompassing description of the classroom as a whole. For example, the Student-Teacher Relationship Scale (STRS, Pianta 1994) asks teachers to report their beliefs about the level of closeness and conflict with an individual child. Teachers are asked to report on items such as "I share an affectionate, warm relationship with this child" keeping in mind only the target child. Conceptually, the 
averaged score from this measure reflects the teacher's perception of their general relationship with their class rather than the overall functioning of the class.

Biases in teacher ratings of teacher child relationships have also been found (Howes, Phillipsen, Peisner-Feinberg, 2000). For example, teachers are more likely to rate closeness in their relationships with girls than with boys (Howes et al., 2000). Although teacher-child relationships significantly predict some of the variance in the quality of the classroom environment and achievement on social outcomes, there remains a portion of unexplained variance (Stuhlman \& Pianta, 2002). Other contributing factors (e.g., physical attributes of the class) have also been identified to uniquely predict some of the variance in outcomes associated with the quality of the classroom environment (Early et al., 2006).

For example, environmental subfactors, such as the use of materials, health, safety and supervision in the classroom, uniquely predict academic success across the prekindergarten year (Early, et al., 2006). The Early Childhood Environment Rating ScaleRevised (ECERS-R; Harms et al., 1998) is an observational tool that includes teacherchild relationships as only a single factor of classroom environment. In addition to assessing teacher-child relationships, the ECERS-R incorporates environmental characteristics of the pre-kindergarten and kindergarten classrooms in order to obtain a more global measure of the classroom climate. Attempts to address the relation between children's classroom experiences and their achievement in the broad construct of the classroom environment must recognize the multidimensional levels of interactions and activities in the classroom (Pianta et al., 2002). 
Another limitation of teacher reports as a measure of classroom experience relates to teacher rated perceptions of child competencies. Teacher perceptions of child competencies have also been used as an index for general classroom behaviour which is argued to reflect the global classroom climate (Howes, 2000). Similar to measures of teacher-child relationships, the use of teacher rated behavioural competencies lacks the comprehensiveness of a global measure of classroom climate. More importantly, findings also suggest that rater effects significantly contribute to the variance in teacher rated child compentencies (e.g., Carnivez, Watkins, Shaefer, 2002; Konold, Mashburn et al., 2006; Kraemer, Measelle, Ablow, Essex, Boice, Kupfer, 2003; McConaughy \& Ritter, 1995; Walthall, Konold, \& Pianta, 2005). For example, teachers may rate all children the same on the various categories (halo effect) or they may be too lenient or to severe in their ratings on child competencies (Englehard, 2002; Mashburn et al., 2006). In addition, teacher's perceptions of competencies will significantly vary depending on their psychological characteristics such as motivation, mental state, or the time during which the ratings were made (e.g., Kramer et al., 2003). Teacher ratings are also found to be influenced by their level of education and economic backgrounds (Mashburn \& Henry, 2004; Mashburn et al., 2006).

To summarize, a substantial body of literature exists highlighting the importance of a positive teacher-child relationship in early childhood. However, it is argued herein that for the purposes of measuring classroom environment, this approach may prove to be too narrow. Teacher-child relationships make up only a single component of global classroom environment. By relying solely on teacher scores of perceived teacher-child 
relationships and child competencies, other important factors that contribute to classroom environment may be neglected.

In order to resolve this issue without discounting the importance of teacher perceptions, some studies have combined teacher reports with other sources of information (such as peer nominations and observations) to obtain a more comprehensive rating of the functioning of a class (Howes, 2000; Stormshak et al., 1999). For example, Howes (2000) combined scores from three selected measures, Student-Teaching Relationship Scale (STRS; Pianta, 1994), the Peer Play Scale (PPS; Howes \& Matheson 1992), and the Classroom Behavior Inventory (CBI; Schafer, Edgerton, \& Aaronson, 1978). Scores from the PPS, which is an observation scale designed to assess the type of interaction between children, were combined with scores from the STRS. The PPS includes three focused 5 minute observation periods over the course of three hours. During this time observers are coding target children's behaviours within the class. The PPS consists of factors such as; onlooking behaviours (proximity seeking without interaction with peers), interactive play (joint activity with a peer), complementary play (each peer taking on a role in a joint game or activity), and simple social play (Howes \& Matheson, 1992). Finally, scores from the CBI (Schafer, et al., 1978), which is a teacher report of their perception of children's social adjustment, were also included to obtain an overall score classroom environment rating. In some instances, researchers will average the CBI scores across the entire class on the different behavioural factors (e.g., aggression, distractibility) in order to obtain an overall rating of classroom emotional climate (Howes, 2000, Schafer et al., 1978). Howes (2000) averaged the scores on these three measures for each individual child to obtain an overall score based on teacher 
reports. It is argued however, that the inclusion of multiple assessment methods, a more comprehensive measure of classroom climate is obtained.

Stormshak et al. (1999) used similar methodology by combining teacher reports on the Teacher Observation of the Classroom Adaptation- Revised (TOCA-R;

Werthamer-Larsson, Kellam, \& Wheeler, 1991) and sociometric peer interviews in order to obtain a measure of classroom environment. The TOCA-R (Werthamer-Larsson et al., 1991) asks teachers to rate target children on levels of social competence including aggression, inattention, withdrawal, and prosocial behaviour. Children were presented with a list of their classmates and asked to rate them based on likeability on four behavioural factors (aggression, inattention, withdrawal, and prosocial behaviour). Teacher report scores and peer nominations of the four behavioural components were averaged to obtain a behaviour score for each child. These scores were then averaged across the class which yielded an overall score on those four behavioural components for the entire class.

Observational measures of classroom environment. Research exploring the links between teacher-child relationships, classroom environment, and teaching practices on adjustment difficulties has led to the need for psychometrically sound observational measures designed to code for the overall functioning of the classroom (La Paro, Pianta, \& Stuhlman, 2004). Several observational measures exist that assess global classroom environment (Harms, Clifford, \& Cryer, 1998; Harms \& Clifford, 1980; La Paro, et al., 2004; NICHD ECCRN, 2003; Stipek, 1996). Observational methods of assessment have become a common measurement tool in the classroom environment literature in early childhood (Pianta et al., 2002). Standardized procedures have received extensive 
validation and as such they are often used as a measure of global classroom environment (Ferrar, 1996; Howes, Phillips \& Whitebook, 1992). Each measure targets slightly unique aspects of the quality of the classroom environment (La Paro, Pianta, Stuhlman, 2004).

There is a substantial amount of research focusing on the effects of early classroom quality on behavioural correlates and adjustment difficulties (e.g., Battistich et al., 1995; Burchinal et al., 2002; Dishion et al., 1996; Kellam et al., 1998; Howes, 2000; Stormshak et al., 1999). A trend towards investing resources into education as early as possible has led to the development of measures that are designed specifically to identify issues in pre-kindergarten and kindergarten classrooms (La Paro et al., 2004). As a result of this, several studies have implemented observational measures specifically designed to assess early childhood classroom experiences (e.g., Early et al., 2006; Howes, 2000; Howes et al., 2000; Pianta et al., 2005; Pianta et al., 2002). Fewer measures are available to assess classroom environment in upper-elementary school populations (Classroom Assessment Scoring System (CLASS); La Paro \& Pianta, 2004) and as such, research focusing on classroom environments in this age group is not as extensive.

It is well documented in the literature that early observed classroom factors (e.g., pre-kindergarten and kindergarten) are linked with adjustment difficulties including peer adversity and academic difficulties both in the short and long term (e.g., Gazelle, 2006; Harms et al., 1998; Howes, 2000; La Paro, et al., 2002; Meyer et al., 2003). For example, Meyer et al. (1993) found the methods of instruction in kindergarten classrooms predicted children's reading ability at the end of the school year. Positive classroom factors have also been found to predict observed on-task and social behaviour and teacher reported academic and social competence (Pianta et al, 2002). In a longitudinal study, 
Howes (2000) found that a positive preschool classroom climate predicted children's social competence in the second grade. Positive first-grade global classroom environment has also been found to act as a protective factor against peer adversity and depressive symptoms for shy and anxious children (Gazelle, 2006). Research tends to focus on early classroom environment factors in order to successfully develop and implement preventative programs based on the links between early classroom experiences and later adjustment difficulties. Although it is clear, that early classroom experiences influence adjustment and academic trajectories in early childhood, research exploring the role of classroom experiences in upper-elementary school is not as extensive.

The ECERS-R (Early Childhood Classroom Observation-Revised; Harms et al., 1998), which has been extensively used in the classroom environment literature (e.g., Burchinal, Roberts, Riggins, Zeisel, Neebe, \& Bryant, 2000; Burchinal et al., 2002; Peisner-Feinberg et al., 1999; La Paro et al., 2004; Pianta et al., 2005), describes the physical environment of the early childhood classrooms, the warmth of the teacher-child interactions, and various components of the classroom that predict both concurrent and future child outcomes (Lamb, 1998; Peisner-Feinberg et al., 1999; Shonkoff \& Phillips, 2000). The ECERS-R consists of two factors. The first is Teaching and Interactions which is indicative of teacher-child interactions, disciplinary methods, and teacher encouragement. The second factor, labeled Provisions for Learning, encompasses the physical environment (e.g., learning tools on the walls, bright colors, friendly atmosphere) of the classroom. ECERS-R observations include a 7-point scale of quality that range from adequate, to minimal, to good, to inadequate. This measure has 
demonstrated good psychometric properties and was designed to assess children between the ages of 2 to 5 years.

The Early Childhood Classroom Observation Measure (ECCOM; Stipek, 1996) is another example of an observational measure designed to assess various components of classroom environment that are different from those assessed by the ECERS-R. Contrary to the ECERS-R, this measure codes for instruction methods, management, and cultural sensitivity as a quality index of preschools and kindergarten classrooms.

The Classroom Assessment Scoring System (CLASS; La Paro \& Pianta, 2004) is designed to assess the positive emotional climate, including enthusiasm, enjoyment, and emotional connection between both the teacher and child and peer interactions. Negative emotional climate is also examined which includes anger, hostility, and level of aggression demonstrated by the teacher and/or the children. The CLASS also incorporates factors that are related to the management of the class such as; overcontrol, flexibility demonstrated by the teacher, and classroom schedules. Finally, CLASS codes for the observed instructional support that of the classroom including concept development, the degree to which teachers promote higher-order thinking, and problem solving (La Paro et al., 2004). CLASS observations consist of 30 minute observation intervals, during which they would observe each target child on a $20-$ second observe and a 40-second record cycle. During the 30-seconds this cycle occurs five times for each child.

In summary, observed classroom quality factors and have been widely associated with later adjustment difficulties in populations as young a two years of age. These findings offer teachers and school boards a broad range of information regarding the 
importance of a positive classroom experience for their students. Based on the knowledge gained via observations and teacher reports of classroom environment, empirically based program development can be implemented in the classrooms to promote a more positive environment.

Although limitations exist with teacher reported classroom assessment measures, they are often used in one form or another in the classroom environment literature (e.g., Bryant, et al., 1991; Burchinal, et al., 2002; Mashburn et al., 2006; Pianta et al., 2002). However, due to these limitations, some studies employ observations as a more objective assessment of the environment (e.g., Gazelle, 2006; Howes, 2000). Observations are highly useful in that they provide yet another mode of measurement for very young populations. For the current studies, however, an upper elementary school sample was employed.

Observational methods were not used as a mode of assessment for the current study for two primary reasons. First, at present, there are no published measures specifically designed and validated to assess classroom environment in an upperelementary school populations. A new observational measure designed for use with older children (CLASS, for grades three to six), is currently being developed (H. Gazelle, personal communication, March, 2007) but has yet to be extensively tested and validated.

Notwithstanding, consistent with research focusing on the processes of the selfsystem and personal motivation theories (e.g., Ames, 1992; Maehr \& Midgley, 1991; Urdan \& Shoenfelder, 2006), it was predicted that the way in which a child perceives their environment will significantly and uniquely affect their level of engagement in their classroom environment. Although observations were not employed in the current study, it 
is nonetheless important to review some of the observational tools that are often employed as an assessment of classroom environment. In future studies it would be interesting to assess the unique contributions of both observed and perceived environment. The role of perceived classroom environment is discussed in a later section.

Concurrently, a body of literature also exists that suggests that, although observed classroom environment is important to assess as a meaningful predictor variable, perhaps a more important factor may be the child's perceptions of their classroom experiences (e.g., Aldridge \& Fraser, 1998a, 1998b; Ferguson \& Fraser, 1998; Fraser, 1982; Fraser \& Aldridge, 2001; Fraser \& Fisher, 1982; Majeed, Fraser, Aldridge, 2002). For example, if a child does not believe that the functioning of their classroom is positive, regardless of the observed quality, they will be more likely to lack motivation and engagement in the class. Consequently, this student will likely experience both academic and peer relation difficulties as a result of this perception. Therefore, the current study employed an assessment of perceived classroom environment rather than observed or teacher reported classroom environment. It was also of interest whether certain types of children are likely to perceive their classroom environment differently than their peers. For example, it is widely recognized that aggressive children demonstrate a hostile-attribution even while in a benign or non-hostile environment (Boivin, et al., 1995; Dodge \& Price, 1994). Based on this finding, it was predicted that these aggressive children would be more likely to perceive their environments more negatively, and therefore experience more academic and social difficulties. The following section presents an overview of the perceived classroom environment literature and describes the role of this variable in the trajectory of social outcomes. 


\section{Perceptions of Classroom Environment}

A substantial amount of evidence exists supporting an association between perceived classroom environment and later outcome difficulties (e.g., Aldridge \& Fisher, 2000; Aldridge, Fraser, \& Huang, 1999; Ferguson \& Fraser, 1998; Fraser, Fisher, \& McRobbie, 1996; Fraser \& Wilkinson, 1993; Henderson, Fisher, \& Fraser, 2000). Remaining within the framework of the child-by-environment approach, researchers have explored the predictive nature of perceptions of classroom environment on academic outcomes (Church, Elliot, \& Gable, 2001; Fraser \& Wilkinson, 1993; Henderson et al., 2000). These differences become especially relevant for program development and implementation. The following section will provide a review the empirical and theoretical research focusing on the role of classroom perceptions on social adjustment difficulties and academic outcomes.

Historical review. The early writings of psychologists such as Lewin $(1935,1936)$ and Murray (1938) emphasized the importance of including environmental characteristics when exploring human behaviour (as cited in Fraser \& Fisher, 1983). Theories presented by these early researchers suggest that the interaction between environmental characteristics (e.g., classroom experiences) and personal characteristics is the true predictor of human development and behaviour manifestation. Expanding upon these theories, a growing body of literature has been devoted to the study of perceived classroom environment as an influential environmental factor contributing to both learning and social outcomes (e.g., Aldridge \& Fraser, 1999; Dorman, Adams, \& Ferguson, 2002; Fisher \& Fraser, 1983; Fraser, 1982; Fraser \& Fisher, 1983; Fraser \& Wilkinson, 1993; Fraser, Williamson, \& Tobin, 1987; Ferguson \& Fraser, 1998; 
Henderson, Fisher, \& Fraser, 2000; Majeed et al., Van Tartwijk, Brekelmans, Wubbels, Fisher \& Fraser, 1998). It has been consistently demonstrated that classroom perceptions are related to and predictive of later outcomes (Goodenow, 1992; Hymel, Comfort, Schoenert-Reichl, \& McDougall, 1996; Ladd, 1990; Patrick, Ryan, \& Kaplan, 2007).

The study of perceived classroom environment is based on the hypothesis that the way in which a student perceives their environment is based on their personal and background characteristics, which in turn affect the way they think about and approach their social world (Patrick et al., 2007). Drawing upon this system, student's perceptions about their classroom experiences may influence the way in which they engage in their class and peer relationships. As a result, their engagement in the class will depend somewhat on the way they perceive, or think about, this environment. Up to this point, the literature has largely focused on academic outcomes associated with the perceptions of classroom environment (Church, et al., 2001). Research focusing on academic outcomes is clearly important and has direct implications to the classroom and the school systems. More recently however, it has been suggested that social outcomes may also be associated with classroom experiences and warrant investigation (Patrick et al., 2007). It must first be noted that the classroom perception literature focuses on adolescent and undergraduate populations. Although the current study included an upper-elementary school population, some of the findings based on older samples are described in order to provide a thorough review of the research.

Relevance of studying perceived environment. It is argued herein that perceived classroom environment is a highly useful variable when identifying factors that contribute to the differences in social outcomes for several reasons. First, based on the 
average perception scores within a class, significant differences have been reported across different classrooms (Aldridge \& Fraser, 2000). Thus, overall perceptions of classroom environment (based on the average of individual student perception reports) appear to differ from one class to another (Aldridge \& Fraser, 1999; Fraser \& Fisher, 1983). These differences allow for between-class analyses, which would explore the variability of behavioural correlates across classes as well as the assessment of withinclass differences.

Second, exploring classroom perceptions as a predictor variable is meaningful as research consistently identifies links between perceptions of classroom environment and later achievement (e.g., Fraser, 1982; Fraser \& Fisher, 1982; Fraser \& Fisher, 1983). As a result of this, focusing on perceptions of classroom characteristics may be a highly useful intervention tool. For example, if a student perceives their class to be negative and not conducive to their learning, they will be less likely to become engaged in the subject (Patrick, et al., 2007). Therefore, intervention programs can be designed to focus on classroom perceptions in order to make accommodations that promote a better learning environment for that particular student.

In addition to being assessed as a predictor variable of academic outcomes, perception of classroom environment has also been assessed as a dependent variable in research applications including the evaluation of intervention programs (Teh \& Fraser, 1995), transitions from middle school to high school (Ferguson \& Fraser, 1998), and gender differences in classroom perceptions (Fisher, Fraser, \& Rickards, 1997).

Results from a growing body of literature assessing perceived classroom environment highlight the importance of including this variable when attempting to 
explain some of the individual differences associated with early development. It is consistently found that perceived classroom environment does account for some of this variance however there remains many unanswered questions (Roeser, et al., 1996). The goal of the present research was to not only replicate some of these previous findings, but also to address some of these remaining research questions. The following section describes research assessing the role of classroom perception to later adjustment difficulties.

Perceived classroom environment. Perceived classroom environment can be conceptualized as either the shared perceptions of a group of students in a particular environment, or as a rating of an individual student's perceptions of their classroom experiences (Fraser, 1986). The exploration of classroom perception stems from the traditional person-environment interaction approach which, suggests that success on various dimensions is most likely to occur if the environment and the person are compatible (Bem, 1979; Fraser \& Fisher, 1982; French 1963; Graham, 1976). Therefore, based on this assumption, positive classroom perceptions indicate a general "satisfaction" with one's environment whereas negative classroom perceptions indicate "dissatisfaction" with one's classroom experiences. Research indicates that children achieve better in classrooms that they perceive to be positive (Sinclair \& Fraser, 2002; Fraser \& Fisher, 1983). Therefore, based on these findings it is argued that positive classroom perceptions lead to academic achievement. It should be noted however, most of the studies assessing perceived classroom environment have been conducted in junior high and high school populations (e.g., Aldridge \& Fraser, 1999; Fraser \& Fisher, 1982; Fraser \& Fisher, 1983; Fraser et al., 1987; Henderson et al., 2000; Sinclair \& Fraser, 
2002) as well as undergraduate populations (Church, et al., 2001). Further, these studies almost exclusively involved the prediction of academic and learning outcomes (e.g., Fraser, 1986, 1989, 1994, 1998a, 1998b; Fraser \& Fisher, 1982, 1983; Haertel, Walberg, 1981; Walberg, 1986).

Findings from a study exploring goal outcomes (e.g., mastery goals, performanceapproach goals, and performance avoidance goals), perception of classroom environment was obtained in an undergraduate psychology class (Church et al., 2001). Perception of classroom environment for this particular study consisted of self- reported ratings of lecture engagement (the extent to which the student believes that the professor makes the lecture interesting and engaging), evaluation focus (the extent to which student's perceive their professor's emphasis of the importance of grades in the course), and harsh evaluation (the extent to which the student perceives the grading structure of the course as conducive to the likelihood to get a good grade). Students were more likely to adopt mastery goals, which are the goals that focus on the development of competence and task mastery, if they perceived their classroom more positively. To the contrary, a negative association between classroom perception variables and performance-approach and performance-avoidant goals was found. For example, when a student perceives that their professor emphasizes the importance of grades (evaluation focus), they are more likely to adopt performance-approach goals. These findings further support the hypothesis that the way in which we perceive our environment will affect our performance within that class.

In younger samples (grades 6-8), similar associations have been demonstrated (Patrick et al., 2007; Sinclair \& Fraser, 2002). Patrick et al., (2007) explored the processes through which perceived classroom environment impacts student engagement 
and performance. More specifically, the role of perceived classroom environment variables involved in the development of subsequent engagement in a specific academic topic was explored (in this case mathematics). Level of engagement includes selfregulation strategies (e.g., planning, monitoring, and regulating cognitions) and taskrelated interaction (e.g., the student's involvement in suggesting and receiving ideas, thoughts, and reasoning during whole class instructions). Classroom environment variables contributed to both self-regulation strategies and task-related interaction even while controlling for prior achievement and gender. This suggests that classroom environment is contributing to the way in which children engage in their academic activities. Interestingly, task-related interactions (but not self-regulation strategies) predicted later academic outcomes even while continuing to control for prior achievement and gender. These findings highlight the role of perception of the classroom experience in the trajectory academic difficulties or successes in grades six through eight classrooms.

Associations between perceptions of classroom experiences and subsequent outcomes have been consistently demonstrated in populations ranging from Grade 5 students through to undergraduate students. Differences in the environmental variables included in the assessments can make the generalizability of the findings problematic. Nonetheless, there is a consensus in the literature that there are significant associations between perceptions of classroom variables in one capacity or another and later adjustment and academic outcomes. There are some limitations in the current literature that have been addressed by the current study and will be reviewed in a later section. First 
however, findings will be reviewed that explore the role of gender differences on the associations between classroom perceptions and outcomes just presented.

Gender differences. Significant differences in the way boys and girls perceive their classroom environment has been reported (Sinclair \& Fisher, 2002). Girls tend to rate their perceived classroom environments more positively than boys (Byrne, Hattie, \& Fraser, 1986; Owens \& Straton, 1980; Sinclair \& Fraser, 2002; Teh \& Fraser, 1994). For example, Sinclair and Fraser (2002) found that girls rate cooperation and teacher empathy significantly more positively than boys, whereas mean ratings of task orientation (e.g., the extent to which it is important to the class to stay on task) did not differ significantly by gender. However, the role association between gender and classroom perceptions remains relatively speculated.

Limitations in the literature. Although great strides have been made to identify factors within a classroom that either promote or hinder cognitive and social development, there are limitations in the literature that require further exploration. First, it is clear that the way in which a child thinks about their class affects their ability to succeed. However, the assessments up to this point have not included children that fall outside of the "normal range" on certain behavioural characteristics (e.g., shy or aggressive children). For example, are aggressive children more likely to perceive their classrooms differently than other children? Based on social cognitive research, perhaps aggressive children will be more likely to perceive their classrooms more negatively than non-aggressive children.

These hypotheses fall under the constructs of social-cognitive theory suggesting that aggressive children perceive social situations to be more hostile (hostile-attribution 


\section{Classroom Perceptions}

bias) than non-aggressive children (Dodge \& Price, 1994). Assuming that aggressive children were to perceive their classrooms differently than less-aggressive children, one would suspect based on associations found in the classroom environment and aggression research that they will also demonstrate significant differences on academic outcomes (e.g., poor grades) and social outcomes (e.g., peer rejection). Therefore, using the example of aggression, it is argued that a major component lacking in the current literature is exploring the unique associations between classroom perceptions and outcomes for special populations.

In order to remain within the theoretical framework of the child-by-environment framework, the current research attempted to replicate some of these associations and further explored the relations between perceived classroom environment and adjustment difficulties including social outcomes (e.g., peer victimization, depressive symptoms, and feelings of loneliness).

\section{Measuring Perceived Classroom Environment}

Several measures exist specifically designed to assess varying components of perceived classroom environment (e.g., Johnson, Johnson, \& Anderson, 1983; Moos, 1979; Moos \& Trickett, 1974; Fraser \& Rentoul, 1980; Ryan \& Patrick, 2001; Tricket \& Moos, 1973). Classroom perception measures have demonstrated good psychometric properties cross-culturally (Aldridge \& Fraser, 2002). Some measures incorporate global assessments of classroom environment in an attempt to capture the overall working of the class, whereas other measures are designed to target engagement or success in specific subject matters (Fraser \& Wilkinson, 1993). Measures assessing perception of classroom environment are self-report questionnaires which are often modified to ensure the age 
appropriateness of the items. A review of some of the most widely used measures is now presented.

Classroom Environment Scale. The Classroom Environment Scale (CES; Moos, 1979; Moos \& Trickett, 1974; Tricket \& Moos, 1973) is one of the earliest developed and most widely used self-report assessment tool of perceived classroom environment (Moos, 1979; Moos \& Moos, 1978; Trickett \& Moos, 1974). The CES was developed to target a high school students and consists of nine dimensions including; Involvement (e.g., "students daydream a lot in this class"), Affiliation (e.g., "students in this class get to know each other well"), Teacher-Support (e.g., "the teacher takes a personal interest in the students"), Task Orientation (e.g., "the teacher often takes time out from the lesson plan to talk about other things"), Competition (e.g., "some students always try to see who can answer questions first"), Order and Organization (e.g., "assignments are usually clear so everyone knows what to do"), Rule Clarity (e.g., "there is a clear set of rules for students to follow"), Teacher Control (e.g., "students don't always have to stick to the rules in this class"), and Innovation (e.g., "new and different ways of teaching are not tried very often in this class"). Response format consists of True or False answers and the measure consists of 90 items with 10 items representing each scale. Alpha reliabilities coefficients for this scale have been reported to range from .60 to .90 (Fraser \& Fisher, 1981, 1983). The CES has also been found to differentiate significantly between classrooms (Fraser, 1982; Fraser \& Fisher, 1982). In addition, the eta-squared scores, which provide an estimate of the proportion of variance that is attributed by classroom membership, ranged from .18-.43 (Fraser \& Fisher, 1983). 
The CES targets children's perception about what they believe all of their classmates feel rather than how they themselves specifically feel within the classroom. Therefore, the unit of analysis is "classroom average perception" rather than at the level of the individual student (Fraser \& Fisher, 1983). This is done because an average of all of the student's responses on the actual form provides a good measure of the global atmosphere of the class, rather than how a target child feels within the class. It has been suggested that ratings of classroom perceptions do in fact differ significantly between classrooms therefore this unit of analysis can be argued to be relevant (Fraser \& Fisher, 1983).

Individualized Classroom Environment Questionnaire. In contrast to the CES which is designed to obtain an average classroom perception score for the overall class, the Individualized Classroom Environment Questionnaire (ICEQ; Fraser \& Rentoul, 1979) targets individual perceptions of both the classroom environment. This widely used measure targets five dimensions including Personalization (e.g., the teacher considers students' feelings"), Participation (e.g., "the teacher lectures without students asking or answering questions), Independence (e.g., "students choose their partners for group work"), Investigation (e.g., "students find out the answers to questions and problems from the teacher rather than from investigators"), and Differentiation (e.g., "different students use different books, equipment, and materials"). In general the measure distinguishes between a more conventional environment and an open or individualized classroom environment. Responses on the ICEQ range from 'Almost Never' to 'Very Often'. Predictive validity of the ICEQ has been demonstrated meaning that the contribution of children's perceptions significantly predicts later outcomes on some of 
the subscales (Fraser, 1990; Fraser \& Rentoul, 1980). Additionally, the ICEQ has also been used in order to provide further support for the child-by-environment fit hypothesis in that it has been used to assess the discrepancy between perceived classroom environment and the preferred classroom environment (Fraser \& Rentoul, 1980). Good internal consistency has been reported with alpha coefficients ranging from .61 to .79 (Fraser \& Fisher, 1981). Discriminant validity (mean magnitudes of the correlation of a scale with the other scales) ranged from .07 to .28 (Fraser \& Fisher, 1981). When both the ICEQ and the CES are used, neither measure has unique predictive validity to a given outcome (Fraser \& Fisher, 1982).

Classroom Life Measure. The Classroom Life Measure (CLM; Johnson, Johnson, \& Anderson, 1983) is yet another classroom perception measure which has been primarily employed and validated among children enrolled in fifth to ninth grade.. The CLM include two teacher-related subscales including teacher emotional support, which refers to the belief that the teacher cared about and liked the student as a person (e.g., "Does your teacher try to help you when you are sad or upset?"), and teacher academic support, which refers to the perception that the teacher cared about how much the student learned and wanted to help him or her learn (e.g., "Does your teacher like to see your work?"). In addition, subscales including student emotional support, which referred to the belief that the student's classmates cared about and liked the student as a person (e.g., "In this class other students are; nice to me, like me, care about my feelings, really care about me"), and student academic support, which involved a perception that classmates cared about how much the student learned and wanted to help him learn (e.g., "In this class other students; want me to do well in school, want me to be successful, care about how 
much I learn, want me to come to class everyday") were also incorporated from the earlier CLM questionnaire. The CLM has been found to demonstrate moderate psychometric properties (Johnson et al., 1983; Wentzel, 1994) with reliability ratings (Cronbach's alpha coefficient) ranging from .51 to .83 .

Perception of Classroom Environment Measure. Recently, the Perception of Classroom Environment Measure (PCE; Patrick \& Ryan, 2005; Patrick, et al., 2007; Ryan \& Patrick, 2001) was modified from the original CLM. In addition to the subscales described on the CLM, the newer version includes supplementary subscales that provide a broader measure of perception of classroom environment. These subscales include promoting mutual respect, which targets the extent to which the teacher was perceived as encouraging respect among classmates (e.g., "My teacher encourages us to share ideas with one another in class"), and task-related interaction, referring to the extent to which the teacher was perceived as encouraging interaction among peers around specific academic tasks (e.g., "I help other kids with math when they don't know what to do"). Participants will be asked to respond on a five point Likert scale ranging from 1 (almost never) to 5 (often). This version of the measure demonstrates moderate psychometric properties including reliability ratings (Cronbach's alpha coefficients) ranging from .64 (Teacher Academic Support subscale) to .88 (Student Academic Support subscale).

What Is Happening In This Class? There are several measures available that target various aspects of children's perceptions of their classroom environment. However, many of the measures previously described have been designed and validated with reference to specific academic classes. It is argued herein that children's perceptions of their social environment in the classroom context also play an important role in the 


\section{Classroom Perceptions}

development of adjustment difficulties. Therefore, for the purposes of the current investigation, a classroom perception measure entitled What Is Happening In This Class? (WIHIC; Fraser, 1998) was adapted and employed. The WIHIC is a measure designed to assess student's attitudes in terms of enjoyment, interest in school, and how much they look forward to class (Aldridge \& Fraser, 1999; Dorman, 2003; Fraser, 1998; Fraser, McRobbie, \& Fisher, 1996). This particular measure has been widely used and validated, and consists of subscales that are of particular relevance to the research questions of interest in the present investigation. A thorough description of the WIHIC is presented in the Methods section.

\section{Classroom Climate and Child Characteristics}

Almost all of the studies exploring the role of observed, teacher reported, and perceived classroom environment variables focus on the adjustment or academic outcomes across the entire sample (e.g., Aldrige \& Fraser, 1999; Fisher \& Fraser, 1983; Fraser, Williamson, \& Tobin, 1987). Although these findings are clearly useful in terms of highlighting the important role of classroom environment for both individual students and the overall class, it is argued that the literature is lacking in the assessment of specific behavioural subgroups of children. For example, do shy and aggressive children perceive their classrooms differently than non-shy and non-aggressive children? If so, is the relation between classroom perception and adjustment difficulties different for these particular subgroups? In order to address these questions in the current investigation, the unique role of perceived classroom environment for shy and aggressive kids (as identified by their peers) was explored. 
It was hypothesized that aggressive and shy children would perceive their classroom environments more negatively than comparison children. It was also predicted that the heterogeneity in adjustment difficulties experienced by aggressive and shy children would be partly accounted for by their perceptions of their classroom experiences. For example, it was speculated that a more negative perception of classroom environment might exacerbate socio-emotional difficulties particularly for shy and aggressive children. This is consistent with social-cognitive motivational theories (Ames, 1992; Steinkamp \& Maehr, 1984) suggesting that the way in which children perceive their environment will predict their level of engagement and success within the constructs of that environment (Patrick et al., 2007). More specifically, social-cognitive theory posits that students' beliefs about the likelihood of success on specific tasks, their competence, and their desirability of outcomes, will predict their level of success (Bandura, 1982; Pajares, 1996; Urdan \& Shoenfelder, 2006). It is well documented in the social development literature that children frame their social world through their experiences (Higgins, 1990; Murphy \& Medin, 1985; Stromquist \& Strauman, 1991). More specifically, children develop internal mental representations that characterize how they perceive people and how they represent, interpret, and categorize social events (Burks, Dodge, Price, \& Laird, 1999). Based on these experiences, children develop schemas about their social world which subsequently predicted how they will behave within that social framework (Bargh, Lombardi, \& Higgins, 1988; Higgins, \& King 1981; Higgins \& Parsons, 1983; Ruble \& Rholes, 1984). For example, it has been widely reported that overtly aggressive children demonstrate a hostile attribution bias to most social situations (Dodge \& Price, 1994). This finding suggest that aggressive children are 
more likely to interpret a social situation more negatively or with more hostility, regardless of whether there is actual hostile intent.

This assumption and assessment stemming from a social- cognitive framework is not a new phenomenon in the perception of classroom environment literature. What is new however, is the assessment of the role of perceived classroom environment when including groups of highly aggressive or shy children. It is important to assess these individual differences among subgroups of children in order to develop and implement useful interventions programs that emphasize program development of positive classroom environments. The following sections provide theoretical and empirical background of the rational for including groups of shy and aggressive children when exploring the effects of perceived classroom environment.

Shyness. Shy children experience an approach-avoidance conflict when presented with social situations (Asendorf, 1991). That is, although shy children may want to interact with their peers, they tend to withdraw from social encounters because of underlying social wariness (Coplan, Prakash, O'Neil, \& Armer, 2004). Shy children are at an increased risk for adjustment difficulties such as peer rejection, peer victimization, and depressive symptoms (Coplan \& Armer, 2007; Gazelle et al., 2005; Rubin \& Coplan, 2004; Rubin, et al., 2009). However, there is heterogeneity in occurrence of these difficulties among shy children. Gazelle (2006) predicts that classroom environment contributes to these differences in outcomes. For instance, can a positive classroom environment act as a buffer to the trajectory of difficulties for shy children?

Some research has assessed the social-cognitive processes of shy or socially withdrawn children (Wichmann, Coplan, \& Daniels, 2004). For example, Wichmann et 
al., (2004) found that although socially withdrawn children reported social cognitions more closely related to comparison (non-aggressive and non-shy) children, a trend was determined towards reported differences in social cognitions when presented with a social situation. However, only a small number of studies have formally assessed the social cognitions of shy or socially withdrawn children.

Gazelle (2006) assessed the moderating role of classroom environment on the development of peer relation, academic, and adjustment difficulties specifically for children identified with early signs of shyness (i.e., anxious solitary behaviours). She reported that shy children in grade 1 classes characterized by a more negative environment experienced more peer rejection than shy children in a more positive classroom environment. Similarly, shy boys (not girls) were more likely to be accepted in a positive first grade classroom than shy boys in a negative first grade classroom. The sex difference may be attributed to the preferred social acceptance of girls being more timid and shy and therefore perhaps the level of acceptance would not differ based on the environment of the classroom. However, shy girls were more likely to be victimized in a negative first grade classroom than shy girls in a positive first grade classroom. First grade classroom environment also moderated the relationship between shy trajectories and depressive symptoms for girls. Shy girls were significantly more likely to experience depressive symptoms if they were placed in a negative classroom environment than those that were place in a positive class. No significant difference was found between positive and negative classrooms for girls that were low in shyness.

In summary, past research reports a link between classroom environment variables and shy behaviours. These findings suggest that classroom environment may be 


\section{Classroom Perceptions}

a contributing factor to the heterogeneity in adjustment difficulties for shy children. What is not addressed in the literature however is whether these differences remain when shy children's perceptions of classroom environment is assessed rather than observed classroom environment.

Aggression. In addition to shyness, it was also predicted that aggressive children would rate their perceived classroom environment significantly differently than their less aggressive peers. Due to the reported heterogeneity in subtypes of aggression (Coie \& Dodge, 1998), the present investigation identified children that were nominated by their peers to be more physically, relationally, and/or verbally aggressive. Physical aggression is characterized as the more traditional form of aggression referring to overt acts of aggression (Burgess, Wojslawowicz Bowker, Oh, Rubin, Booth-LaForce, \& RoseKrasnor, 2006). Relational aggression "involves the exclusion of peers and classmates from other activities and peer group gatherings, and indirect damage of others' reputation" (Burgess et al., under review. p. 6). For example, relationally aggressive behaviours may include spreading rumours, negative gossip, social exclusion, or the 'silent treatment' (Crick \& Grotpeter, 1995). Verbal aggression is characterized as name calling or verbal abuse (Burgess et al., under review). Therefore, it is argued that an all encompassing measure of aggression, which includes subtypes of aggression that are commonly reported in the literature, will provide a broader perspective of the unique associations between a behavioural subgroup and potential differences in the role of perceived classroom environment.

Consistent with a social-cognitive perspective, it was also predicted that aggressive children would be more likely to rate their classroom more negatively overall 
than less aggressive children. It has been widely demonstrated that children rated as highly aggressive demonstrate a hostile attribution bias in social situations (Boivin, et al., 1995; Dodge \& Price, 1994;). More specifically, aggressive children are more likely to interpret social situations with more hostility regardless of the social situation or interaction (Dodge \& Price, 1994). As such, it is argued that aggressive children will be more likely to report negative perceptions of their classroom environment resulting from an inherent negative interpretation of social encounters. Similarly, it was also predicted that classroom perceptions would account for some of the heterogeneity in adjustment outcomes among aggressive children. For example, it was speculated that aggressive children who report a negative perception of their classroom environment will also be more likely to report social adjustment difficulties than aggressive children that perceive their classroom more positively. Overview of Current Research

A review of the research highlighting links between classroom environment and adjustment difficulties has now been presented. Empirical and conceptual predictions have been presented emphasizing the importance of including perceptions of classroom environment when exploring developmental trajectories and individual differences in outcomes. Classroom environment has been demonstrated to contribute to academic skills (e.g., reading, language, and mathematic abilities) in addition to behavioural outcomes (e.g., social competence, aggression, and shyness). It has also been demonstrated that the classroom variables, such as perceived classroom environments can be used as meaningful predictor variables to later social and academic outcomes. 
Although the study of early classroom experience is a relatively new field of research, great strides have been made in identifying early experiences as important variables that contribute to adjustment difficulties. The current studies attempted to replicate some of the findings just presented as well as expand upon the current literature to include an exploration of perception of classroom environment in a population that has been relatively understudied. More specifically, this investigation explored the unique role of perceived classroom environment in the socio-emotional adjustment of aggressive and shy children. In addition, due to the lack of an age appropriate measure of perceived classroom environment for an upper-elementary school sample, a newly modified measure of classroom perception was developed and evaluated. Two studies were conducted. In Study 1, the psychometric properties and validity of the newly modified measure of perceived classroom environment were assessed. In Study 2, associations between perceived ratings of classroom environment and social adjustment outcome variables were explored. 


\section{Study 1}

\section{Validation of a Newly Adapted Measure of Perceived Classroom Environment} Purpose

The primary purpose of Study 1 was to explore the psychometric properties of a newly adapted measure of perceived classroom environment. More specifically, Study 1 explored the factor structure and the construct validity of a modified version of a widely used classroom perception measure entitled What Is Happening In This Class? (WIHIC; Fraser, 1998). Herein, the newly modified WIHIC will be referred to as the WIHIC-R. The original version of the WIHIC is a self-report questionnaire designed to assess children's perceptions of their classroom experiences and includes seven dimensions; Student Cohesiveness, Teacher Support, Involvement, Investigation, Task Orientation, Cooperation, and Equity. The WIHIC has been validated cross culturally in Australia and Taiwan (Aldridge, Fraser, Huang, 1999), Singapore (Fraser \& Chionh, 1999), Korea (Kim, Fisher, \& Fraser, 1999), and Indonesia (Margianti, Fraser, Aldridge, 2000) and has been found to demonstrate good psychometric properties (Dorman, 2003; Fraser, 1998). However, the WIHIC in its original form is designed for, and most often employed among, high-school samples.

For the purposes of the present paper, the original version of the WIHIC was adapted to ensure the questionnaire was relevant and applicable among an upperelementary school sample. Modifications included incorporating age-appropriate language on the items when required. In addition, in its original form, the WIHIC consists of 56 items. For the purposes of the present paper, some items were excluded in order to create a shorter version of the measure that would be easier for younger children 
to complete. In addition, some of the subscales were not as conceptually relevant for the present study (and with young children in general). As such, items from the Investigation and Task Orientation subscales from the original measure were also excluded.

In addition to the assessment of the factor structure of the WIHIC-R, Study 1 was also designed to explore the construct validity of the adapted measure. In order to investigate the construct validity of the WIHIC-R, relations with conceptually relevant outcome variables (e.g., loneliness, domains of self-concept, and peer victimization) were assessed. These variables are described below.

\section{Hypotheses}

Based on previous classroom perception research with older children (Allen \& Fraser, 2007; Aldridge, Fraser, \& Huang, 1999; Chionh \& Fraser, 1998; Riah \& Fraser, 1998; Zandvliet \& Fraser, 1998), a five-factor structure was predicted (see Table 1); (1) Student Cohesiveness, or the extent to which children know, help, and are supportive of each other; (2) Teacher Support, the extent to which the teacher helps, befriends, trusts, and is interested in the students; (3) Involvement, the extent to which children have attentive interest, participate in discussions, do additional work, and enjoy the class; (4) Cooperation, the extent to which students cooperate with each other rather than compete with one another on learning tasks; and (5) Equity, which is the extent to which students are treated equally by the teacher. Consistent with past research (Sinclair \& Fraser, 2002), it was also expected that boys would report poorer classroom environments (i.e., lower subscale perception scores on the Teacher Support, Cooperation, and Task Orientation subscales) than girls. 
Further, it was hypothesized that subscale perception scores would be associated with conceptually relevant outcome variables including social dissatisfaction, loneliness, peer victimization, and lower self-concept (e.g., abilities in school and among peers). Unique associations between adjustment difficulties and subscale perceptions scores were predicted. More specifically, it was predicted that less positive child perceptions of classroom environment would be associated with greater socio-emotional difficulties including loneliness, social anxiety and peer victimization, as well as lower self concept in school and with peers.

\section{Methods}

\section{Participants}

Participants in the study were $n=328$ elementary school children aged $8-12$ years (153 boys, 178 girls, $M_{\text {age }}=9.45, S D=.93$ ). Children were recruited from 4 public schools in the Southern Alberta area and were enrolled in grade $3(n=111)$, grade 4 $(n=110)$, or grade $5(n=106)$. Demographic information included parental education and ethnicity. Maternal education in the current sample consisted of $3.1 \%$ with an elementary school education, $23.5 \%$ with a high school education, $35.2 \%$ with a college education, $28.7 \%$ with an undergraduate degree, and $9.5 \%$ with a graduate degree. Paternal education in the current sample consisted of $3.4 \%$ with an elementary school education, $24.8 \%$ with a high school education, $31.7 \%$ with a college education, $28 \%$ with an undergraduate degree, and $12.1 \%$ with a graduate degree. Maternal ethnicity of the current sample consisted of $87.1 \%$ Caucasian, $6.6 \%$ Asian, $.9 \%$ Hispanic, $1.6 \%$ Black, $.3 \%$ Aboriginal, $.9 \%$ Other, and $2.5 \%$ Biracial. Paternal ethnicity of the current sample consisted of $88 \%$ Caucasian, 5.4\% Asian, 1.9\% Black, .6\% Hispanic, .6\% Aboriginal, 
$1.9 \%$ Other, and $1.6 \%$ Biracial. The large majority of the sample $(94.2 \%)$ reported English as the language spoken in the home. It should be noted that demographic information for Study 1 was anonymous. However, demographic information was assessed in Study 2.

Procedures

Upon the approval of the school board, principles at several schools were invited to participate in the study. For the schools that agreed to participate, a recruitment package was sent home with their students in grades 3, 4, and 5 students across 4 elementary schools. The information package included a brief description of the study (see Appendix A), a consent form (see Appendix B), and a form designed to collect demographic data (i.e., parental education, ethnicity, and language; see Appendix C). Upon parental consent, a schedule was set up with each of the teachers. Children that received parental consent were removed from the class during the scheduled time in order to participate. Testing occurred in a group setting either in a space in each of the schools that was allotted for the study (i.e., classroom or library). Participants were informed that there were no 'right' or 'wrong' answers and that their answers would remain confidential from their friends, their teachers, and their parents. Participants were also informed that they were not required to answer questions that they were not comfortable answering.

\section{Measures}

What Is Happening In This Class? Participants were asked to complete the newly adapted What Is Happening In This Class (WIHIC-R; see Appendix D) designed to assess perceptions of classroom environment. This classroom perception measure, which 
was widely derived from the original WIHIC (Aldridge \& Fraser, 1999; Dorman, 2003; Fraser, 1998; Fraser, McRobbie, \& Fisher, 1996), was designed to assess student's attitudes in terms of enjoyment, interest in school, and how much they look forward to class. For the purposes of the current investigation, children were asked to respond to items on the Student Cohesiveness, Teacher Support, Involvement, Cooperation, and Equity subscales. The original WIHIC questionnaire was designed to be used with high school students and consists of items such as; "In this class, I am able to depend on other students", "I am friendly to members of this class", "The teacher helps me when I have trouble with the work". Some of the items from the original WIHIC were excluded due the sophistication of the language. This issue is described in more detail below.

The WIHIC demonstrates good internal consistencies with Cronbach's alpha coefficients ranging from .81-.93 (Aldridge \& Fraser, 1999; Aldridge, Fraser, \& Huang, 1999; Dorman, 2002). The Cronbach's alpha coefficients are comparable when both the individual and the class mean are used as the unit of analysis. Relatively high alpha coefficients for each scale on the WIHIC suggest that items on each scale are assessing similar concepts. These findings are consistent with reliability coefficients in other crosscultural samples as well (e.g., Chinoh \& Fraser, 1998; Riah \& Fraser, 1998).

For the purposes of the current study, the language of several of the items from the original WIHIC was adapted (see Table 1) in order to ensure an understanding of the items among a younger sample of children. It is also important to note that although most items of the WIHIC-R were derived from the original WIHIC, some of the items were also derived from the Elementary and Middle School Classroom Environment Inventory (ICE; Sinclair \& Fraser, 2002). Similar to the WIHIC-R, the development of the ICE was 
also theoretically and conceptually based on the original WIHIC. However, the ICE has not been as widely employed and demonstrates only moderate psychometric properties (Sinclair \& Fraser, 2002). Nonetheless, the ICE does include items that are conceptually relevant and age appropriate for the current sample and as a result, some of these items have also been included on the WIHIC-R (e.g., "my teacher is fair to all the students in my class", "I discuss ideas in class").

In its original form, the WIHIC consists of 56 items. To reduce the time strain and to maximize face validity for younger children, some of the original items were not included on the WIHIC-R (e.g., "I get the same opportunity to contribute to class discussions as other students", "I know the goals for this class"). Children were asked to respond on a 5- point scale ranging from 1- Never, 2- Almost Never, 3- Sometimes, 4Almost Always, 5- Always. Each student received both an overall perception score and a subscale perception score for each individual subscale. Table 1 includes the items from the WIHIC-R as well as the original items from which these the items were derived. For the current sample, the means, $S D$, and ranges of the WIHIC-R items are summarized in Table 2.

Self-Description Questionnaire- I. Participants were asked to complete the peer relations subscale and the global school subscale of the Self-Description Questionnaire I (SDQ; Marsh 1988, 1990, see Appendix E). The SDQ-I is a widely used measure of self concept designed to elicit indices of self-concept in pre-adolescent populations. The SDQ-I is conceptualized within the frameworks of the hierarchical model of self concept proposed by Shavel, Hubner and Stanton (1976). According to this model, self concept is segmented into separate domains rather than a unidimensional conceptualization of the 
self (Kaminski, Shafer, Neumann, \& Ramos, 2005; Marsh, 1988, 1990; Marsh \& Shavelson, 1985). The SDQ-I elicits a score for multiple sub-factors of self-concept including; four nonacademic self-perception factors (e.g., peer relations, parent relations, physical appearance, and physical abilities), and two academic variables (e.g., mathematics, readings). In addition to the academic and nonacademic subfactors, the SDQ-I also includes global self and global school ratings. The complete SDQ-I consists of 76 Likert-scale items with possible responses ranging from; 1=false, 2=Mostly False, 3=Sometimes False, $4=$ Mostly true, $5=$ True. This SDQ-I is advantageous in that it and can be administered either individually or in groups. For the purposes of the current investigation, only the global school and peer relations subscales were employed.

Items from the peer relations subscale target self-concepts about peer relationships. There are 9 items on this subscale and they include questions such as; "I am easy to like", "I have lots of friends", and "Most kids have more friends than I do". Good psychometric properties have been extensively reported (e.g., Marsh, 1988 as cited in Kaminski et al., 2005; Marsh, 1990; Marsh, Smith, Barnes, \& Butler, 1983). Strong internal consistency $(\alpha=.86)$ of the peer relations subscale (Kaminski et al., 2005) and good validity are also consistently reported (Marsh, Relich, \& Smith, 1983). 
Table 1- Revised Items and Subscales of the WIHIC-R

Student Cohesiveness

\begin{tabular}{|l|l|}
\hline \multicolumn{1}{|c|}{ Original Items } & \multicolumn{1}{|c|}{ Revised Items } \\
\hline 1. I make friendships among students in this class. & 1. I make friends in my class. \\
\hline 2. I am friendly to members in this class. & 2. I am friendly to other kids in my class. \\
\hline 3. Members of my class are friends. & 3. Kids in my class are friends with each other. \\
\hline 4. I work well with other students in my class. & 4. I work well with other kids in my class. \\
\hline 5. Students in this class like me. & 5. Kids in my class like me. \\
\hline
\end{tabular}

\section{Teacher Support}

\begin{tabular}{|l|l|}
\hline \multicolumn{1}{|c|}{ Original Items } & \multicolumn{1}{|c|}{ Revised Items } \\
\hline 6. The lecturer takes a personal interest in me. & 6. My teacher gives me attention when I need it. \\
\hline 7. The lecturer considers my feelings. & 7. My teacher cares about my feelings. \\
\hline 8. The lecturer helps me when I have trouble with & 8. My teacher helps me when I need help with my \\
my work. & work. \\
\hline 9. The lecturer talks to me. & 9. My teacher talks to me. \\
\hline 10. The teacher is interested in my problems. & 10. My teacher cares about my problems. \\
\hline
\end{tabular}

\section{Involvement}

\begin{tabular}{|l|l|}
\hline \multicolumn{1}{|c|}{ Original Items } & Revised Items \\
\hline 11. I discuss ideas in class. & 11. I talk about my ideas in class. \\
\hline 12. The lecturer asks me questions. & 12. My teacher asks me questions. \\
\hline 13. I ask the lecturer questions. & 13. I ask my teacher questions. \\
\hline 14. I explain my ideas to other students. & 14. I tell my ideas to other kids in my class. \\
\hline 15. I answer questions during class. & 15. I answer questions in my class. \\
\hline
\end{tabular}




\section{Classroom Perceptions}

Table 1 (continued) - Revised Items and Subscales of the WIHIC-R

\section{Cooperation}

\begin{tabular}{|l|l|}
\hline \multicolumn{1}{|c|}{ Original Items } & \multicolumn{1}{c|}{ Revised Items } \\
\hline t6. When I work in a group in the class, there is & 16. When I work with other kids, there is teamwork. \\
\hline 17. I do group work in class. & 17. I like to do my schoolwork with other kids. \\
\hline 18. I like to work alone instead of in groups. & 18. I like to do my schoolwork by myself. \\
\hline 19. I work well with other students in my class. & 19. I am good at working with other kids. \\
\hline 20. I learn from other students in this class. & 20. Kids in my class teach me things. \\
\hline
\end{tabular}

\section{Equity}

\begin{tabular}{|c|c|}
\hline Original Items & Revised Items \\
\hline $\begin{array}{l}\text { 21. The teacher gives as much attention to my } \\
\text { questions as to other students' questions. }\end{array}$ & $\begin{array}{l}\text { 21. My teacher listens to me just as much as he/she } \\
\text { listens to other kids. }\end{array}$ \\
\hline $\begin{array}{l}\text { 22. I get the same amount of help from the teacher as } \\
\text { do other students. }\end{array}$ & $\begin{array}{l}\text { 22. My teacher helps me just as much as he/she } \\
\text { helps other kids. }\end{array}$ \\
\hline $\begin{array}{l}\text { 23. I am treated the same as other students in this } \\
\text { class. }\end{array}$ & $\begin{array}{l}\text { 23. My teacher treats me the same as other kids in } \\
\text { my class. }\end{array}$ \\
\hline 24. My teacher is fair to all students in class. & 24. My teacher is fair to all the kids in the class. \\
\hline 25. My teacher likes all the students in class. & $\begin{array}{l}\text { 25. My teacher likes all the kids in my class the } \\
\text { same. }\end{array}$ \\
\hline
\end{tabular}


Table 2 - Table of Means, $S D$, and Range for the WIHIC-R Items

\begin{tabular}{|c|c|c|c|}
\hline Item & Mean & Standard Deviation & Range \\
\hline 1 & 3.96 & .90 & $1.00-4.00$ \\
\hline 2 & 3.69 & 1.05 & $1.00-4.00$ \\
\hline 3 & 3.38 & .98 & $1.00-4.00$ \\
\hline 4 & 3.81 & .88 & $1.00-4.00$ \\
\hline 5 & 4.14 & 1.07 & $1.00-4.00$ \\
\hline 6 & 4.47 & .66 & $1.00-3.00$ \\
\hline 7 & 3.71 & .92 & $1.00-4.00$ \\
\hline 8 & 3.71 & .97 & $1.00-4.00$ \\
\hline 9 & 3.63 & 1.13 & $1.00-4.00$ \\
\hline 10 & 4.15 & 1.01 & $1.00-4.00$ \\
\hline 11 & 1.02 & .81 & $1.00-3.00$ \\
\hline 12 & 4.23 & .86 & $1.00-4.00$ \\
\hline 13 & 3.64 & .86 & $1.00-4.00$ \\
\hline 14 & 3.23 & 1.06 & $1.00-4.00$ \\
\hline 15 & 4.19 & .10 & $1.00-4.00$ \\
\hline 16 & 3.93 & .87 & $1.00-4.00$ \\
\hline 17 & 3.94 & .911 & $1.00-4.00$ \\
\hline 18 & 3.37 & 1.01 & $1.00-4.00$ \\
\hline 19 & 3.89 & .87 & $1.00-4.00$ \\
\hline 20 & 4.31 & .98 & $1.00-4.00$ \\
\hline
\end{tabular}


Table 2 (continued) - Table of Means, $S D$, and Range for the WIHIC-R Items

\begin{tabular}{|l|c|c|c|}
\hline 21 & 3.92 & .87 & $1.00-4.00$ \\
\hline 22 & 4.24 & .94 & $1.00-4.00$ \\
\hline 23 & 3.74 & .86 & $1.00-4.00$ \\
\hline 24 & 3.33 & 1.04 & $1.00-4.00$ \\
\hline 25 & 4.28 & 1.07 & $1.00-4.00$ \\
\hline
\end{tabular}

Items from the general school subscale target student's ratings of their skills, abilities, interests, and enjoyment of school subjects in general. There are 10 items on this subscale that elicit responses for questions such as; "I am interested in school subjects", "I look forward to all school subjects", and "I hate all school subjects". Strong internal consistency $(\alpha=.87)$ has been demonstrated (Kaminski et al., 2005). In the current sample, the internal consistency was similar for both the peer relations subscale $(\alpha=.83)$ and the global school subscale $(\alpha=.88)$.

Loneliness and Social Dissatisfaction Scale. Participants were asked to complete the Loneliness and Social Dissatisfaction Scale (LSDQ; Asher \& Wheeler, 1985, see Appendix F) as a measure of loneliness and social satisfaction in the classroom. The LSDQ has been widely used in an upper elementary school population (Asher \& Wheeler, 1985). This particular measure was derived from a body of research assessing the outcomes associated with unpopular children (Asher, Hymel, \& Renshaw, 1984). The LSDS was slightly modified from an older version of a similar measure (Asher et al., 1984; Hymel, Freigang, Franke, Both, Bream, \& Borys, 1983) assessing loneliness and social dissatisfaction. The current measure extends to include items specifically 
addressing feelings of loneliness and social dissatisfaction in school (e.g., "I like school"; "I have lots of friends in my class"; "I feel alone at school"). The LSDS demonstrates good psychometric properties (Asher \& Wheeler, 1985).

The LSDS contains 16 items (plus 8 'filler items' relating to children's interests and hobbies) targeting children's feelings of loneliness (e.g., "I'm lonely at school"), feelings of social adequacy versus inadequacy (e.g., "I can find a friend in my class when I need one"), and children's subjective estimations of peer status (e.g., "I am well liked by the kids in my class"). Children report on a 5-point scale ranging from; 1- "that's not true about me at all", 2- "that's hardly ever true about me", 2- "that's sometimes true about me", 4- "that's true about me most of the time", and "that's always true about me". Loneliness scores are found to remain relatively stable $(r=.55)$ over a one year period. In addition, the LSDQ scales are found to be internally consistent with a Cronbach's alpha of .90 (Asher \& Wheeler, 1985). In the current sample, the internal consistency for the LSDS was strong $(\alpha=.83)$.

Peer victimization. Self-reports of peer victimization were also obtained as a measure of peer victimization in the classroom. Participants will be asked to complete the peer victimization subscale on the Perceptions of Peer Support Scale (PPSS; Ladd, Kochenderfer \& Coleman, 1996, see Appendix G). This particular subscale includes four items that target children's perceptions of peers in their class. Participants respond on a 3point scale ranging from; 1- "no", 2- "sometimes", and 3- "a lot". Victimization scores are obtained by averaging responses on all four items on the subscale eliciting a score between 1.00 and 3.00 (Ladd \& Kochenderfer, 1996; Ladd, Kochenderfer \& Coleman, 1996). 
Validity and reliability have been widely demonstrated in the literature (Alsaker, 1993; Boulton \& Underwood, 1992; Kochenderfer-Ladd, \& Ladd, 2002; Ladd \& Kochenderfer, 1996; Ladd et al., 1996). In order to assess the validity, Kochenderfer and Ladd (1996) conducted observations in a kindergarten sample and compared the observational data to the self report data obtained on the PPSS (Kochenderfer \& Ladd, 1996). The observational data and self-reports were highly correlated suggesting that the trained observers were accurately identifying victims. Moderate stability of the measure has also been demonstrated over a 5-year period with stability ratings ranging from .13 to .52 (Buhs, Ladd, \& Herald, 2006). Reliability coefficients for each of the scales have been demonstrated to range from .73 to .80 (Buhs et al., 2006). In the current sample, the internal consistency for the PPSS was moderate $(\alpha=.75)$.

Social anxiety. The revised version of the Social Anxiety Scale for Children (SASC-R; La Greca \& Stone, 1993; see Appendix H) was also administered to the participants in the current project. The SASC-R contains 22 items, 18 items concerning social anxiety and 4 filler items (La Greca \& Stone, 1993; Ginsburg, La Greca, \& Silverman, 1998, - previously approved - 04-044). There are three subscales on the SASC-R: Fear of Negative Evaluation from Peers (FNE, 8 items, contains items pertaining to children's worries about peers' negative perceptions of them), Social Avoidance and Distress-Specific to New Peers or Situations (SAD-New; 6 items, consists of questions related to social avoidance or distress felt in new situations or when around unfamiliar peers), and Generalized Social Avoidance and Distress (SAD-General; 4 items, contains items that reflect social avoidance or distress in more general situations, other than when the situations or the peers are unfamiliar). For the SASC-R children will 
be asked to indicate how true each statement is for them. The items on the SASC-R are rated on the following 5-point Likert scale: 1) not at all, 2) hardly ever, 3) sometimes, 4) most of the time, and 5) all the time. The SASC-R has been shown to be appropriate for use with children who are in the age range of the participants in the current investigation (Ginsburg et al., 1998; La Greca, Dandes, Wick, Shaw, \& Stone, 1988; La Greca \& Stone, 1993). In the current sample, the internal consistency for the SASC-R was strong $(\alpha=.92)$.

Results

\section{Data Screening}

Preliminary analyses were first conducted in order to ensure that the assumptions of multiple regression (i.e., multicollinearity, outliers, normality) were not violated. First, the intercorrelations between the independent variables (i.e., subscale perception scores) and the dependent variables (i.e., anxiety, loneliness, victimization, and self-concept) were explored. For the most part, the correlations between the independent variables and the dependent variables were greater than .3 , indicating that multicollinearity is not an issue (Pallant, 2007; Tabachnick \& Fidell, 2007). Further, the correlations between the independent variables are less than .7 also indicating that multicollinearity is not a concern. Second, the Normal Probability Plot (P-P) was examined to assess for outliers,

normality, homoscedasticity, and independence of residuals. Findings suggest that these assumptions were not violated (Pallant, 2007; Tabachnick \& Fidell, 2007).

Preliminary Analysis- WIHIC-R Perceived Form

In order to assess the factor structure of the perceived form of the What is Happening in this Class? - Revised measure, a principal components factor analysis was 
conducted. Assumptions of factor analysis were assessed to ensure the suitability of the data for conducting factor analyses. First, in terms of sample size, it is suggested that a ratio of at least five cases for each of the variables or a sample $>300$ exist (Stevens, 1996; Tabachnick \& Fidell, 1996). The current sample consists of a ratio of 13.8 cases for each variable and an overall sample of $\mathrm{N}=328$ suggesting this assumption has not been violated. Second, the factorability of the correlation matrix was assessed and results indicated that a large majority of the correlations are $r=.3$ or greater. The Bartlett's test of sphericity was found to be significant at $p=.000$ and the Kaiser-Meyer-Olkin value was .89 providing further support that factor analysis is appropriate. Third, outliers were assessed and a few outliers were identified on some of the items. In order to assess this further, factor analysis was run with the outliers included and again with the exclusion of the outliers and the pattern for each remained the same. Finally, the linearity assumption was also not violated as there is no clear evidence of a curvilinear relationship and the ratio of cases to variables is adequate (Pallant, 2003). The means, $S D$, and range for all study variables are presented in Table 3.

Principal Components Analyses (PCA) with both varimax and direct oblimin rotation were conducted on the WIHIC-R. Results using each rotation technique were similar therefore the interpretation of the varimax rotation is described here (Stevens, 2002). Consistent with previous analyses of similar measures, items with factor loadings higher than .40 on one factor and lower than .40 on all other factors were included (Aldridge \& Fraser, 1999; Allen \& Fraser, 2007). With all items included in the analyses, a five factor structure emerged. However, some of the items did not load as predicted. For 
Table 3 - Means, SD, and Range for All Study Variables

\begin{tabular}{|l|l|l|l|}
\hline \multicolumn{1}{|c|}{ Variable } & \multicolumn{1}{|c|}{ Mean } & \multicolumn{1}{c|}{ SD } & \multicolumn{1}{c|}{ Range } \\
\hline Victimization & 1.57 & .48 & $1.00-2.00$ \\
\hline Self-Concept- Peer & 3.59 & .80 & $1.00-4.00$ \\
\hline Self-Concept- School & 3.74 & .80 & $1.00-4.00$ \\
\hline Perception- Teacher & 4.17 & .78 & $1.00-4.00$ \\
\hline Perception- Student & 4.01 & .53 & $1.00-2.50$ \\
\hline Perception-Involvement & 3.62 & .64 & $1.00-3.50$ \\
\hline Anxiety & 2.46 & .75 & $1.00-4.00$ \\
\hline
\end{tabular}

example, item -14 (“I like to do my school work by myself") did not load in the predicted. As a result, 6 items were systematically removed (see Table 4). Analyses were then re-computed and a three-factor structure emerged. The scree-plot (Cattell, 1966; Gorsuch, 1983; Tabachnick \& Fidell, 2007; Zoski \& Jurs, 1996) is displayed in Figure 1 and indicates support for a 3-factor solution.

The first factor was labeled Teacher Support \& Equity and consisted of $\mathrm{n}=9$ items that were originally predicted to load on either the Teacher Support or Teacher Equity factor. This factor accounted for $34.64 \%$ of the variance with factor loadings ranging from .58 to .81 and high internal consistency $(\alpha=.92)$. The second factor was labeled Student Cohesiveness and included $\mathrm{n}=6$ items originally predicted to load on the Student Cohesiveness and Cooperation subscales. This factor accounted for $12.19 \%$ of the variance, with factor loadings ranging from .48 to .75 and moderate internal consistency 
Table 4 - Items removed from WIHIC-R

\begin{tabular}{|l|l|}
\hline Item 9 & My teacher talks to me. \\
\hline Item 14 & I tell my ideas to other kids in my class. \\
\hline Item 16 & When I work with other kids, there is teamwork. \\
\hline Item 17 & I like to do my schoolwork with other kids. \\
\hline Item 18 & I like to do my schoolwork by myself. \\
\hline Item 24 & My teacher is fair to all the kids in the class. \\
\hline
\end{tabular}

Figure 1

Scree Plot of WIHIC-R- Factors

Scree Plot

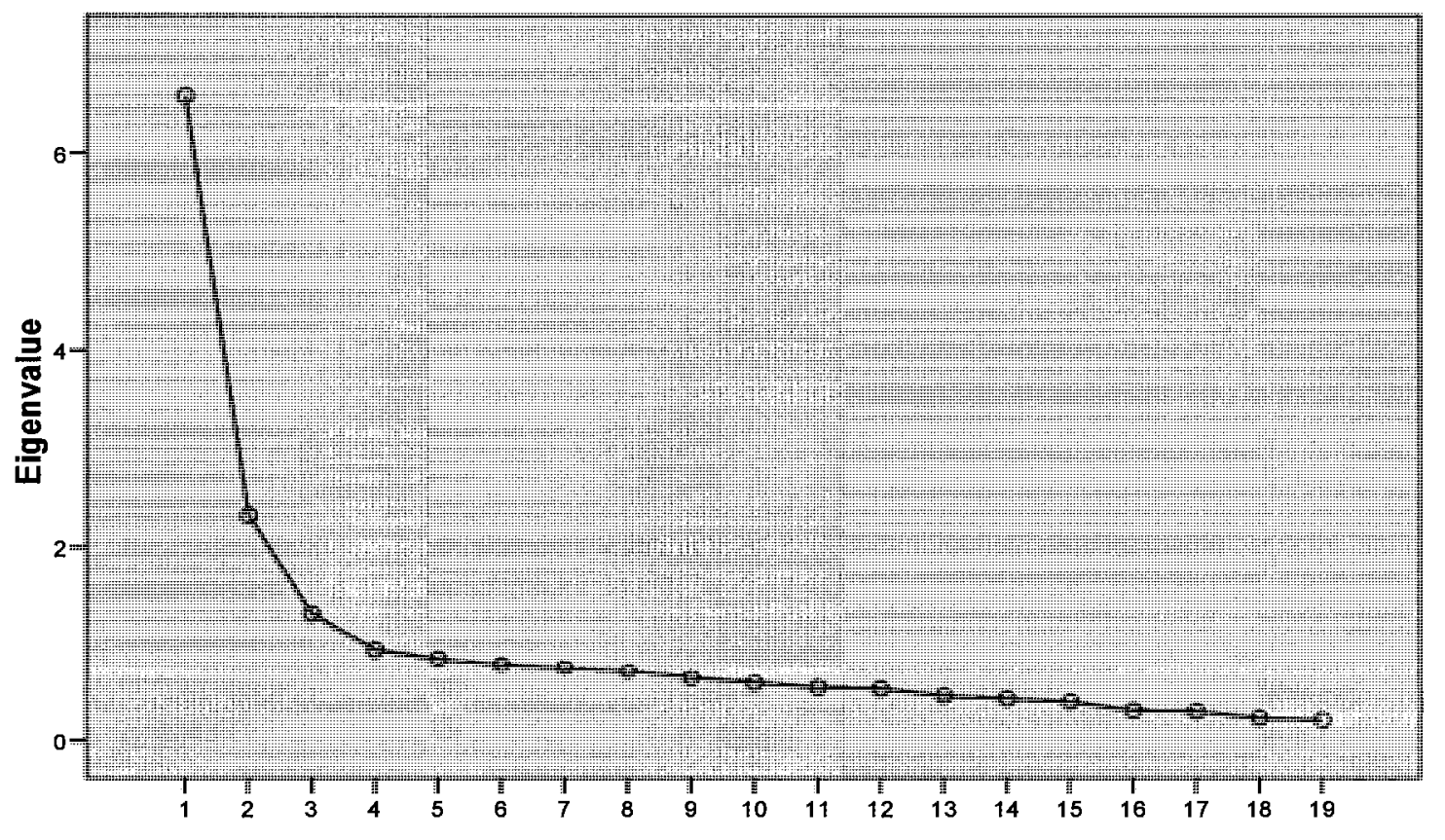


$(\alpha=.69)$. Finally, the third factor was labeled Involvement and included $n=4$ items (of the originally hypothesized 6 items). This factor accounted for $6.99 \%$ of the variance, with factor loadings ranging from .52 to .68 and moderate internal consistency $(\alpha=.70)$. The three subscales were moderately inter-correlated (see Table 5).

Grade and gender effects. In order to assess potential grade and gender effects on perception scores, a $2 \times 2 \times 3$ repeated measures MANOVA was conducted with gender and grade as the between subjects factors and the perception subscales as the within-subject factors. Results indicated a significant effect of Grade, $F(4,628)=4.37, p=.000$; Wilks' $\lambda=.92$. The effect of gender and the grade $\mathrm{x}$ gender interaction were not significant. It is important to note that because the data was anonymous for the current study; demographic variables were not able to be linked with child variable scores. Demographic variables were examined in Study 2. Follow up univariate indicated significant grade differences in terms of perceptions of teacher support and perceptions of involvement. Post-hoc comparisons (LSD) indicated that perceptions of teacher support was significantly higher in Grade $4(M=4.39, S D=.62)$ than Grade $3(M=4.14, S D=.72)$ or Grade $5(M=3.97, S D=.93)$, which did not differ significantly from each other. Further, perceptions of involvement in Grade $4(M=3.74, S D=.58)$ were significantly higher than in Grade $3(M=3.52, S D=.62)$ but not Grade $5(M=3.60, S D=.70)$. 
Table 5 -Factor Loadings on WIHIC-R Items

\begin{tabular}{|c|c|}
\hline Items & Factor Loadings \\
\hline \multicolumn{2}{|l|}{ Teacher Support } \\
\hline 2. My teacher gives me attention when I need it. & .58 \\
\hline $\begin{array}{l}\text { 5. My teacher listens to me just as much as he/she listens to other } \\
\text { kids. }\end{array}$ & .79 \\
\hline 7. My teacher cares about my feelings. & .81 \\
\hline 10. My teacher helps me just as much as he/she helps other kids. & .79 \\
\hline 12. My teacher helps me when I need help with my work. & .68 \\
\hline 15. My teacher treats me the same as other kids in my class. & .80 \\
\hline 20. My teacher is fair to all the kids in my class. & .81 \\
\hline 22. My teacher cares about my problems. & .81 \\
\hline 25. My teacher likes all the kids in my class the same. & .81 \\
\hline \multicolumn{2}{|l|}{ Student Cohesiveness } \\
\hline Items & Factor Loadings \\
\hline 1. I make friends in my class. & .59 \\
\hline 4. When I work with other kids, there is teamwork. & .48 \\
\hline 6. I am friendly to other kids in my class. & .64 \\
\hline 11. Kids in my class are friends with each other. & .57 \\
\hline 19. I am good at working with other kids. & .49 \\
\hline 21. Kids in my class like me. & .75 \\
\hline
\end{tabular}


Table 5-(continued) Factor Loadings on WIHIC-R Itens

\begin{tabular}{|l|c|}
\hline \multicolumn{2}{|c|}{ Involvement } \\
\hline Items & Factor Loadings \\
\hline 3. I talk about my ideas in class. & .73 \\
\hline 8. My teacher asks me questions. & .52 \\
\hline 13. I ask my teacher questions. & .68 \\
\hline 23. I answer questions in my class. & .64 \\
\hline
\end{tabular}

\section{Correlations between variables}

Correlations between all study variables are presented in Table 6. As expected, outcome variables were highly intercorrelated. For example, both school and peer selfconcept were negatively related to adjustment difficulties including victimization, loneliness, and anxiety. Further, high incidences of each of the adjustment outcomes were positively correlated with one another suggesting that children who report difficulties will likely experience these difficulties across several dimensions of social adjustment.

Intercorrelations between subscale perceptions scores are also presented in Table 6. As expected, these variables are positively intercorrelated indicating that children who report satisfaction on one dimension of their classroom experience (i.e., teacher support) are likely to also report satisfaction on other dimensions (i.e., student cohesiveness or involvement). Finally, the intercorrelations between the independent variables and the dependent variables are also presented in Table 6. As expected, subscale perception scores are negatively related with adjustment difficulties including anxiety, victimization, and loneliness. Further, subscale perception scores and self-concept (both school and 
peer) are positively related indicated that children who report a positive experience in their classroom are also likely to report higher self-concept in school and with peers. Construct Validity

In order to assess the validity of the measure, predictions were made with regard to perceived classroom environment scores and conceptually relevant outcome variables (i.e., loneliness, peer victimization, anxiety, self-concept). It was also of interest whether these associations differed as a function of child gender. A series of hierarchical multiple regression analyses were conducted - with separate equations were computed to predict each outcome variable. Results from these preliminary analyses indicated that none of the perception $\mathrm{x}$ gender interaction effects were significant in the prediction of each of the outcome variables. Further, controlling for gender did not alter the results. Therefore, gender was not included as a variable in the final analyses presented below. Similarly, a series hierarchical multiple regression analyses were conducted both controlling for grade effects and not controlling for grade. As the patterns did not differ, grade was not controlled for in the following analyses. Perception subscale scores were entered at Step 1. 
Table 6 - Intercorrelations between all Study Variables

\begin{tabular}{|c|c|c|c|c|c|c|c|}
\hline Variables & 2 & 3 & 4 & 5 & 6 & 7 & 8 \\
\hline 1. Perception- Student & $.42 * * *$ & $.43 * * *$ & $-.35 * * *$ & $-.52 * * *$ & $-.27 * * *$ & $.43^{* * *}$ & $.31 * * *$ \\
\hline 2. Perception- Teacher & & $.35 * * *$ & $-.45 * * *$ & $-.22 * * *$ & $-.15 * *$ & .08 & $.31 * * *$ \\
\hline 3. Perception- Involvement & & & $-.15^{* *}$ & $-.21 * * *$ & $-.15^{* *}$ & $.27 * * *$ & $.29 * * *$ \\
\hline 4. Victimization & & & & $.36 * * *$ & $.34 * * *$ & -.07 & $-.18^{* *}$ \\
\hline 5. Loneliness & & & & & $.39 * * *$ & $-.55 * * *$ & $-.38 * * *$ \\
\hline 6. Anxiety & & & & & & $-.24 * * *$ & $-.19^{* *}$ \\
\hline 7. Self-Concept: Peer & & & & & & & $.38 * * *$ \\
\hline 8. Self-Concept: School & & & & & & & \\
\hline
\end{tabular}

${ }^{* * *} p<.001,{ }^{* *} p<.01, * p<.05$ 
Victimization. Results from regression analyses predicting victimization are summarized in Table 7. As a block, the three classroom perception scores contributed significant additional variance to the prediction of victimization. This appeared to be primarily due to the significant individual relations between victimization and both Student Cohesiveness and Teacher Support. Children with higher perception scores on either the Student Cohesiveness subscale or the Teacher Support subscale were less likely to report victimization. A significant main effect for Involvement and victimization was not found.

Loneliness. Results from regression analyses predicting loneliness are summarized in Table 7. As a block, the three classroom perception scores contributed a significant amount of additional variance to the prediction of loneliness. This appeared to be due to the significant individual relation between loneliness and Student Cohesiveness. Children that report higher levels of Student Cohesiveness report lower levels of loneliness. Significant main effects for the remaining subscale perception scores were not found.

Anxiety. Results from regression analyses predicting anxiety are summarized in Table 7. As a block, the three classroom perception scores contributed a significant amount of additional variance to the prediction of victimization. This appeared to be due to the significant individual relation between anxiety and Student Cohesiveness. Children with higher perception scores on Student Cohesiveness were less likely to report anxiety. Main effects for the two remaining subscales and anxiety were not significant.

Self Concept: Peer. Results from regression analyses predicting self-concept with pees are summarized in Table 7. As a block, the three classroom perception scores 
contributed a significant amount of additional variance to the prediction of self-concept among peers. This appeared to be due to significant individual relations between selfconcept and each of the individual subscales. First, children with higher Student Cohesiveness perception scores report higher self-concept with regards to peers. Second, children that report higher Involvement perception scores are also more likely to report higher self-concept with peers. Finally, children that report higher Teacher Support perception scores are more likely to report lower levels of self-concept with peers. This finding is particularly interesting, as it would have been anticipated that children who perceive their teacher to be highly supportive would also feel better about themselves when interacting with peers. However, this finding may represent those children that have close relationships with their teachers, but do not feel that they are as confident with their peers.

Self-concept: School. Results from regression analyses predicting self-concept in school are summarized in Table 7. As a block, the three classroom perception scores contribute a significant amount of additional variance to the prediction of self-concept at school. This appeared to be due to significant individual relations between self-concept in school and each of the subscale perception scores. First, children with higher Student Cohesiveness perception scores were more likely to report higher self-concept in terms of school. Second, children that report higher levels of Teacher Support perception scores were more likely to report higher self-concept in terms of school. Finally, children that report high levels of Involvement perception scores are more likely to also report higher self-concept with regards to school. 
Table 7 - Hierarchical Regression Analyses predicting Social Adjustment outcomes from Gender and Subscale Perception Scores.

\begin{tabular}{|c|c|c|c|c|c|c|c|}
\hline Outcome Variable & Predictor Variables & $\mathrm{R}^{2}$ & $\mathrm{~F}$ & $\Delta \mathrm{R}^{2}$ & $\Delta \mathrm{F}$ & $\beta$ & $s r$ \\
\hline \multirow[t]{4}{*}{ Peer Victimization } & Step 1 & .25 & $26.37^{* * *}$ & & & & \\
\hline & Student Cohesiveness & & & & & $-.21 * * *$ & -.18 \\
\hline & Teacher Support & & & & & $-.40 * * *$ & -.35 \\
\hline & Involvement & & & & & .07 & .06 \\
\hline Outcome Variable & Predictor Variables & $\mathrm{R}^{2}$ & $\mathrm{~F}$ & $\Delta \mathrm{R}^{2}$ & $\Delta \mathrm{F}$ & $\beta$ & $s r$ \\
\hline \multirow[t]{4}{*}{ Loneliness } & Step 1 & .28 & $30.37 * * *$ & & & & \\
\hline & Student Cohesiveness & & & & & $-.53 * * *$ & -.45 \\
\hline & Teacher Support & & & & & -.01 & -.01 \\
\hline & Involvement & & & & & .02 & .02 \\
\hline
\end{tabular}

$+p<.08,{ }^{*} p<.05,{ }^{* *} p<.01,{ }^{* * *} p<.00$ 
Table 7 (continued) - Hierarchical Regression Analyses predicting Social Adjustment outcomes from Gender and Classroom Perception Scores.

\begin{tabular}{|c|c|c|c|c|c|c|c|}
\hline Outcome Variable & Predictor Variables & $\mathrm{R}^{2}$ & $\mathrm{~F}$ & $\Delta \mathrm{R}^{2}$ & $\Delta \mathrm{F}$ & $\beta$ & $s r$ \\
\hline \multirow[t]{4}{*}{ Anxiety } & Step 1 & .12 & $11.04^{* * *}$ & & & & \\
\hline & Student Cohesiveness & & & & & $-.24 * * *$ & -.20 \\
\hline & Teacher Support & & & & & -.05 & -.04 \\
\hline & Involvement & & & & & -.04 & -.03 \\
\hline Outcome Variable & Predictor Variables & $\mathrm{R}^{2}$ & $\mathrm{~F}$ & $\Delta \mathrm{R}^{2}$ & $\Delta \mathrm{F}$ & $\beta$ & $s r$ \\
\hline \multirow[t]{4}{*}{ Self-Concept- Peer } & Step 1 & .21 & $21.62 * * *$ & & & & \\
\hline & Student Cohesiveness & & & & & $.44 * * *$ & .38 \\
\hline & Teacher Support & & & & & $-.14^{* *}$ & -.14 \\
\hline & Involvement & & & & & $.13^{*}$ & .12 \\
\hline
\end{tabular}

$+p<.08, * p<.05, * * p<.01, * * * p<.001$ 
Table 7 (continued) - Hierarchical Regression Analyses predicting Social Adjustment outcomes from Gender and Classroom Perception Scores.

\begin{tabular}{|c|c|c|c|c|c|c|c|}
\hline Outcome Variable & Predictor Variables & $\mathrm{R}^{2}$ & $\mathrm{~F}$ & $\Delta \mathrm{R}^{2}$ & $\Delta \mathrm{F}$ & $\beta$ & $s r$ \\
\hline \multirow[t]{4}{*}{ Self-Concept- Schoo } & 1 Step 1 & .16 & $14.79^{* * *}$ & & & & \\
\hline & Student Cohesiveness & & & & & $.17^{* *}$ & .15 \\
\hline & Teacher Support & & & & & $.18^{* *}$ & .16 \\
\hline & Involvement & & & & & $.15^{*}$ & .13 \\
\hline
\end{tabular}

$+p<.08,{ }^{*} p<.05,{ }^{* *} p<.01,{ }^{* * *} p<.001$ 


\section{Discussion - Study 1}

The current study was among the first to assess children's perceptions of classroom environment in an upper-elementary school sample. Previous research had focused almost exclusively on older children and adolescents (e.g., Allen \& Fraser, 2007; Aldridge, Fraser, \& Huang, 1999; Chionh \& Fraser, 1998; Riah \& Fraser, 1998; Zandvliet \& Fraser, 1998). Overall, results indicated that younger children appear to be able to reliably report perceptions of their classroom experiences. However, children in this younger age range did not make the same "fine-grained" differentiations between specific classroom domains (i.e., teacher support and teacher equity). For example, strong evidence exists for a five-factor structure of classroom perception among an adolescent population, whereas in the current sample a three-factor structure is more appropriate (i.e., Aldridge \& Fraser, 1999; Fraser, 1998). Nonetheless, results from the current study provide support for the WIHIC-R as a valid and reliable measure of classroom perceptions among a younger population.

Findings from the current sample indicated that younger children tended to perceive their classroom in three broad categories; (1) teacher characteristics, or the way in which the teacher provides support and is fair to the students in the class; (2) student characteristics, or the way in which children in the class treat one another; and (3) personal characteristics, the extent to which children perceive their own engagement or participation in their classroom environment. Although the predicted five-factor structure was not supported in the current sample, the factor-structure in the current sample represented a "conceptually-interpretable" similar pattern of classroom perception. 
Acceptable (albeit moderate) internal consistency was found for each of the WIHIC-R subscales. It should be noted that the original version of the WIHIC, which has been vastly employed cross-culturally among junior-high-school populations (Aldridge, Fraser, \& Huang, 1999; Chionh \& Fraser, 1998; Riah \& Fraser, 1998; Zandvliet \& Fraser, 1998) consistently yields Cronbach's alpha reliabilities ranging between .81 and .96. However, the moderate alphas reported in the current analyses may be due to the younger age of the present sample. More specifically, moderate alphas in the present study are consistent with those reported in a recent study assessing differences between students' and parents' perceptions of the classroom environment (Allen \& Fraser, 2007) among an upper elementary school population. Findings from the psychometric testing of their version of the WIHIC yield alphas ranging from .67 to .89 which are much more consistent with those presented here.

Results also indicated significant associations between classroom perception scores and conceptually relevant outcome variables. It was predicted that classroom perception would be associated with several social adjustment outcomes. Overall, it is found that children with more negative views of their classroom experiences also reported experiencing adjustment difficulties at school. For example, children who report generally positive interactions among their classmates are less likely to experience social anxiety than children that report more 'negative' interactions among their classmates. Similarly, children who report that their teacher is generally fair and supportive of all the students in the class are less likely to experience peer victimization. These findings are particularly relevant for two reasons. 
First, the current study is among the first to assess classroom perceptions among an upper elementary school population. Findings suggest that although younger children perceive the dimensions of the classroom environment somewhat differently than expected in an older population (i.e., three broader subscales rather than the five more specific classroom characteristics), their ability to report on their classroom experiences remains valid. This finding replicates those from a recent study exploring the association between elementary school children's perceptions of their classroom and achievement in science (Allen \& Fraser, 2007).

Second, this study is the only known study to explore the association of classroom perceptions and social adjustment outcomes rather than academic outcomes (e.g., Fraser, 1986, 1994, 1998; Fraser \& Walberg, 1991). It is important to note however, that it has been widely reported that student achievement is enhanced by classroom perceptions (e.g., Allen \& Fraser, 2007; Fraser, 1994; Fraser \& Fisher, 1994). For example, Fraser's (1994) review of 40 studies clearly demonstrates a significant association between student's perception and achievement using a variety of samples, instruments, measures and outcomes. Findings from the current study provide further support for the association between student perception and outcomes, while highlighting the role of social adjustment.

Concurrently, a body of literature exists exploring the association between observed classroom emotional climate (i.e., global classroom atmosphere: the teacher's behavior, students' responses to the teacher, the teacher's response to students, and interactions among students) and social outcomes in an elementary school sample (e.g., NICHD ECCRN, 2003; Pianta, LaParo, \& Hamre, 2003). Although the methodology 
differs from self-reported perceptions used in the current study, similar associations between classroom factors and adjustment outcomes have been demonstrated. For example, based on observations of classroom emotional climate (CEC), it is reported that students enrolled in an 'unsupportive' classroom are at risk of experiencing adjustment difficulties including peer exclusion (NICHD ECCRN, 2003). Further, although an unsupportive classroom environment poses difficulties for children in general, this is especially true for children identified as anxious solitary (Gazelle, 2006). These findings provide further support for the association between classroom characteristics, whether assessed using observations or self-reported perception, and adjustment outcomes. The current study does not explore the role of specific child characteristics in relation to classroom perception and adjustment outcomes, however this question will be addressed in Study 2, which is presented in a later section.

It is important to note that the correlational design employed in this study does not allow for inferences regarding causality. Notwithstanding, modern models of development emphasize that development is a product of dynamic interactions between multiple levels within the child and their environment. Therefore, guided by a child-byenvironment model, a first step in raising empirical research efforts to match the sophistication of developmental theory is examining the extent to which environmental factors (i.e., classroom environment) influence the development of adjustment outcomes. It would be interesting in future research to further assess the nature of this association from a longitudinal perspective.

It was also interesting to note that despite predictions with regards to gender, none of the gender by perception interaction effects were significant. This suggests that the 


\section{Classroom Perceptions}

association between classroom perceptions and adjustment outcomes do not differ for boys and girls. Historically, classroom perception research has not explored the role of gender in the relation between perceptions and outcomes (Fraser, 1994). Therefore, the findings in the current study provide preliminary evidence that the relation between classroom perception and adjustment outcomes does not differ for boys and girls. This issue was further explored in Study 2.

In summary, the current study provides psychometric support for a new measure of classroom perception among an upper-elementary school sample. Findings suggest that although a younger sample does not differentiate classroom characteristics in the same way as an adolescent population, they are nonetheless able to different among domains of their classroom experiences. Further, relations between conceptually relevant socio-emotional adjustment outcomes and perception scores provide preliminary evidence for the construct validity of the WIHIC-R. These findings are particularly significant, as this study is the first known study to explore the association between perception and social outcomes. Historically, classroom perception has been linked with academic outcomes rather than social outcomes. This study was also among the first to explore the role of gender in terms of classroom perceptions and outcomes variables. Interestingly, none of the gender interactions were significant. These findings suggest that perhaps the associations between classroom perception and outcomes are the same for boys and girls. This issue was further explored in Study 2. The findings in the current study provided support for the WIHIC-R allowing for further investigation into the role of classroom perceptions in an upper elementary school sample. 


\section{Study 2}

\section{The Role of Perceptions of Classroom Environment in the Socio-Emotional Adjustment of Shy and Aggressive Children}

A primary goal of Study 2 was to assess the relations between self-reported perceptions of classroom environment and children's social adjustment. More specifically, this study explored the associations between perceptions of classroom characteristics (i.e., Teacher Support and Equity, Student Cohesiveness, and Involvement) and indices of socio-emotional functioning (e.g., internalizing problems, peer relationship difficulties). A second goal was to explore the potential moderating role of perceived classroom climate in the adjustment of "at risk" children. Therefore, Study 2 explored the buffering and exacerbating functions of classroom perceptions in the relations between aggression, shyness, and adjustment outcomes.

\section{Hypotheses}

To begin with, classroom perception subscales were again expected to be associated with outcome assessments. For example, it was predicted that children with a more negative perception of their classroom environment (on each subscale) would be more likely to report peer relationship difficulties (i.e., peer victimization, loneliness) and internalizing problems (i.e., anxiety, depressive symptoms, school avoidance, lower selfconcept in school and among peers).

In addition, both shyness and aggression were expected to be associated with more negative classroom perceptions. For aggressive children, negative classroom perceptions were postulated to result from an inherent hostile-attribution bias (Boivin, et al., 1995; Dodge \& Price, 1994). For shy children, negative classroom perception might 
arise from a bias in interpreting their environment as more threatening (Wichmann et al., 2004). Moreover, it has been widely reported in the literature that aggressive and shy children are at an increased risk of experiencing adjustment difficulties (e.g., Boivin et al., 1995; Coplan, Girardi, Findlay, \& Frohlick, 2007; Morison \& Masten, 1991; Ollendick et al., 1990). Thus, it was also expected that both aggression and shyness would be associated with a broad range of social adjustment difficulties including negative self-concept, victimization, anxiety, depressive symptoms, school avoidance, and loneliness.

However, it was also speculated that classroom perceptions might moderate the relations between behavioural characteristics and adjustment difficulties. In other words, although both shyness and aggression were expected to be related to increased adjustment difficulties, it was expected that these associations would be attenuated (i.e., 'buffering effect") among children with more positive perceptions of their classroom environment. Methods

\section{Participants}

Participants in the study were $n=297$ elementary school children aged $7-11$ years (143 boys, 148 girls, $M_{\text {age }}=8.99, S D=.88$ ). Children were recruited from 38 classes in 6 schools in the Southern Alberta area. Participants were enrolled in grade $3(n=89)$, grade $4(n=101)$, or grade $5(n=78)$. Demographic information included parental education and ethnicity. Maternal education in the current sample consisted of $4.5 \%$ with an elementary school education, $20.3 \%$ with a high school education, $40.1 \%$ with a college education, $26 \%$ with an undergraduate degree, and $8.7 \%$ with a graduate degree. Paternal education for the current sample consisted of 5.5\% with an elementary school degree, $26.2 \%$ with a 
high school education, $36.4 \%$ with a college education, $22.5 \%$ with an undergraduate degree, and $9.5 \%$ with a graduate degree. Maternal ethnicity of the current sample consisted of $91.2 \%$ Caucasian, 4.6\% Asian, 7\% Hispanic, 4\% Black, 1.4\% Aboriginal, and $1.8 \%$ Other. Paternal ethnicity of the current sample consisted of $90 \%$ Caucasian, 3.3\% Asian, 1.9\% Black, 4\% Hispanic, 2.2\% Aboriginal, 2.2\% Other. The large majority of the sample (98.6\%) reported English as the language spoken in the home.

Procedure

Upon the approval of the school board, principals at several schools were invited to participate in the study. For the schools that agreed to participate, a recruitment package was sent home with their students in grades 3,4 , and 5 students across 6 elementary schools. The information package included a brief description of the study (see Appendix I), a consent form (see Appendix B), and a form designed to collect demographic data (i.e., parental education, ethnicity, and language; see Appendix C). Upon parental consent, a schedule was set up with each of the teachers. Children that received parental consent were removed from the class during the scheduled time in order to participate. Testing occurred in a group setting either in a space in each of the schools that was allotted for the study (i.e., classroom or library). Participants were informed that there were no 'right' or 'wrong' answers and that their answers would remain confidential from their friends, their teachers, and their parents. Participants were also informed that they were not required to answer questions that they were not comfortable answering. Measures

What Is Happening In this Class? For a description of WIHIC-R, refer to the Measures section of Study 1. Participating children were asked to complete WIHIC-R. 
For the current sample, the reliability coefficient's for the WIHIC-R ranged from $\alpha=.87$ for the Teacher Support subscale, $\alpha=.76$ for the Student Cohesiveness subscale, and $\alpha=.68$ for the Involvement subscale.

Extended Class Play. The Extended Class Play (ECP: Burgess, Wojslawowicz Bowker, Oh, \& Rubin, 2006; see Appendix J) is a peer report measure of shynesswithdrawal, aggression, victimization and prosocial behaviours. The ECP was designed in an attempt to modify and improve upon earlier peer report measures of behavioural characteristics (e.g. Class Play: Lambert \& Bower, 1961; Revised Class Play; RCP: Masten, Morison, \& Pellegrini, 1985). The original RCP consists of three broad subscales one of which includes child characteristics which are referred to as Sensitive/Isolated, Aggressive/Disruptive, and Sociability/Leadership (Burgess et al., 2006). However, recent research suggests that there heterogeneity among these broader definitions of social behaviour. Using the Sensitivity/Isolated subscale as an example, researchers have identified subtypes of social withdrawal (e.g. active isolation from the peer group versus shyness) that lead to different adjustment difficulties (Burgess et al., 2006). For example, shy children that are actively isolated from their peer group are more likely to experience externalizing difficulties whereas withdrawn children are more likely to experience internalizing difficulties. Similarly, recent research demonstrates a differentiation between relational and physical forms of aggression (Coie \& Dodge, 1998; Crick \& Grotpeter, 1995). However, the RCP does not different between these subtypes of aggression rather this measure only includes physically aggressive acts. Therefore, it may be misleading to assess a broad definition of Sensitivity/Isolated when exploring their effect of adjustment outcomes. 
As a result of the limitations of the RCP, the ECP was modified to include subscales encompassing multiple levels of these broader behavioural constructs. This measure has been previously employed and tested using an upper-elementary school sample (Burgess et al., 2003). In order to complete this measure, children were provided with a list of all of the participating children in their class. Children were asked to nominate one boy and one girl that would suit a role in an imaginary play. Each of the stories consists of typically 'positive' and 'negative' roles. It is explained to the children that they may nominate a classmate more than once.

Five separate factors emerge when exploratory factor analyses of the ECP is performed. These distinct subscales include Aggression, Shyness/Withdrawal, Victimization/Exclusion, Prosocial Behaviours, and Popularity/Sociability (Burgess et al., 2006). As described in Burgess et al., (2006), the ECP was extended from the RCP to include two additional aggression items (e.g. "Someone who thinks self is great", "Someone who spreads rumors about other kids so that people won't like them anymore"), five additional items targeting reticence, shyness, and social disinterest (e.g. "Someone who stays by himself", "Someone who likes spending time alone", "Someone who rarely starts up a conversation", "Someone who talks quietly or rarely", "Someone who gets nervous participating in class discussions") and three additional items describing victimization (e.g. "Someone who has mean things said to them", "Someone who gets picked on", and "Someone who is hit/kicked by others"). For the current sample, the reliability coefficients were $\alpha=.89$ for Aggression and $\alpha=.83$ for Shyness.

Self Description Questionnaire. For a description of the SDQ-I, refer to the Measures section of Study 1. For the purposes of the current study, the peer relations and 
global school subscales of the SDQ-I were administered to assess domains of selfconcept as outcome variables. For the current sample, the reliability coefficient for each of the SDQ-I subscales was $\alpha=.76$ for the peer relations subscale and $\alpha=.88$ for the global school subscale.

Loneliness and Social Dissatisfaction Scale. For a description of the LSDS, refer to the Measures section of Study 1. For the purposes of the current study, the LSDS was administered in order to assess self-reported feelings of loneliness and social dissatisfaction as an outcome variable. For the current sample, the reliability coefficient for the LSDS was $\alpha=.91$.

Child Depression Inventory-Short form. The Child Depression Inventory-Short form (CDI-Short Form; Kovacs, 1992; see Appendix K) is a self-report questionnaire for children and adolescents. The original Children's Depression Inventory (CDI; 1983) was derived based on the need of a depression inventory for children that is similar to the measures available for adults. The CDI-Short Form, which was administered in the current investigation, is designed to assess depressive symptoms including disturbed mood, hedonic capacities, vegetative functions, self evaluation, and interpersonal behaviours (Kovacs, 1992). Children responded on a 3- point likert scale ranging from; 0never, 1-sometimes, 2-always. The CDI- Short Form total score can range from 0 to 54 and consists of 10 items. An advantage of the CDI-Short Form is that it is short (administration time is 15 minutes or less) which is particularly useful when conducting assessments among a preadolescent population. Sample items of the CDI- Short Form include; "I am sad once in awhile", "I do not like myself", "things bother me many times". The alpha reliability coefficient of the CDI-Short Form was reported as .80 and 
the scale correlated $r=.89$ with the full CDI (Kovacs, 1992). For the current sample the reliability coefficient for the CDI-short form was $\alpha=.91$.

Peer Victimization Scale. For a description of the Perceptions of Peer Support Scale (PPSS; Ladd, Kochenderfer \& Coleman, 1996), refer to the Measures section in Study 1. For the purposes of the current study, the PPSS was administered in order to obtain a self-report rating of peer victimization. For the current sample, the reliability coefficient for the PPSS was alpha $\alpha=.77$.

School Liking and Avoidance Questionnaire. For the purposes of the current study, the School Liking and Avoidance Questionnaire (SLAQ; Ladd \& Price, 1987; see Appendix L) was administered in order to obtain a self-report measure of children's attitudes about school. The SLAQ consists of fourteen items that have been derived from earlier measures designed to target attitudes toward school (SSI; Frith \& Narikawa, 1979; Ladd \& Price, 1987). In the present study, the school avoidance subscale was particularly of interest. This subscale includes five items that target children's negative attitudes towards school ("Do you wish you didn't have to come to school?" or "Do you ask your Mom or Dad to let you stay home from school?"). Children were asked to respond on a 5point scale ranging from; 1-"never", 2-"hardly ever", 3-“Sometimes", 4-"most of the time", or 5-“all of the time". Scores will be obtained by averaging items within each scale (Ladd, Kochenderfer, \& Coleman, 1997). The SLAQ demonstrates good psychometric properties with Cronbach's as ranging from .72 to .81 on the school avoidance. Construct validity of the SLAQ has been widely reported (Birch \& Ladd, 1997; Ladd et al., 1996). For the current sample, the reliability coefficient for the School Avoidance subscale was $\alpha=.87$. 
Social anxiety. For a description of the SASC-R, refer to the Measures section of Study 1. For the purposes of the current study the SASC-R was employed to obtain a self-reported rating of social anxiety. For the current sample, the reliability coefficient for the SASC-R was $\alpha=.93$.

\section{Results}

\section{Data screening}

Preliminary analyses were first conducted in order to ensure that the assumptions of multiple regression (i.e., multicollinearity, outliers, normality) were not violated. First, the intercorrelations between the independent variables (i.e., classroom perceptions, aggression, and shyness) and the dependent variables (i.e., anxiety, loneliness, victimization, self-concept, school and avoidance) were explored. For the most part, the intercorrelations between the independent variables and the dependent variables were greater than .3, indicating that multicollinearity is not an issue (Pallant, 2007; Tabachnick $\&$ Fidell, 2007). Further, the correlations between the independent variables are less than .7 also indicating that multicollinearity is also not a concern. Second, the Normal Probability Plot (P-P) was examined to assess for outliers, normality, homoscedasticity, and independence of residuals. Findings suggest that these assumptions were not violated (Pallant, 2007; Tabachnick \& Fidell, 2007).

Confirmatory Factor Analysis. A three-factor structure (including 19- items) was established for the WIHIC-R in Study 1 using exploratory factor analyses. Thus, a confirmatory factor analysis (CFA) was conducted in the study 2 sample. A CFA allows for an assessment of fit between observed data and an 'a priori' conceptualization that is a theoretically based prediction of the relations between observed indicators and latent 
variables (Mueller \& Hancock, 2001). The hypothesized model is presented in Figure 2 where the circles represent the latent variables (or factors), and the rectangles represent the items predicted to load on the corresponding factors. The three factor model (from Study 1) of perception of Teacher Equity \& Support, Student Cohesiveness, and Involvement was hypothesized. Covariance between the three latent variables (or factors) was allowed given the prediction that the specific dimensions of children's classroom perceptions are somewhat related. The model was tested using the maximum likelihood modeling in AMOS.

Preliminary analyses of the individual parameter estimates were first assessed in order to explore the appropriateness of the proposed model. Results of these analyses indicate a good fit of the model with estimate values ranging from .27 to .90 and include positive variances. Standard errors (S.E.) were also assessed and found to range from .03 to .08 also indicating a good fit. Finally, preliminary analyses of the critical ratios (C.R.) also indicate a good fit with values $> \pm 1.96$.

In terms of the overall fit of the model, several fit statistics were assessed. First, the $\chi^{2}(149, N=268)=291.46, \mathrm{p}=.00$ was significant indicating a significant difference between the sample and the estimated population covariance. Although a significant $\chi^{2}$ typically indicates a poor fit, there is much debate in the literature about the sensitivity to sample size and as such $\chi^{2}$ should not be used as the sole measure of appropriate fit (Stevens, 2002; Tabachnick \& Fidell, 2007; Byrne, 2001). Nonetheless, it is argued that a good-fitting model may be indicated when the ratio of $\chi^{2}$ to degrees of freedom is less than two (Tabachnick \& Fidell, 2007). In the current data set, this ratio is equal to 1.96 
indicating that perhaps the model does fit appropriately, however, due to the limitations of the $\chi^{2}$ statistic, several other fit indices are also presented.

The normed fit index (NFI; Bentler-Bonett, 1980) indicates a moderate fit of the model (NFI=.84) where values $>.95$ indicate a good fit (Hu \& Bentler, 1999). The incremental fit index (IFI; Bollen, 1989) also indicates a moderate fit of model (IFI= .91) where values outside of the $0-1$ range indicate a good fit. The comparative fit index (CFI; Bentler, 1988) also indicates a moderate fit of the model $(\mathrm{CFI}=.91)$ where values $>.95$ are considered a good fit. The root mean square error of approximation (RMSEA; Browne \& Cudeck, 1993) indicates a good-fitting model ( $\mathrm{RMSEA}=.06)$ with values $\leq .06$ representing a good fit. The expected cross-validation index (ECVI; Browne \& Cudeck, 1989) is a comparative statistic in which the hypothesized model is compared with the independence model and the saturated model. The ECVI value for the hypothesized model is the smallest $(\mathrm{ECVI}=1.541)$ as compared to the other two models $(\mathrm{ECVI}=6.89 \&$ ECVI $=1.57$ respectively) indicating the hypothesized model is the best fitting model. Therefore, results from the CFA indicate that the proposed three factor model of classroom perception fits the data adequately. 
Figure 2

Confirmatory Factor Analysis - Factor Structure

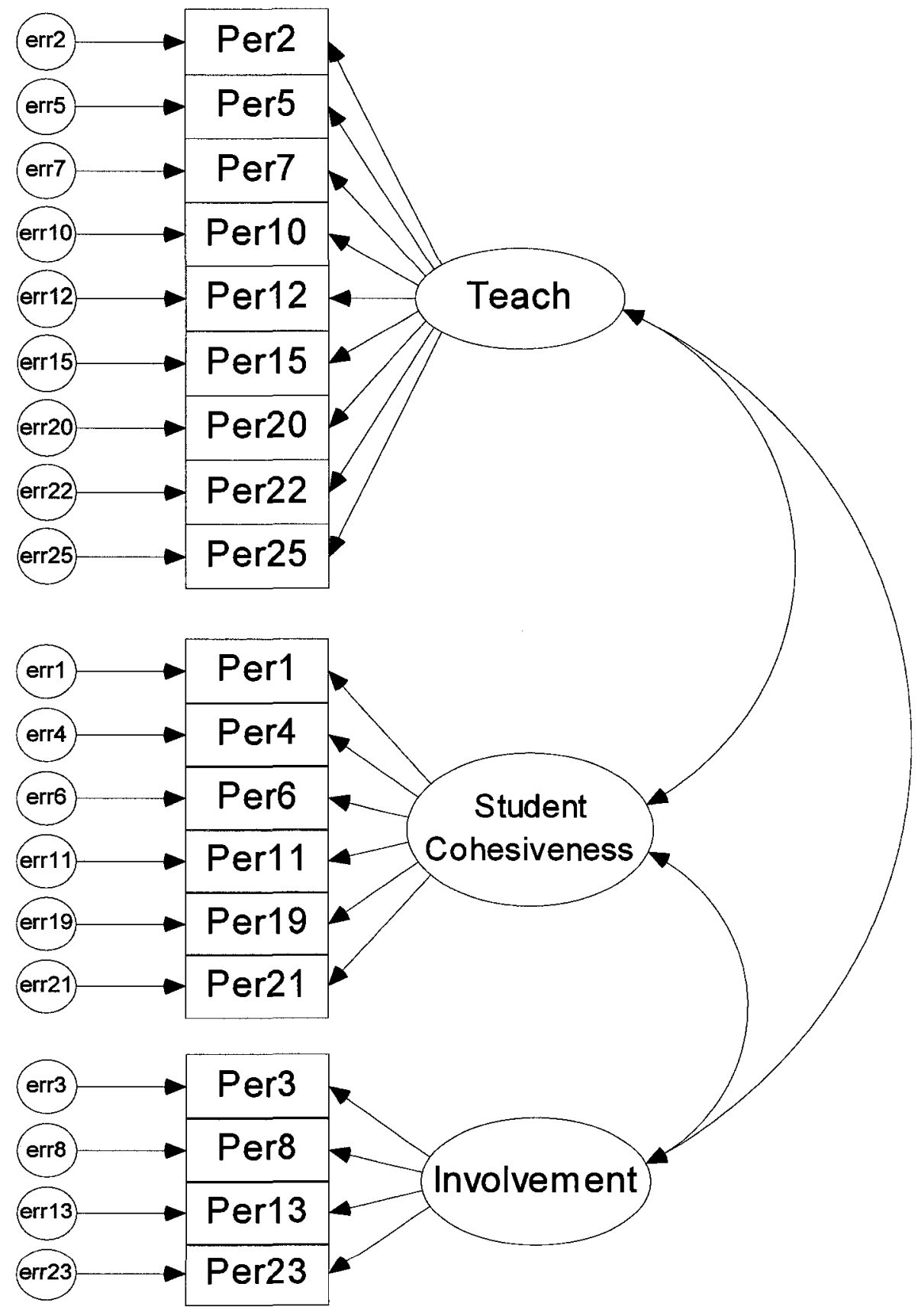


Classroom Perceptions

\section{Preliminary Analyses}

Internal consistencies among the subscales were moderate with Cronbach's alphas of $\alpha=.87$ for the Teacher Support \& Equity subscale accounting for $33.64 \%$ of the variance, $\alpha=.76$ for the Student Cohesiveness subscale which accounting for $10.54 \%$ of the variance, and $\alpha=.68$ for the Involvement subscale which accounting of $7.55 \%$ of the variance. Intercorrelations between the subscale perception scores are presented in Table 8. As expected, the classroom perception subscales were moderately related to one another.This relation suggests that although children differentiate unique aspects of their classroom environment, they are also likely to be broadly satisfied or dissatisfied of the overall environment as well.

Correlations between outcome variables are also presented in Table 8. As expected, these variables were highly intercorrelated. For example, positive self-concept with peers and in school was negatively related to adjustment difficulties including victimization, loneliness, depressive symptoms, anxiety, and school avoidance. Further, high incidences of each of the adjustment outcomes were positively correlated with one another suggesting that children who report difficulties will likely experience these difficulties across several dimensions of social adjustment.

Associations between behavioural characteristics (i.e., aggression and shyness) and classroom perceptions are also displayed in Table 8. As expected, shyness and aggression were both negatively related with classroom perception subscales scores. This inverse relation suggests that children with shy and aggressive tendencies are generally less satisfied with their classroom environment. Interestingly, aggression and perception 
of involvement were not significantly related. Shyness and aggression variables were also positively related to one another.

Finally, associations between classroom climate subscale scores and outcomes are summarized in Table 8. As expected, classroom perception scores were negatively associated with socio-emotional adjustment difficulties including victimization, loneliness, victimization, anxiety, and school avoidance. These relations suggest that children who report a more positive classroom experience are also less likely to report adjustment difficulties. Further, classroom perception scores are positively correlated with self-concept outcomes suggesting that children who report more positive classroom experiences are also more likely to report positive self-concept. The means, $S D$, and range for all study variables are summarized in Table 9. 
Table 8 - Intercorrelations between Subscale Perception scores, Behavioural Characteristics, \& Outcome Variables

\begin{tabular}{|c|c|c|c|c|c|c|c|c|c|c|c|}
\hline 1 & 2 & 3 & 4 & 5 & 6 & 7 & 8 & 9 & 10 & 11 & 12 \\
\hline $\begin{array}{l}\text { 1. Perception- } \\
\text { Student }\end{array}$ & $.54 * * *$ & $.40^{* * *}$ & $-.23 * *$ & $-.18^{* *}$ & $.66^{* * *}$ & $.56^{* * *}$ & $-.37 * * *$ & $-.70 * * *$ & $-.49 * * *$ & $-.30 * * *$ & $-.33 * * *$ \\
\hline $\begin{array}{l}\text { 2. Perception- } \\
\text { Teacher }\end{array}$ & & $.38 * * *$ & $-.31 * * *$ & $-.17^{* *}$ & $.45^{* * *}$ & $.49 * * *$ & $-.30 * * *$ & $-.55^{* * *}$ & $-.54 * * *$ & $-.24 * * *$ & $-.31 * * *$ \\
\hline $\begin{array}{l}\text { 3. Perception- } \\
\text { Involvement }\end{array}$ & & {[} & -.12 & $-.28 * * *$ & $.35^{* * *}$ & $.46^{* * *}$ & -.06 & $-.31 * * *$ & $-.26 * * *$ & -.10 & $-.22 * * *$ \\
\hline 4. Aggression & & & & $.32 * * *$ & -.10 & -.11 & .04 & .11 & .12 & .06 & $.20 * *$ \\
\hline 5. Shyness & & & & & $-.20 * *$ & $-.25^{* * *}$ & .09 & $.22 * *$ & $.16^{*}$ & .08 & $.18^{* *}$ \\
\hline $\begin{array}{l}\text { 6. Self-Concept: } \\
\text { Peer }\end{array}$ & & & & & L & $.50^{* * *}$ & $-.32 * * *$ & $-.77 * * *$ & $-.51 * * *$ & $-.37 * * *$ & $-.14 * *$ \\
\hline $\begin{array}{l}\text { 7. Self-Concept: } \\
\text { School }\end{array}$ & & & & & & 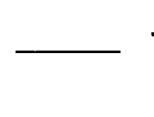 & $-.30 * * *$ & $-.51 * * *$ & $-.41 * * *$ & $-.25 * * *$ & $-.37 * * *$ \\
\hline 8. Victimization & & & & & & & & $.50 * * *$ & $.47 * * *$ & $.46^{* * *}$ & $.21 * *$ \\
\hline 9. Loneliness & & & & & & & & & $.67 * * *$ & $.43^{* * *}$ & $.23 * * *$ \\
\hline 10. Depressive symptoms & & & & & & & & & & $.44 * * *$ & $.35^{* * *}$ \\
\hline 11. Anxiety & & & & & & & & & & & $.20 * *$ \\
\hline 2. School Avoid & & & & & & & & & & & \\
\hline
\end{tabular}

$* * * p<.001, * * p<.01, * p<.05$ 
Table 9 - Means, $S D$, and Range for All Study Variables

\begin{tabular}{|l|l|l|l|}
\hline \multicolumn{1}{|c|}{ Variable } & \multicolumn{1}{|c|}{ Mean } & \multicolumn{1}{c|}{ Range } \\
\hline Perception - Teacher & 4.35 & .63 & $1.00-3.00$ \\
\hline Perception - Student & 4.04 & .62 & $1.00-3.00$ \\
\hline Perception - & 3.59 & .69 & $1.00-4.00$ \\
Involvement & & & \\
\hline Self Concept - Peer & 3.66 & .80 & $1.00-4.00$ \\
\hline Self Concept - School & 3.94 & .78 & $1.00-3.70$ \\
\hline Victimization & 1.54 & .49 & $1.00-2.00$ \\
\hline Loneliness & 1.83 & .77 & $1.00-4.00$ \\
\hline Depression & .25 & .32 & $1.00-1.50$ \\
\hline Anxiety & 2.60 & .96 & $1.00-4.00$ \\
\hline School Avoidance & 2.88 & 1.16 & $1.00-4.00$ \\
\hline ECP - Shyness & 1.55 & 2.71 & $1.00-19.00$ \\
\hline ECP - Aggression & 2.89 & 4.19 & $1.00-19.00$ \\
\hline
\end{tabular}

\section{Classroom Perceptions and Adjustment Outcomes}

In order to assess the predictive role of subscale perception scores on adjustment outcomes (e.g., self-concept, victimization, depressive symptoms, anxiety, and school liking and avoidance), hierarchical multiple regression was employed (replicating the analyses in Study 1 except for the additional inclusion of demographic variables). Again, the inclusion of grade and demographics did not alter the findings. Thus, in the results presented below, grade and parental education have not been controlled for. Subscale 
perception scores and gender were entered at Step 1 of the equation followed by gender by subscale perception score interaction terms entered at Step 2 .

Self-Concept-Peer. Results from the regression analyses predicting self-concept with peers are summarized in Table 10. As a block, the three classroom perception scores contributed a significant amount of additional variance to the prediction of self-concept with peers. Indeed, significant unique positive associations were particularly evident between self-concept and teacher support and student cohesiveness perception scores. Children with higher perceptions of teacher support were more likely to report self concept with peers. Further, children with higher perceptions of student cohesiveness were also more likely to report higher self concept with peers. None of the gender $\mathrm{x}$ subscale perception interaction terms were significant.

Self-Concept-School. Results from the regression analyses predicting self-concept in school are summarized in Table 10. As a block, the three classroom perception scores contributed a significant amount of additional variance to the prediction of self-concept in school. Indeed, significant unique associations were evident between self-concept and each of the three perception subscale scores. Children with higher perception scores on each of these subscales were more likely to have higher self-concept. None of the gender $\mathrm{x}$ subscale perception interaction terms were significant.

Victimization. Results from the regression analyses predicting victimization are summarized in Table 10. As a block, the three classroom perception scores contributed a significant amount of additional variance to the prediction of victimization. Again, significant unique associations were evident between victimization and each of the three perception subscale scores. First, children that report higher Teacher Support \& Equity 
and Student Cohesiveness perception scores were less likely to report victimization. However, contrary to expectations there was significant positive association between Involvement and victimization. It should be noted that given the negative association between Involvement and victimization found in Study 1, and the non-significant correlation between these two variables in the current study, the positive association reported here could be a suppression effect. Suppression effects occur when the presence of one variable increases the predictive ability of another (e.g., Tabachnick \& Fidell, 2007).

A gender $\mathrm{x}$ teacher support perception score was also found. Simple effects analyses were conducted by re-computing the regression analyses separately for boys and girls. Results indicated that the significant association between perceptions of student cohesiveness and victimization was stronger for girls $(\beta=-.40, p<.00)$ than for boys $(\beta=-$ $.21, \mathrm{p}<.05)$

Depressive symptoms. Results from the regression analyses predicting depressive symptoms are summarized in Table 10. As a block, the three subscale perception scores contributed a significant amount of additional variance to the prediction of depressive symptoms. This appeared to be due to the significant individual relations between victimization and Teacher Support \& Equity and Student Cohesiveness perception scores. Children with higher Teacher Support \& Equity perception scores are less likely to experience depressive symptoms. Similarly, children with higher Student Cohesiveness perception scores are also less likely to experience depressive symptoms. There were no significant gender by perception interactions for depressive symptoms. 


\section{Classroom Perceptions}

Social anxiety. Results from the regression analyses predicting social anxiety are summarized in Table 10. As a block, the three subscale perception scores contributed a significant amount of additional variance to the prediction of anxiety. Again, significant unique associations were evident between social anxiety and each of the three perception subscale scores. A significant main effect was found for gender was also found, with girls reporting greater social anxiety than boys. A significant main effect was also found for perceptions of Teacher Support and anxiety. Children with higher perceptions of teacher support reported less anxiety. Finally, a significant main effect for Student Cohesiveness perception scores and anxiety was also found. Children with higher perceptions of student cohesiveness were also less likely to report anxiety. There were no significant gender by perception interactions for anxiety.

School-Avoidance. Results from the regression analyses predicting school avoidance are summarized in Table 10. As a block, the three subscale perception scores contributed a significant amount of additional variance to the prediction of school avoidance. This appeared to be due to the significant individual relations between schoolavoidance and perceptions of Teacher Support and Student Cohesiveness. A significant main effect for gender was also found. Boys reported more school avoidance than girls. Children with lower Teacher Support \& Equity perception scores were more likely to report school avoidance. Similarly, children with lower perceptions of student cohesiveness were also more likely to report school avoidance. There were no significant gender by perception interactions for school avoidance.

Loneliness. Results from the regression analyses predicting loneliness are summarized in Table 10. As a block, the three subscale perception scores contributed a 


\section{Classroom Perceptions}

significant amount of additional variance to the prediction of loneliness. This appeared to be due to the significant individual relations between loneliness and perceptions of Teacher Support and Student Cohesiveness. Children that report higher perceptions of teacher support were less likely to report loneliness. Finally, children that report higher perceptions of student cohesion were also less likely to report feelings of loneliness. None of the gender by perception interactions were significant. 
Table 10 - Hierarchical Regression Analyses predicting Social Adjustment outcomes from Gender and Subscale Perception Scores.

\begin{tabular}{|c|c|c|c|c|c|c|c|}
\hline Outcome Variable & Predictor Variables & $\mathrm{R}^{2}$ & $\mathrm{~F}$ & $\Delta \mathrm{R}^{2}$ & $\Delta \mathrm{F}$ & $\beta$ & $s r$ \\
\hline \multirow[t]{9}{*}{ Self-Concept- Peer } & Step 1 & .46 & $55.09 * * *$ & & & & \\
\hline & Gender & & & & & -.05 & -.05 \\
\hline & Teacher Support & & & & & $.13^{*}$ & .11 \\
\hline & Student Cohesivene & & & & & $.57 * * *$ & .47 \\
\hline & Involvement & & & & & .07 & .07 \\
\hline & Step 2 & .46 & $31.57 * * *$ & .00 & .57 & & \\
\hline & Gender x Involvem & & & & & -.05 & -.04 \\
\hline & Gender $\mathrm{x}$ Teacher $\mathrm{S}$ & & & & & -.00 & -.00 \\
\hline & Gender $\mathrm{x}$ Student $\mathrm{C}$ & ess & & & & .06 & .05 \\
\hline
\end{tabular}

$+p<.08,{ }^{*} p<.05,{ }^{* *} p<.01,{ }^{* * *} p<.00$ 
Table 10 (continued) - Hierarchical Regression Analyses predicting Social Adjustment outcomes from Gender and Subscale Perception Scores.

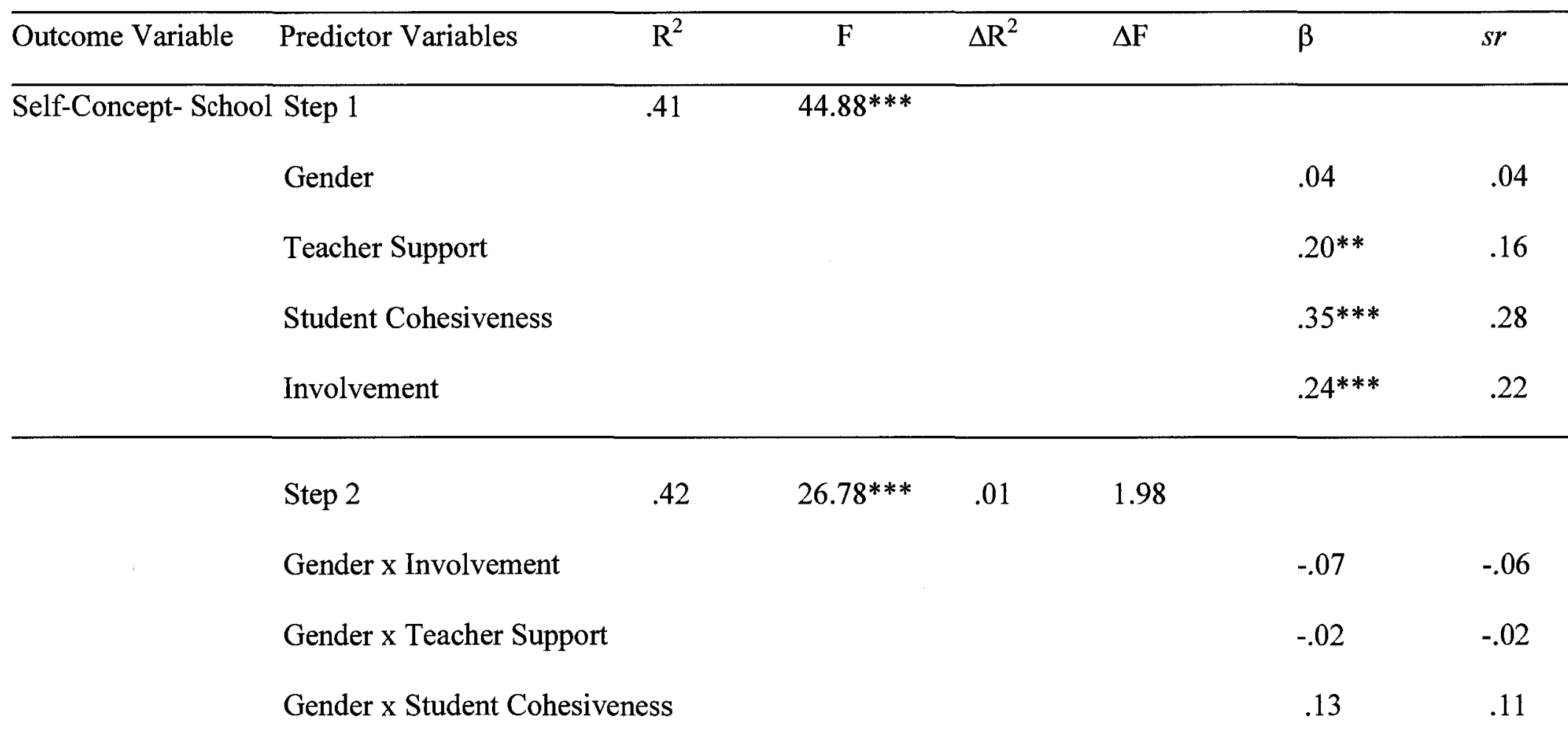

$+p<.08, * p<.05, * * p<.01,{ }^{* * *} p<.00$ 
Table 10 (continued) - Hierarchical Regression Analyses predicting Social Adjustment outcomes from Gender and Subscale Perception Scores.

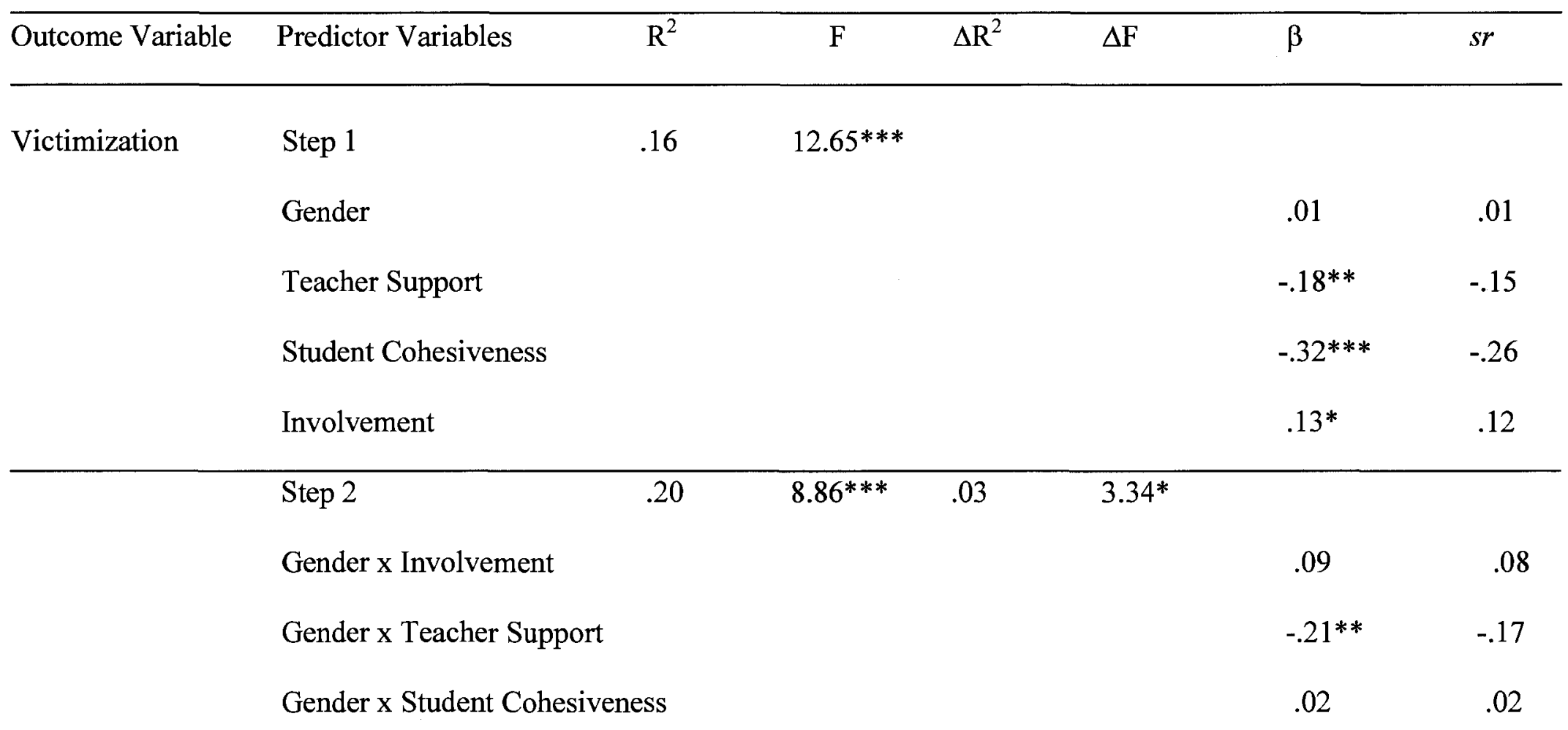

$+p<.08, * p<.05, * * p<.01, * * * p<.00$ 
Table 10 (continued) - Hierarchical Regression Analyses predicting Social Adjustment outcomes from Gender and Subscale Perception Scores.

\begin{tabular}{|c|c|c|c|c|c|c|c|}
\hline Outcome Variable & Predictor Variables & $\mathrm{R}^{2}$ & $\mathrm{~F}$ & $\Delta \mathrm{R}^{2}$ & $\Delta \mathrm{F}$ & $\beta$ & $s r$ \\
\hline \multirow[t]{9}{*}{ Depressive symptom } & s Step 1 & .35 & $34.11 * * *$ & & & & \\
\hline & Gender & & & & & .06 & .06 \\
\hline & Teacher Support & & & & & $-.40 * * *$ & -.32 \\
\hline & Student Cohesivene & & & & & $-.28 * * *$ & -.23 \\
\hline & Involvement & & & & & .00 & .00 \\
\hline & Step 2 & .35 & $19.84 * * *$ & .01 & .87 & & \\
\hline & Gender x Involvem & & & & & .07 & .06 \\
\hline & Gender $\mathrm{x}$ Teacher $\mathrm{S}$ & & & & & .03 & .02 \\
\hline & Gender $\mathrm{x}$ Student $\mathrm{C}$ & less & & & & -.01 & -.00 \\
\hline
\end{tabular}

$+p<.08, * p<.05, * * p<.01, * * * p<.00$ 
Table 10 (continued) - Hierarchical Regression Analyses predicting Social Adjustment outcomes from Gender and Subscale Perception Scores.

\begin{tabular}{|c|c|c|c|c|c|c|c|}
\hline Outcome Variable & Predictor Variables & $\mathrm{R}^{2}$ & $\mathrm{~F}$ & $\Delta \mathrm{R}^{2}$ & $\Delta \mathrm{F}$ & $\beta$ & $s r$ \\
\hline \multirow[t]{9}{*}{ Anxiety } & Step 1 & .13 & $9.86^{* * *}$ & & & & \\
\hline & Gender & & & & & $.20 * *$ & .19 \\
\hline & Teacher Support & & & & & $-.16^{*}$ & -.13 \\
\hline & Student Cohesivene & & & & & $-.26 * * *$ & -.21 \\
\hline & Involvement & & & & & .04 & .04 \\
\hline & Step 2 & .14 & $5.66^{* * *}$ & .00 & .18 & & \\
\hline & Gender x Involvem & & & & & .04 & .04 \\
\hline & Gender $\mathrm{x}$ Teacher $\mathrm{S}$ & & & & & -.02 & -.02 \\
\hline & Gender $\mathrm{x}$ Student $\mathrm{C}$ & ess & & & & -.03 & -.02 \\
\hline
\end{tabular}


Table 10 (continued) - Hierarchical Regression Analyses predicting Social Adjustment outcomes from Gender and Subscale Perception Scores.

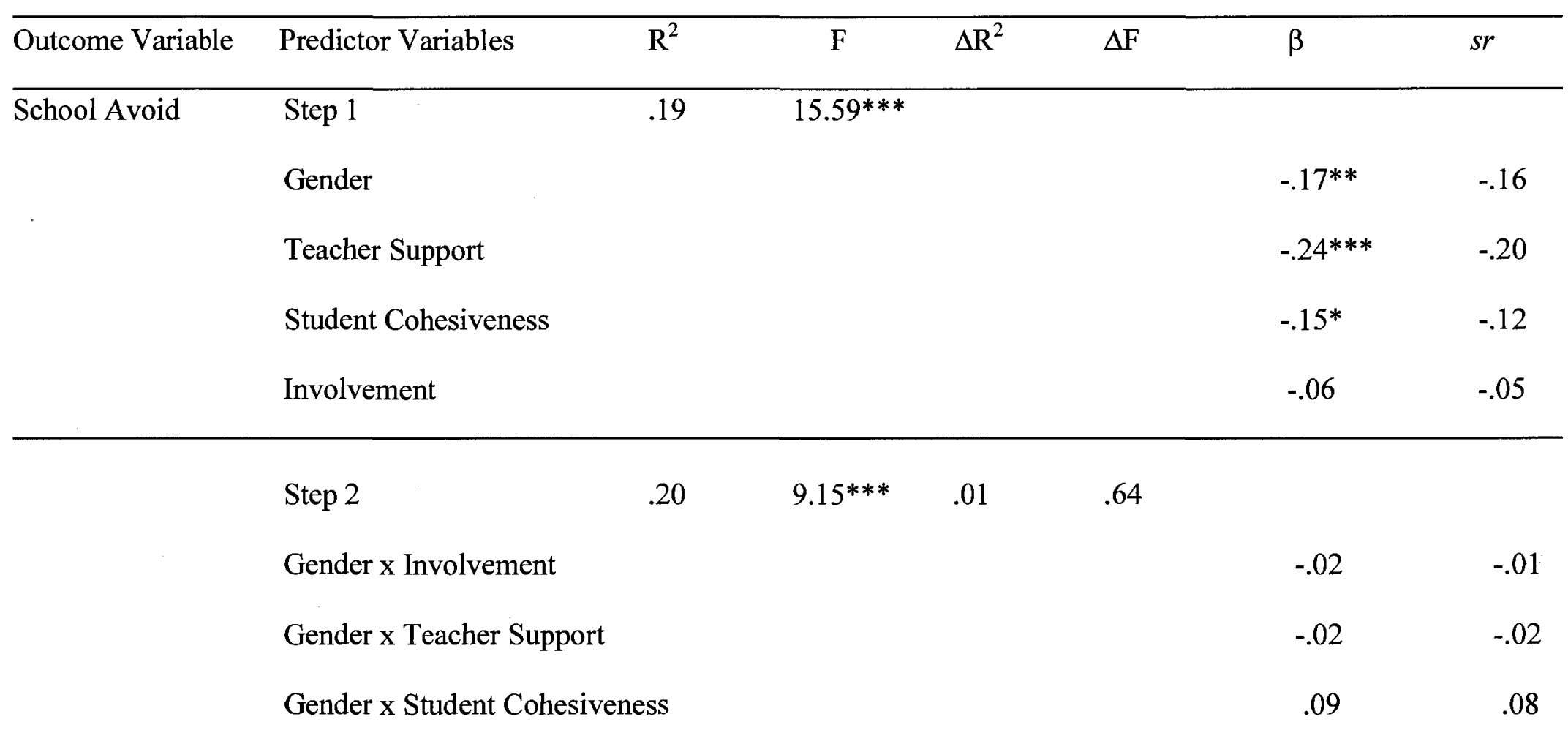

$+p<.08, * p<.05, * * p<.01, * * * p<.00$ 
Table 10 (continued) - Hierarchical Regression Analyses predicting Social Adjustment outcomes from Gender and Subscale Perception Scores.

\begin{tabular}{|c|c|c|c|c|c|c|c|}
\hline Outcome Variable & Predictor Variables & $\mathrm{R}^{2}$ & F & $\Delta \mathrm{R}^{2}$ & $\Delta \mathrm{F}$ & $\beta$ & $s r$ \\
\hline \multirow[t]{9}{*}{ Loneliness } & Step 1 & .54 & $76.40^{* * *}$ & & & & \\
\hline & Gender & & & & & .08 & .08 \\
\hline & Teacher Support & & & & & $-.26 * * *$ & -.21 \\
\hline & Student Cohesiveness & & & & & $-.58 * * *$ & -.47 \\
\hline & Involvement & & & & & .02 & .02 \\
\hline & Step 2 & .54 & $43.98 * * *$ & .01 & .88 & & \\
\hline & Gender x Involvement & & & & & .06 & .06 \\
\hline & Gender x Teacher Sup & & & & & .03 & .02 \\
\hline & Gender x Student Coh & ness & & & & -.03 & -.02 \\
\hline
\end{tabular}

$+p<.08,{ }^{*} p<.05, * * p<.01, * * * p<.00$ 


\section{Behavioural Characteristics and Perception Scores}

In order to assess the associations between behavioural characteristics (i.e., aggression and shyness), gender, and perception scores, a series of hierarchical multiple regression were computed. Analyses were first conducted controlling for grade and parental education. However, similar findings were obtained when compared to a second regression in which grade and parental education were not controlled. Therefore, throughout the results presented below, grade and parental education have not been controlled for. Gender, shyness and aggression scores were entered at Step 1, followed by the gender $\mathrm{x}$ shyness and gender $\mathrm{x}$ aggression interaction terms, which were entered at Step 2. The correlation between the aggression and shyness scores was $r=.32(p<001)$. Perception of Teacher Support \& Equity. Results from the regression analyses predicting Teacher Support \& Equity perception scores are summarized in Table 11. A significant main effect for aggression was found. Children rated as more aggressive by peers were less likely to perceive their teachers as supportive and equal. There was no main effect of shyness but a significant gender $\mathrm{x}$ shyness interaction was found. Simple effects analyses were conducted by re-computing the regression analyses separately for boys and girls. Results indicated that the negative association between perception of teacher support and shyness was stronger for boys $(\beta=-.09, p=.33)$ than for girls $(\beta=.01$, $p=97)$.

Perception of Student Cohesiveness. Results from the regression analyses predicting Student Cohesiveness are summarized in Table 11. A significant main effect for aggression was again found. Children that were rated as more aggressive by their peers were less likely to perceive student cohesion in the classroom. A significant main 
effect for shyness in the prediction of student cohesion was not found but a significant gender $\mathrm{x}$ shyness interaction was found. Simple effects analyses were conducted by recomputing the regression analyses separately for boys and girls. Results again indicated that the negative association between perception of student cohesiveness and shyness was stronger for boys $(\beta=-.21, \mathrm{p}=.03)$ than for $\operatorname{girls}(\beta=.02, \mathrm{p}=.85)$.

Perception of Involvement. Results from the regression analyses predicting Involvement are summarized in Table 11. A significant main effect for shyness was found in the prediction of Involvement. Children rated as highly shy were less likely to perceive involvement in the classroom. Significant main effect for aggression in the prediction of involvement was not found and none of the interaction terms were found significant. 
Table 11 - Hierarchical Regression Analyses predicting Perception Scores from Behavioural Characteristics

\begin{tabular}{|c|c|c|c|c|c|c|c|}
\hline Outcome Variable & Predictor Variables & $\mathrm{R}^{2}$ & $\mathrm{~F}$ & $\Delta \mathrm{R}^{2}$ & $\Delta \mathrm{F}$ & $\beta$ & $s r$ \\
\hline \multirow[t]{7}{*}{ Teacher Support } & Step 1 & .11 & $7.15^{* * *}$ & & & & \\
\hline & Gender & & & & & .06 & .04 \\
\hline & Shyness & & & & & -.04 & -.04 \\
\hline & Aggression & & & & & $-.27 * *$ & -.23 \\
\hline & Step 2 & .13 & $5.18 * * *$ & .02 & 2.08 & & \\
\hline & Gender x Shyness & & & & & $.59 *$ & .14 \\
\hline & Gender x Aggression & & & & & -.20 & -.08 \\
\hline
\end{tabular}


Table 11 (continued) - Hierarchical Regression Analyses predicting Perception Scores from Behavioural Characteristics

\begin{tabular}{|c|c|c|c|c|c|c|c|}
\hline Outcome Variable & Predictor Variables & $\mathrm{R}^{2}$ & $\mathrm{~F}$ & $\Delta \mathrm{R}^{2}$ & $\Delta \mathrm{F}$ & $\beta$ & $s r$ \\
\hline \multicolumn{2}{|c|}{ Student Cohesiveness Step 1} & .07 & $4.70 * * *$ & & & & \\
\hline & Gender & & & & & -.01 & -.01 \\
\hline & Shyness & & & & & -.13 & -.11 \\
\hline & Aggression & & & & & $-.20^{*}$ & -.17 \\
\hline & Step 2 & .11 & $4.39 * * *$ & .04 & $3.71^{*}$ & & \\
\hline & Gender x Shyness & & & & & $.71^{*}$ & .17 \\
\hline & Gender x Aggression & & & & & -.12 & -.05 \\
\hline
\end{tabular}


Table 11 (continued) - Hierarchical Regression Analyses predicting Perception Scores from Behavioural Characteristics

\begin{tabular}{|c|c|c|c|c|c|c|c|}
\hline Outcome Variable & Predictor Variables & $\mathrm{R}^{2}$ & $\mathrm{~F}$ & $\Delta \mathrm{R}^{2}$ & $\Delta \mathrm{F}$ & $\beta$ & $s r$ \\
\hline \multirow[t]{7}{*}{ Involvement } & Step 1 & .01 & $6.33 * * *$ & & & & \\
\hline & Gender & & & & & -.16 & -.12 \\
\hline & Shyness & & & & & $-.31 * * *$ & -.27 \\
\hline & Aggression & & & & & -.14 & -.12 \\
\hline & Step 2 & .01 & $3.78 * * *$ & .00 & .07 & & \\
\hline & Gender x Shyness & & & & & -.05 & -.01 \\
\hline & Gender x Aggression & & & & & -.03 & -.01 \\
\hline
\end{tabular}

$+p<.08, * p<.05, * * p<.01, * * * p<.00$ 
Classroom Perceptions

\section{Classroom Perceptions, Child Behaviours, and Adjustment Outcomes}

The goal of these final analyses was to address associations between behavioural characteristics, classroom environment, and outcome variables. Of particular interest was the potential moderating role of classroom perceptions in the relations between behavioural characteristics (i.e., shyness, aggression) and outcome variables. As previously described, analyses were first conducted controlling for grade and parental education. However, since results did not differ, results are presented here without controlling for these variables. For these analyses, a "global" classroom environment score (aggregating across subscales) was employed to reduce the number of variables in the equation (particularly with regard to interaction terms). As noted earlier, the three sub-scale scores were all significantly intercorrelated. For each equation, gender, shyness, aggression, and total perception scores were entered at Step 1. Two-way interaction terms, including gender $\mathrm{x}$ shyness, gender $\mathrm{x}$ aggression, and gender $\mathrm{x}$ total perception, were entered at Step 2. Finally, the three-way interaction terms including, gender $x$ shyness $\mathrm{x}$ perception and gender $\mathrm{x}$ aggression $\mathrm{x}$ perception, were entered at Step 3. It should be noted that none of the three-way interaction terms were significant. Thus, to ease presentation, these results are not described in the following sections.

Self-Concept-Peers. Results from the regression analyses predicting self-concept with peers are summarized in Table 12. Significant main effects for aggression and classroom perception were found. Children rated as more aggressive by peers reported higher self-concept with peers. As well, children with more positive classroom perceptions reported higher self-concept with peers. Significant main effects for shyness were not found. As well, none of the two- way interaction terms were significant. 
Self-Concept-School. Results from the regression analyses predicting selfconcept in school are summarized in Table 12. A significant main effect for classroom perceptions was found. Children that reported higher classroom perceptions scores were also more likely to report higher self-concept in terms of school. None of the remaining main effects or two-way interaction terms were significant.

Victimization. Results from the regression analyses predicting victimization indicate some "suppression effects". Suppression effects occur when the presence of one variable increases the predictive ability of another (Tabachnick \& Fidell, 2007). For example, the inclusion of a mediating variable into the regression equation changes the direction of the relation between two other variables. In the current sample, a suppression effect was indicated for victimization. Further, a suppression effect may also be detected when the standardized regression coefficient takes on a value great than \pm 1.00 (Thayer, 1991). This issue was also apparent in the current sample. For example, a significant gender $\mathrm{x}$ shy interaction $(\beta=-1.14, \mathrm{p}=.000)$ was found in the prediction of victimization. Suppression leads to uncertainties in the absolute interpretation of the findings and therefore the results from the regression analyses predicting victimization were not interpreted.

Depressive symptoms. Results from the regression analyses predicting depressive symptoms are summarized in Table 12. A significant main effect for classroom perceptions and depressive symptoms was found. Children with more positive classroom perceptions were less likely to report depressive symptoms. A significant shyness $\mathrm{x}$ gender interaction was also found. Regression analyses were re-computed separately for 
boys and girls. Results indicate that the positive relation between shyness and depressive symptoms was stronger for boys $(\beta=.25, \mathrm{p}=.01)$ than for $\operatorname{girls}(\beta=-.03, \mathrm{p}=.83)$.

A significant shyness $\mathrm{x}$ perception interaction was also found. Results from simple slopes analyses are shown in Figure 3. Among children with lower classroom perceptions, there was a positive association between shyness and depressive symptoms. However, among children with more positive classroom perceptions, this relation was attenuated. These findings suggest that a more positive classroom perception may act as a "buffer" against depressive symptoms for shy children. Alternatively, it may also be the case that shy children who also tend to be depressed are more likely to perceive their classroom environments as more negative. 
Figure 3

Shyness x Perception Interaction Predicting Depressive Symptoms

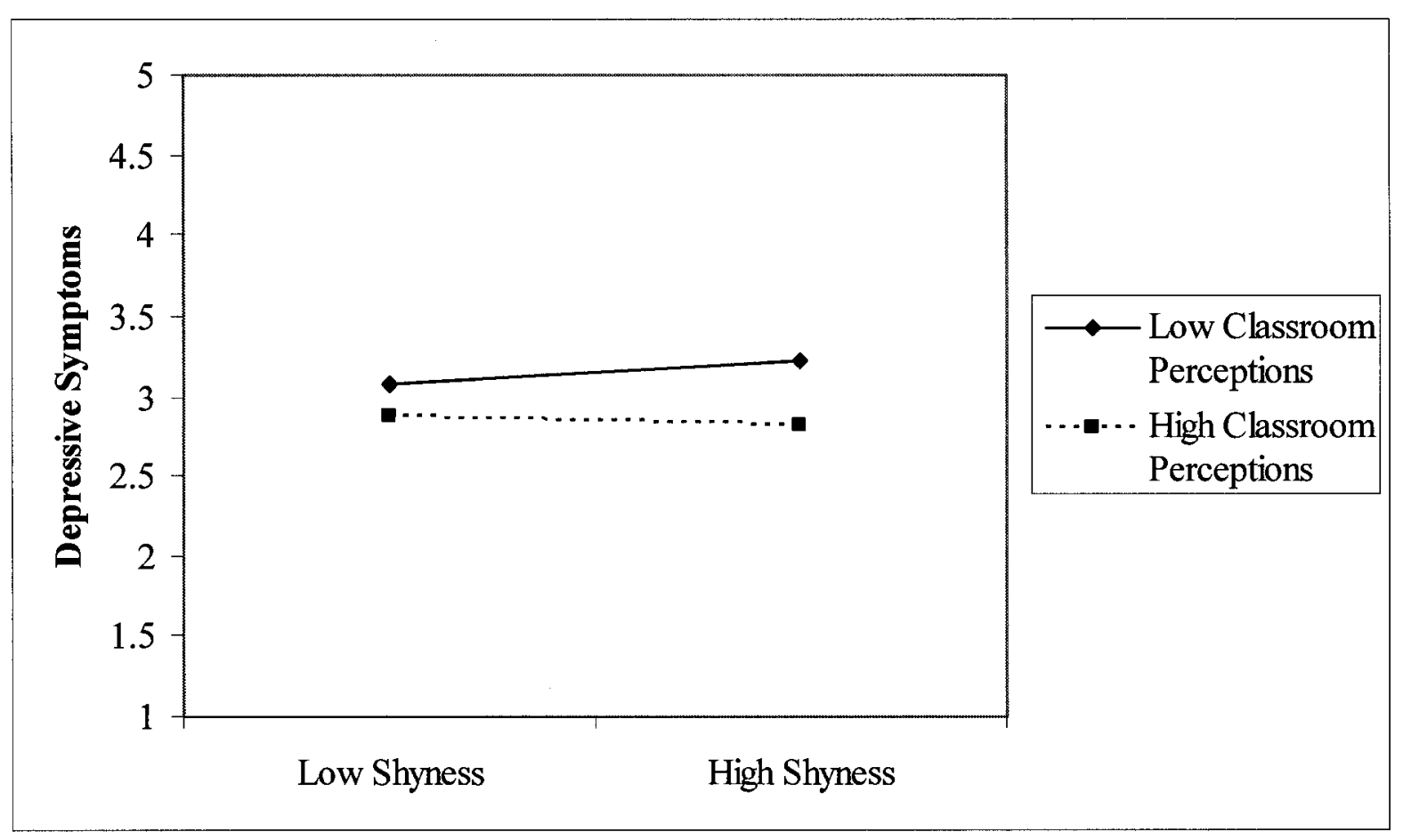


Anxiety. Results from the regression analyses predicting anxiety are summarized in Table 12. A significant main effect for gender was found. Girls tended to report higher levels of anxiety than boys. A significant main effect for classroom perceptions was also found. Children with more positive classroom perceptions reported lower levels of social anxiety. None of the interaction terms were significant.

School avoidance. Results from the regression analyses predicting school avoidance are summarized in Table 12. Significant main effects were found for classroom perceptions. Children with more positive classroom perceptions were less likely to report school avoidance. A significant main effect for gender was also found. Boys were more likely to report school avoidant tendencies than girls. Further, a significant shyness $\mathrm{x}$ gender interaction was significant in the prediction of school avoidance. Regression analyses were re-computed separately for boys and girls. Results indicate that the positive relation between shyness and school avoidance was stronger for boys $(\beta=.12, p=.20)$ than for girls $(\beta=.04, p=.73)$.

A significant perception $\mathrm{x}$ aggression interaction was also found. Simple slopes analyses are presented in Figure 4. Among children with higher classroom perceptions, there was a positive relation between aggression and school avoidance. However, among children with more negative classroom perceptions, this association diminished (and in fact became somewhat negative). These findings suggest that aggressive children with lower classroom perceptions are less likely to want to avoid school. Therefore, aggressive children seem to prefer to be in classrooms that are less positive as typically defined in the classroom environment literature. The interpretation of these findings will be discussed in more detail in the discussion section. 
Figure 4

Aggression x Perception Interaction Predicting School Avoidance

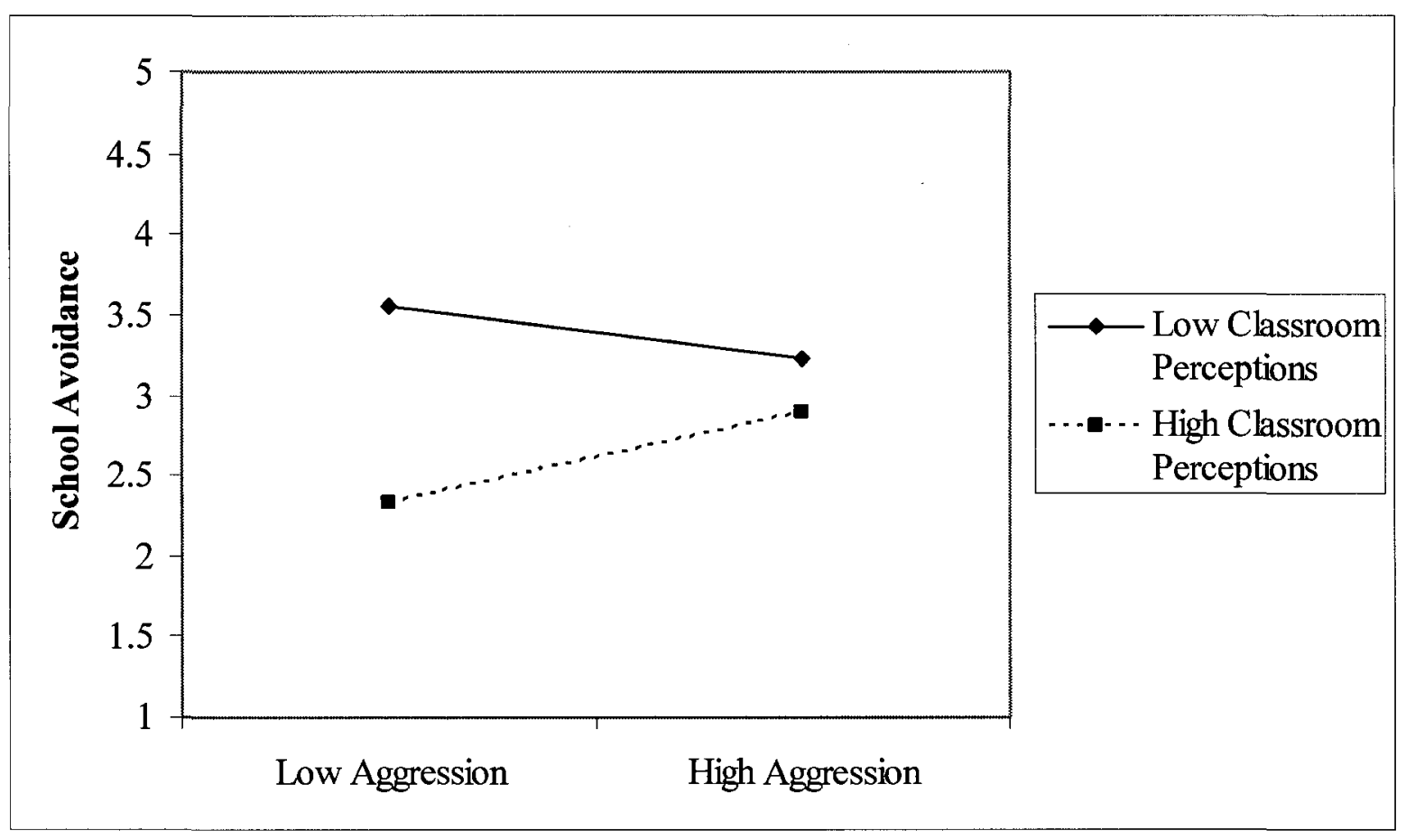


Loneliness. Finally, results from the regression analyses predicting loneliness are summarized in Table 12. A significant main effect for classroom perceptions was found. Children with higher perception scores tended to report less loneliness. The remaining main effects and the two-way interactions were not significant. 
Table 12 - Hierarchical Regression Analyses predicting Self-Concept- Peers from Perception Scores and Behavioural Characteristics.

\begin{tabular}{|c|c|c|c|c|c|c|c|}
\hline Outcome Variable & Predictor Variables & $\mathrm{R}^{2}$ & $\mathrm{~F}$ & $\Delta \mathrm{R}^{2}$ & $\Delta \mathrm{F}$ & $\beta$ & $s r$ \\
\hline \multirow[t]{11}{*}{ Self- Concept- Peer } & Step 1 & .43 & $33.30 * * *$ & & & & \\
\hline & Gender & & & & & .10 & .07 \\
\hline & Shyness & & & & & .05 & .05 \\
\hline & Aggression & & & & & $.20^{* *}$ & .17 \\
\hline & Total Perception & & & & & $.68 * * *$ & .64 \\
\hline & Step 2 & .43 & $14.61 * * *$ & .00 & .24 & & \\
\hline & Perception x Aggression & & & & & .03 & .02 \\
\hline & Perception x Shyness & & & & & .04 & .03 \\
\hline & Gender x Shyness & & & & & -.03 & -.01 \\
\hline & Gender x Aggression & & & & & -.02 & -.01 \\
\hline & Gender x Perception & & & & & -.02 & -.01 \\
\hline
\end{tabular}


Table 12 (continued) - Hierarchical Regression Analyses predicting Self-Concept- School from Perception Scores and Behavioural Characteristics.

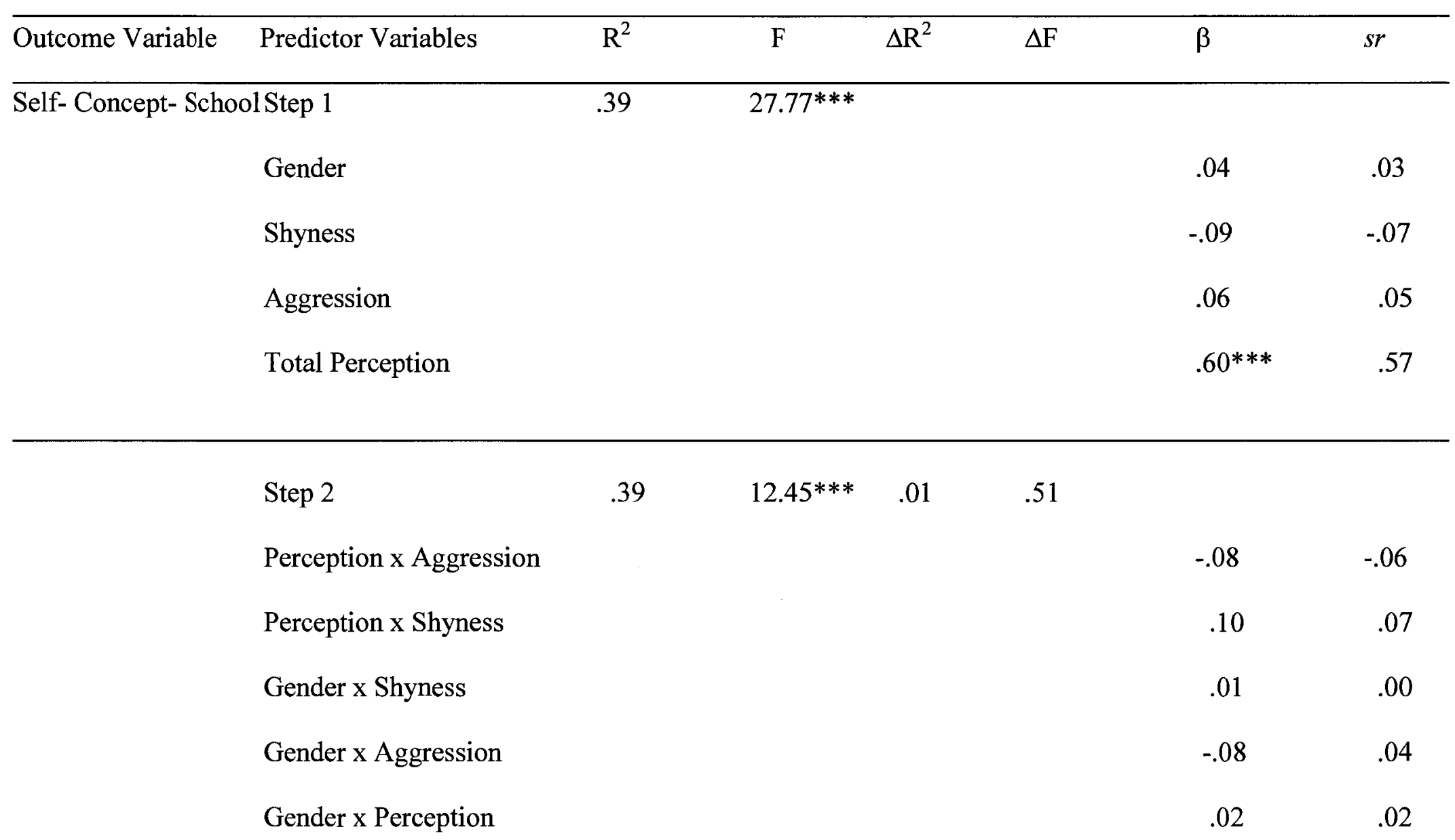

$+p<.08,{ }^{*} p<.05,{ }^{* *} p<.01,{ }^{* * *} p<.00$ 
Table 12 (continued) - Hierarchical Regression Analyses predicting Depressive symptoms from Perception Scores from Behavioural Characteristics.

\begin{tabular}{|c|c|c|c|c|c|c|c|}
\hline Outcome Variable & Predictor Variables & $\mathrm{R}^{2}$ & $\mathrm{~F}$ & $\Delta \mathrm{R}^{2}$ & $\Delta \mathrm{F}$ & $\beta$ & $s r$ \\
\hline \multirow[t]{11}{*}{$\overline{\text { Depressive symptom }}$} & Step 1 & .24 & 13.7 & & & & \\
\hline & Gender & & & & & .07 & .05 \\
\hline & Shyness & & & & & .06 & .05 \\
\hline & Aggression & & & & & .07 & .06 \\
\hline & Total Perception & & & & & $-.46^{* * *}$ & -.44 \\
\hline & Step 2 & .31 & 8.45 & .07 & $3.45^{* *}$ & & \\
\hline & \multicolumn{4}{|c|}{ Perception $\mathrm{x}$ Aggression } & & -.07 & -.05 \\
\hline & \multicolumn{4}{|l|}{ Perception x Shyness } & & $-.19 *$ & -.14 \\
\hline & \multicolumn{4}{|l|}{ Gender x Shyness } & & $-.68 *$ & -.16 \\
\hline & \multicolumn{4}{|l|}{ Gender x Aggression } & & .06 & .02 \\
\hline & \multicolumn{4}{|l|}{ Gender x Perception } & & -.08 & -.06 \\
\hline
\end{tabular}

$+p<.08,{ }^{*} p<.05,{ }^{* *} p<.01,{ }^{* * *} p<.00$ 
Table 12 (continued) - Hierarchical Regression Analyses predicting Anxiety from Perception Scores from Behavioural Characteristics.

\begin{tabular}{|c|c|c|c|c|c|c|c|}
\hline Outcome Variable & Predictor Variables & $\mathrm{R}^{2}$ & $\mathrm{~F}$ & $\Delta \mathrm{R}^{2}$ & $\Delta \mathrm{F}$ & $\beta$ & $s r$ \\
\hline \multirow[t]{11}{*}{$\overline{\text { Anxiety }}$} & Step 1 & .08 & $4.01 * *$ & & & & \\
\hline & Gender & & & & & $.20^{*}$ & .15 \\
\hline & Shyness & & & & & .14 & .12 \\
\hline & Aggression & & & & & -.05 & -.04 \\
\hline & Total Perception & & & & & $-.22 * *$ & -.21 \\
\hline & Step 2 & .10 & $2.21^{*}$ & .02 & .79 & & \\
\hline & Perception x Aggression & & & & & .07 & .05 \\
\hline & Perception x Shyness & & & & & -.03 & -.02 \\
\hline & Gender x Shyness & & & & & -.16 & -.04 \\
\hline & Gender x Aggression & & & & & -.19 & -.07 \\
\hline & Gender x Perception & & & & & -.03 & -.02 \\
\hline
\end{tabular}


Table 12 (continued) -Hierarchical Regression Analyses predicting School Avoidance from Perception Scores from Behavioural Characteristics.

\begin{tabular}{|c|c|c|c|c|c|c|c|}
\hline Outcome Variable & Predictor Variables & $\mathrm{R}^{2}$ & $\mathrm{~F}$ & $\Delta \mathrm{R}^{2}$ & $\Delta \mathrm{F}$ & $\beta$ & $s r$ \\
\hline \multirow[t]{11}{*}{ School Avoidance } & Step 1 & .17 & $9.29 * * *$ & & & & \\
\hline & Gender & & & & & $-.18^{*}$ & -.14 \\
\hline & Shyness & & & & & -.04 & -.03 \\
\hline & Aggression & & & & & .05 & .04 \\
\hline & Total Perception & & & & & $-.34 * * *$ & -.32 \\
\hline & Step 2 & .17 & $7.32 * * *$ & .02 & 1.77 & & \\
\hline & Perception x Aggression & & & & & $.15^{*}$ & .17 \\
\hline & Perception x Shyness & & & & & -.03 & -.02 \\
\hline & Gender x Shyness & & & & & $-.73 * *$ & -.18 \\
\hline & Gender x Aggression & & & & & .09 & .03 \\
\hline & Gender $\mathrm{x}$ Perception & & & & & .16 & .12 \\
\hline
\end{tabular}

$+p<.08, * p<.05,{ }^{* *} p<.01, * * * p<.00$ 
Table 12 (continued) - Hierarchical Regression Analyses predicting Loneliness from Perception Scores from Behavioural Characteristics.

\begin{tabular}{|c|c|c|c|c|c|c|c|}
\hline Outcome Variable & Predictor Variables & $\mathrm{R}^{2}$ & $\mathrm{~F}$ & $\Delta \mathrm{R}^{2}$ & $\Delta \mathrm{F}$ & $\beta$ & $s r$ \\
\hline \multirow[t]{11}{*}{ Loneliness } & Step 1 & .38 & $27.11^{* * *}$ & & & & \\
\hline & Gender & & & & & .01 & .01 \\
\hline & Shyness & & & & & .03 & .03 \\
\hline & Aggression & & & & & -.08 & -.07 \\
\hline & Total Perception & & & & & $-.63 * * *$ & -.59 \\
\hline & Step 2 & .40 & $12.61 * * *$ & .02 & 1.01 & & \\
\hline & Perception x Aggression & & & & & -.03 & -.02 \\
\hline & Perception x Shyness & & & & & -.08 & -.06 \\
\hline & Gender x Shyness & & & & & -.17 & -.04 \\
\hline & Gender x Aggression & & & & & -.10 & -.04 \\
\hline & Gender $x$ Perception & & & & & .00 & .00 \\
\hline
\end{tabular}

$+p<.08,{ }^{*} p<.05,{ }^{* *} p<.01,{ }^{* * *} p<.00$ 


\section{Discussion}

There were several objectives that were explored in the current dissertation. First, building upon a body of literature from the field of education, a newly adapted self-report measure of classroom perceptions was developed and its psychometric properties and preliminary validity were evaluated in an upper elementary school sample. Second, the association between classroom perceptions and conceptually relevant adjustment difficulties were explored. Third, within the framework of a child by environment perspective, the role of classroom perceptions as a potential moderator of the relations between "at risk" behavioural characteristics (i.e., shyness, aggression) and socioemotional functioning (i.e. loneliness, depressive symptoms, victimization) was investigated. The following sections summarize the results from both studies.

\section{Development of a New Measure of Classroom Perceptions}

The classroom perception literature has largely focused on the role of classroom perceptions in the prediction of academic outcome variables among an adolescent population (e.g., Aldridge \& Fisher, 2000; Aldridge, Fraser, \& Huang, 1999; Ferguson \& Fraser, 1998; Fraser, Fisher, \& McRobbie, 1996; Fraser \& Wilkinson, 1993; Henderson, Fisher, \& Fraser, 2000). One of the primary objectives of the current study was to provide psychometric support for measuring classroom perceptions among an upper elementary school sample. This objective was explored in the following ways: (1) the factor structure of the WIHIC-R was examined to determine whether younger children perceive their classroom experiences in the same way as older children; and (2) the construct validity was assessed by exploring the relation between classroom perceptions and conceptually relevant socio-emotional outcomes. 
Findings from Study 1 provided initial evidence for the reliability and validity of the WIHIC-R. It appears that although younger children are able to consistently report on aspects of their classroom experiences, they do not differentiate in as much detail as adolescents. Further support for this assertion was found in Study 2, where confirmatory factor analyses with a separate sample indicated the same three factor solution of the classroom perception measure. These findings provided further support that elementary school children perceive their classroom environment based on three broad dimensions. For both samples, classroom environment was conceptualized in terms of teacher characteristics (i.e., the extent to which the teacher is perceived to be fair, equal, and supportive to all students in the class), student characteristics (i.e., the way in which the students in the class get along), and personal involvement (i.e., the extent to which the student perceives their own involvement and participation in the classroom). The support for the psychometric properties of the WIHIC-R are meaningful in that they allow for a new branch of research exploring the role of younger children's perceptions in both their academic, social, and emotional functioning.

The current investigation provided strong empirical support for the use of the WIHIC-R among an upper elementary school sample. This study was among the first to explore classroom perceptions among this age group (Allen \& Fraser, 2007). A large body of evidence provides support for the impact of early school experiences (i.e., teacher-child relationships, friendships, observed classroom climate) on school functioning (e.g., Brendgen, Bowen, Rondeau, \& Vitaro, 1999; Hartup, 1998; Kon- tos \& Wilcox-Herzog, 1997; Kostelnik, Stein, \& Whiren, 1988; La Paro, Pianta, \& Stuhlman, 2004; Miell \& MacDonald, 2000; Pianta, 1999; Zajac \& Hartup, 1997). A primary 
purpose of the current investigation was to determine whether classroom perceptions impact socio-emotional functioning in the same way as these other school variables. Therefore in order explore classroom perception as a predictor of socio-emotional functioning in the same way it was important to employ a similar age group. Further, the current investigation provided strong support for a significant association between classroom perceptions and overall socio-emotional functioning. Therefore, future research can now build upon these findings with the possibility of targeting classroom perceptions for the purpose of early intervention of social adjustment difficulties. Overall, it is argued that the role of classroom perceptions among a younger sample allows for a broadened approach to complex and dynamic issues of social development. Traditionally, classroom perceptions have been linked with academic outcomes among adolescent populations (e.g., Aldridge \& Fraser, 1999; Dorman, Adams, \& Ferguson, 2002; Fisher \& Fraser, 1983; Fraser, 1982; Fraser \& Fisher, 1983; Fraser \& Wilkinson, 1993; Fraser, Williamson, \& Tobin, 1987; Ferguson \& Fraser, 1998; Henderson, Fisher, \& Fraser, 2000; Majeed et al., Van Tartwijk, Brekelmans, Wubbels, Fisher \& Fraser, 1998). Although this previous research provided evidence that may guide educational programs for older children, it lacked the inclusion of broader dimensions of school functioning outside of academic achievement. In order to explore the association between classroom perception and socio-emotional functioning, it is argued that it is important to examine this issue in younger children.

Grade and gender effects. A few significant grade effects for classroom perception scores were found. This finding suggests that children in different grades tend to report significantly different overall classroom perception scores. However, upon 
closer investigation, these grade differences were primarily a result of differences in the Grade 4 perceptions of teacher support and perceptions of involvement only. Again, as there is very limited research exploring classroom perceptions in an upper-elementary school sample, it is difficult to provide supportive evidence for this finding. Nonetheless, there were some initial concerns whether the Grade 3 children would be able to accurately report on their classroom experiences simply due to the difficulties with the measurement process (i.e., length of questionnaires, reading abilities). However, findings suggest that where grade differences do exist, these differences are primarily due to the Grade 4 children reporting significantly differently than the Grade 3 and Grade 5 children.

It has been reported that boys tend to rate their classroom environments lower than girls (Fisher, Fraser, \& Rickards, 1997). However, due to the younger sample employed in the current study, the role of gender was relatively speculative. Findings from the current investigation did not support gender differences in classroom perceptions. Thus, boys and girls did not appear to perceive their classroom environments in different ways. These findings are somewhat contradictory to the current literature on gender differences in classroom perceptions (Owens \& Barnes, 1982; Sinclair \& Fraser, 2002; Wong \& Fraser, 1995). For example, Sinclair \& Fraser (2002) reported significant gender differences in classroom perceptions on the teacher empathy subscale and the cooperation subscale ${ }^{2}$. Indeed, other researchers have also reported that girls tend to rate

\footnotetext{
${ }^{2}$ It should be noted that following Exploratory Factor Analysis, the Cooperation subscale did not load as a separate factor. Therefore, the Cooperation subscale is not included in the current findings.
} 
their perceived classroom environments more positively than boys (Byrne, Hattie, \& Fraser, 1986; Owens \& Straton, 1980; Teh \& Fraser, 1994).

The lack of gender differences in the current investigation may be reflective of the younger sample. It should be noted, that each of these previous studies reporting gender differences in classroom perceptions was with older samples (e.g., adolescents, university students) than the current investigation. As there are limited studies that explore classroom perceptions among upper elementary school sample, it is difficult to infer why the current investigation did not find significant gender differences in classroom perceptions.

The one previous study with an upper-elementary school sample explored the associations between classroom perceptions and attitudes towards science learning environments (Allen \& Fraser, 2007). Similar to the findings in the current study, Allen and Fraser (2007) did not report any significant gender differences in classroom perception scores. Thus, it could be argued that perhaps boys and girls do not begin to diverge in their perceptions of their classroom experiences until they are older. This interpretation is further supported by the factor structure of the WIHIC-R among this younger sample. As opposed to the adolescent population in which classroom perceptions fall into 5 specific categories (i.e., Teacher Empathy, Teacher Equity, Cooperation, Involvement, and Investigation), younger children seem to perceive their classrooms in terms of three broader categories. Perhaps this finding is indicative that the processes by which boys and girls perceive their environments is similar until they move into middle school. 
Despite the overall lack of gender differences in classroom perceptions, there was at least some evidence that classroom perceptions were associated with outcomes somewhat differently for boys versus girls. For example, findings suggested that the significant negative association between victimization and perceptions of teacher support was stronger for girls than boys. In other words, especially for girls, children that report less positive perceptions of teacher support are more likely to also experience victimization. Although there is some discrepancy in the literature, it has been reported that forms of aggression and victimization differ among girls and boys (Crick, 1997; Crick \& Groetpeter, 1995). For example, girls use more indirect forms of aggression that target social relationships rather than physical harm (Crick, 1997). Drawing from these findings, perhaps girls tend to elicit more teacher involvement when victimization occurs due to the emphasis on their friendships within the classroom. Therefore, if perceptions of teacher support are low girls may feel more at risk of victimization.

Each of the significant interactions provides some evidence for the role of gender in the association between classroom perceptions and adjustment outcomes. However, it should be noted that the remaining interactions were not significant suggesting that the relation between dimensions of classroom perceptions and adjustment outcomes are largely manifested in the same way for boys and girls. Moreover, results from Study 1 did not indicate any significant gender differences. These mixed results indicated that additional research is clearly required to further explore the role of gender in the assessment and outcomes of classroom perceptions.

Classroom Perceptions and Adjustment Outcomes 
In order to assess the construct validity of the WIHIC-R, the relation between each dimension of classroom perceptions (i.e., teacher support, student cohesiveness, and involvement) and conceptually related socio-emotional adjustment outcomes were explored (i.e., victimization, anxiety, loneliness, and self-concept). Specific predictions were made with regard to each dimension of classroom perceptions. For example, it was predicted that children that report lower perceptions of student cohesiveness and involvement would be more likely to experience adjustment difficulties including victimization, loneliness, school avoidance, and depressive symptoms. Further, it was also predicted that children that report lower perceptions of teacher support and equity would be more likely to also report school avoidant strategies.

As predicted, significant associations were found between dimensions of classroom perceptions and adjustment outcomes. For example, results from both studies indicate that children with lower perceptions of their classroom environment report more social adjustment difficulties in general (i.e., victimization, anxiety, loneliness, depression, school avoidance). Interestingly, lower perceptions of teacher support and student cohesiveness were found to be significantly related to broader dimensions of socio-emotional functioning whereas perceptions of involvement were found to be related to more specific aspects of adjustment. For example, perceptions of teacher support and student cohesiveness were significantly and individually related to each of the adjustment outcomes that were measured in the current study (i.e., depressive symptoms, anxiety, school avoidance, loneliness, self-concept, and victimization). However, perceptions of involvement were significantly related to self-concept in school and victimization only. 
Thus, it appears that the strong overall associations between class perceptions and adjustment outcomes vary somewhat as a function of the different dimensions. These results may indicate that perceptions of personal characteristics (i.e., involvement) represent a different mechanism than perceptions of others (i.e., teacher and student characteristics). For example, perception of involvement is essentially a measure of one's belief of their own role and responsibility to actively participate in their classroom. To the contrary, perceptions of teacher support and student cohesiveness are a measure of one's beliefs with regards to the roles of others in the classroom. Therefore, although each of the dimensions of classroom perceptions are related to some aspect of socioemotional functioning, perhaps the relation between the perceptions of one's own involvement versus the involvement of others should be interpreted in different ways.

To further explore this issue, it was predicted that children with lower perceptions of their involvement in the classroom would be at risk for experiencing a broader range of difficulties than the findings presented here suggest. The non-significant associations between perception of involvement and a broad range of adjustment difficulties indicate that, contrary to predictions, perceptions of involvement were not significant associated with adjustment difficulties. Drawing from the social-withdrawal literature, it is argued that perhaps the motivation of involvement significantly influences the association between perception and outcomes. In other words, perhaps children that report lower perceptions of their involvement do not perceive this to be "negative" as originally predicted.

Within a substantive body of research exploring dimensions of social withdrawal, it is argued herein that the motivations driving social interaction may moderate the 
relation between lower perceptions of involvement and global social adjustment difficulties (e.g., Coplan, 2000, Coplan, Prakash, \& Armer, 2004; Rubin, Burgess, \& Coplan, 2002). Positive associations between the high frequency of non-social activities and adjustment outcomes (i.e., depressive symptoms and anxiety) have been demonstrated (Hymel, Rubin, Rowden, \& LeMare, 1990; Rubin \& Mills, 1988). In other words, children that are more likely to participate in non-social activities are more likely to experience some adjustment difficulties. Therefore, within the context of the current findings, children with lower involvement in their classroom (as measured by perceptions of involvement) would be more likely to experience adjustment difficulties. However, findings in the current investigation did not support this association.

In their research, Coplan et al., (2004) distinguished between two sub-types of social withdrawal; (1) Social disinterest, which is characterized by the preference to play alone because they do not have a strong motivation to engage in social interaction; and (2) Conflicted shyness, which is characterized by the desire to play but includes a tendency to withdraw from social interaction due to anxiety and fearfulness. It is argued herein, that perhaps children with lower perceptions of their involvement in their classroom environment avoid experiencing a broader range of adjustment difficulties because they do not necessarily interpret their lack of involvement to be "negative". Perhaps some of these children are simply socially-disinterest and have a preference to be more solitary in their classroom.

Nonetheless, these findings not only provide further support for the use of the WIHIC-R among a younger sample, they also provide initial evidence for a meaningful association between classroom perception and social adjustment. Although this is the first 
known study to explore the relation between classroom perceptions and socio-emotional adjustment, the findings were consistent with studies that assess other classroom variables, including observations (Burchinal, Peisner-Feinberg, Gazelle, 2006; Pianta, \& Howes, 2002; Howes, 2000; Urdan \& Schoenfelder, 2006), and teacher ratings of classroom environment (Harms, Clifford, \& Cryer, 1998; Pianta, 1994; Stormshak et al., 1999; Wertahmer-Larsson, Kellam, \& Wheeler, 1991).

The findings presented here were also consistent with various studies in which the association between classroom characteristics and socio-emotional outcomes are reported (i.e., Burchinal, Peisner-Feinberg, Pianta, \& Howes, 2002; Gazelle, 2006; Pianta et al., 2005; Pianta, La Paro, Payne, Cox, \& Bradley, 2002; Stormshak, et al., 1999). Further, the significant associations reported here were in keeping with the child by environment modeling which posits that environmental characteristics play a significant role in the development of adjustment outcomes (Boyce, Frank, Jenson, Kessler, Nelson, Steinberg, and the Mac Arthur Network on Psychopathology and Development, 1998; Howes, 2000; Pianta, Lopez-Hernandez, \& Ferguson, 1997).

It should be noted however, that the results presented here are associations only. In other words, although significant associations between classroom perceptions and socio-emotional functioning have been identified, the nature of these associations is less clear. It has been theorized in the current study that classroom perceptions influence early socio-emotional functioning. However, it could also be true that children experiencing adjustment difficulties would be more likely to have more negative interpretations of their school environments. For example, perhaps children who are more depressed, more anxious and more victimized perceive their classrooms to be more negative. Indeed, 
depressed and anxious children would be expected to perceive a more negative environment (i.e., Coplan et al., 2004; Wichmann et al., 2004). It could also be speculated that a transactional process exists whereby a child with negative initial perceptions of their environment goes on to feel more depression and anxiety, which in turn leads to an even more negative perception of environment, and so on. Although outside the scope of the current dissertation, it would be interesting to further explore the nature of this association from a longitudinal perspective.

Shyness, Aggression, and Classroom Perceptions

It is well documented in the social development literature that children frame their social world through their experiences (Higgins, 1990; Murphy \& Medin, 1985;

Stromquist \& Strauman, 1991). Within this theoretical framework, it has been argued throughout the current dissertation that the inherent biases of shy and aggressive children would affect the way in which they interpret their environment. For shy children, it has been reported that even though they may want to interact when in a social situation, they tend to withdraw from social encounters because of underlying social wariness (Coplan, et al., 2004). For example, Wichmann et al., (2004) reported that shy-withdrawn children report a self-defeating bias in their interpretation of social interactions. Moreover, evidence from the social anxiety literature indicates that shy-anxious children tend to over-interpret the potential threat levels in their environment (i.e., Amir, Foa, \& Coles, 1998; Franklin, Huppert, Langner, Leiberg, \& Foa, 2005; Stopa \& Clark, 2000). Therefore, regardless of their environment, it was predicted that shy children would perceive their classrooms more negatively due to this underlying social wariness and anxiety. Similar predictions were made with regards to aggressive children. It has been 
reported that when presented with a benign social stimuli, aggressive children are likely to interpret this situation with hostility due to an underlying "hostile attribution bias" (Dodge \& Price, 1994). Therefore, regardless of the nature of the social interaction, aggressive children are likely to perceive social situations with hostility. Building upon these findings within the context of the current study, it was also predicted that aggressive children would be more likely to report more negative classroom perceptions.

Results from the current study indicated that both shyness and aggression were negatively related to classroom perceptions. For example, aggression was negatively associated with perceptions of teacher support and student cohesiveness in the classroom. In other words, highly aggressive children were more likely to report more negative perceptions of teacher support and student cohesiveness. It is interesting to note that the association between aggression and involvement was not significant. Therefore, although children who were more aggressive tended to perceive external variables (i.e., teacher and student characteristics) as more negative, aggression was not related to children's perceptions of their own involvement in the classroom. This may be indicative of the over-inflated self-concept of aggressive children has often been reported (i.e., Baumeister, Bushman, \& Campbell, 2000; Bushman \& Baumeister, 1998; Schreer, 2002). Nonetheless, these findings provide evidence that, perhaps due to a hostile attribution bias, aggressive children tend to perceive their classrooms more negatively than less aggressive children.

Again, it is important to note that the findings presented here represent associations only. Therefore, the nature of the relation between aggression and classroom perceptions is still unclear. For example, it is possible that rather than aggression 
resulting in negative perceptions, perhaps aggressive characteristics (i.e., externalizing behaviours) influence the classroom climate - in turn leading to a more negative perception. Nonetheless, the current findings provide preliminary evidence for the significant association between classroom perceptions and aggression. Due to the often disruptive behaviours association with aggression, a great deal of research has focused on the development of intervention programs designed to reduce the incidence of aggression in schools (i.e., Carlyon, 1997; Hudley, Britsch, Wakefield, Smith, Demorat \& Cho, 1998; Hudley \& Graham, 1995). The results presented here, allow for a broadened approach to intervention. Perhaps interventions could include specific strategies designed to address aggressive children's negative perceptions of their classroom experience.

In contrast to the findings for aggression, shyness was not related to perceptions of teacher support and student cohesiveness but was negatively related to perceptions of involvement in the classroom. In other words, shy children were more likely to report negative perceptions of their own involvement and participation in the classroom. Contrary to the findings associated with aggression, shy children perceive personal characteristics (i.e., involvement or participation) more negatively than external characteristics (i.e., teacher support and student cohesiveness). These results may be due to the attribution styles of shy children. For example, it has been reported that shy children are more likely to blame themselves when something "goes wrong" and attribute success to others when something "goes right" (Wichmann et al., 2004). In the context of the current findings, shy children's perception of their own involvement was more negative whereas shyness was not related to perceptions of the role of others. This finding may also represent the difficulties that shy children often face with the social and 
academic expectations inherent in the classroom environment (i.e., Coplan \& Arbeau, 2008; Eisenberg, Shepard, Fabes, Murphy, \& Guthrie, 1998 Rubin \& Asendorpf, 1993; Stevenson-Hinde \& Glover, 1996). Again, the nature of the association between shyness and classroom perceptions remains unclear.

For shyness, significant interactions with gender were also found in terms of teacher support and student cohesiveness. Results indicate that the negative association between teacher support and shyness was stronger for boys than for girls. Similarly, the relation between student cohesiveness and shyness was also stronger for boys than for girls. In other words, the relation between shyness and some aspects of classroom perceptions (i.e. teacher support and student cohesiveness) is particularly meaningful for boys. It is widely reported that shy boys are at an increased risk of experiencing difficulties than shy girls (i.e., Coplan, Prakash, O’Neil \& Armer, 2004; Eisenberg et al., 1998; Morison \& Masten, 1991; Rubin et al., 1993; Stevenson-Hinde \& Glover, 1996). It has been argued that shy boys are at an increased risk of experience adjustment difficulties due to different social perceptions and acceptability of shyness for girls (Sadker \& Sadker, 1994). For example, in Western societies it is more socially desirable for boys to be boisterous and active. To the contrary, the inhibited nature of a shy girl is more consistent with the social expectations for girls to be more coy and reserved. Therefore within the context of the current findings, perhaps shy boys are treated differently by their teachers and classmates than shy girls - in turn leading to a more negative perception of their classroom experiences. Nonetheless, the current findings provide further evidence for particular difficulties that are often experienced by shy boys. Shyness, Aggression, Classroom Perceptions, and Adjustment Outcomes 
It is now widely reported that social development is a dynamic process which is influenced by multiple levels of a child's social experiences (Coie et al., 1990; Newcomb, Bukowski, \& Pattee, 1993). For example, the child-by-environment model of development posits that both child characteristics and environmental characteristics significantly contribute to adjustment (Gazelle, 2006). Historically, the relation between social adjustment and classroom characteristics has been explored using teacher-reports or observations of classroom climate (Harms, Clifford, \& Cryer, 1998; Pianta, 1994; Gazelle, 2006; Pianta, La Paro, Payne, Cox, \& Bradley, 2002; Stormshak, et al., 1999; Wertahmer-Larsson, Kellam, \& Wheeler, 1991). Building upon this body of literature, it was predicted in the current study that the association between classroom characteristics (i.e., classroom perceptions) and child characteristics (i.e., aggression and shyness) would significantly contribute to socio-emotional adjustment outcomes even when self-reported perceptions of classroom dimensions were employed rather than observations and teacher reports. Findings in the current study support previous reports of an association between behavioural characteristics and classroom environment. As predicted, significant main effects between aggression and shyness and specific dimensions of classroom climate were found. Consistent with the literature, results from the current investigation provide at least some preliminary empirical support for the role of classroom perception as a moderating variable in the association between behavioural characteristics and adjustment outcomes. The pattern of results indicates a complex set of associations between shyness, aggression, and outcomes - with the relations between the behavioural characteristics (i.e., aggression and shyness) moderated by both gender and classroom climate. 
Aggression. Overall, aggression was related with some aspects of socio-emotional functioning. However, the scope of the relations between aggression and adjustment outcomes was not as broad as predicted. More specifically, self-concept with peers was the only measure of adjustment that was significantly related to aggression. Moreover, aggressive children reported higher feelings of self-concept indicating that they are generally quite confident in their abilities among peers. It is argued that the significant association with self-concept, and the lack of significance with the remaining main effects, is reflective of aggressive children's tendencies to report an over-inflated sense of self concept (Coie \& Dodge, 1998; Newcomb et al., 1993; Rubin et al., 1998). It is widely reported that although aggressive children are often rejected by their peers, they themselves do not report that they are rejected. In other words, aggressive children believe that they are accepted by their peers even when they are not (Coie \& Dodge, 1998; Newcomb et al., 1993; Rubin et al., 1998). Therefore, it was found in the current study that aggressive children are not more likely to report socio-emotional adjustment difficulties because they feel quite confident about their abilities in their social world regardless of how they may be perceived by others.

The limited associations may also be due to the reliance on self-reported outcome variables. Socio-emotional functioning in the current study is largely comprised of internalizing outcomes (i.e., loneliness, depressive symptoms, anxiety). A closer inspection of the literature indicates that aggression may not be expected to be strongly related to anxiety and depression (and other internalizing problems) at this age (i.e., Bagwell, Coie, Terry, \& Lochman, 2000; Cairns, Cairns, Neckerman, Gest, \& Garie, 1989; Estell, Cairns, Farmer, Cairns, 2002; Luthar \& McMahon, 1996; Vaillancourt \& 


\section{Classroom Perceptions}

Hymel, 2006). Although aggressive children are in fact at risk of experiencing adjustment difficulties, they are most at risk of externalizing problems rather than internalizing problems. Therefore, if multiple assessments of adjustment were obtained (i.e., peer and teacher reports), and a greater focus on externalizing difficulties was also explored, perhaps the association between aggression and socio-emotional functioning would be more consistent with the existing evidence.

In order to contribute to the existing classroom environment and classroom perception literature, a portion of the current study explored the potentially moderating role of classroom perceptions and gender in the association between aggressive behaviours and socio-emotional functioning. Although there is some evidence to support the moderating role of classroom perceptions in the association between aggression and socio-emotional functioning, gender does not appear to significantly contribute. None of the gender by aggression interactions were significant in the prediction of adjustment outcomes. The lack of significant gender interactions suggests that the nature of the association between aggression and outcomes is the same for boys and for girls.

This finding is somewhat consistent with the existing literature exploring gender as a moderator among the association between aggression and adjustment (Crick, 1997; Card, Stucky, Sawalani, \& Little 2008). However the nature of this relation changes depending upon the type of aggression. For example, Crick (1997) reports that girls are more likely to use indirect forms of aggression (i.e., aimed at damaging the target's social relations) whereas boys are more likely to employ more direct forms of aggression (i.e., physical harm). In terms of gender, it is reported that adjustment difficulties are predicted by normative versus non-normative use of aggression (Crick, 1997). In other words, girls 
that employ direct forms of aggression are more likely to experience maladjustment than girls that use indirect forms of aggression. In the context of the current study, the measure used to assess levels of aggression did not empirically different between the two forms of aggression. However, the peer-nomination measure includes items targeting both direct and indirect forms of aggression. Therefore, perhaps the association between the broader interpretation of aggression and socio-emotional functioning is not as influenced by gender.

As previously described, aggressive children are more likely to experience social adjustment difficulties including peer rejection (Coie \& Dodge, 1998; Feshbach, 1970; Ladd, 2005; Parke \& Slaby, 1983; Hawley, Little, \& Rodkin, 2007). However, among aggressive children there is heterogeneity in the occurrence of these negative outcomes. In other words, although aggressive children tend to be more likely to experience social adjustment difficulties, not all aggressive children do (Card, Stucky, Sawalani, \& Little 2008). It is argued that other contributing variables (i.e., socio-metric status, classroom characteristics) may "buffer" aggressive children from experiencing these difficulties. The current study explored the potential moderating role of classroom perceptions between aggression and negative adjustment outcomes. It was predicted that aggressive children with higher classroom perceptions would be less likely to experience adjustment difficulties than aggressive children with lower classroom perceptions.

Although the current study provided some support for the moderating role of classroom perceptions in the association between aggression and aspects of socioemotional functioning, it should be noted that significant associations are limited to school-avoidance only. It was originally predicted that classroom perceptions would be 
associated with a broader range of socio-emotional functioning; however, the findings presented here do not provide support for this.

Nonetheless, findings in the current investigation provided some preliminary evidence for classroom perceptions as a moderator in the association between aggression and social adjustment difficulties. One significant perception by aggression interaction was found in the prediction of school avoidance. Among children with lower classroom perceptions, aggression and school avoidance were negatively related. However, among children with more positive classroom perceptions, the relation between aggression and school avoidance was positive. This was an unexpected but somewhat intriguing result. According to the generalized definitions of classroom environment, this finding could be interpreted to suggest that aggressive children actually prefer to attend more "negative" classroom environments. Theses findings appear somewhat counterintuitive as one would predict that children would want to be in classrooms that are considered to be "positive". However, aggressive children report that they are more likely to try to avoid these types of classrooms. Further, this association is unique to aggressive children suggesting that perhaps they are interpreting their classroom experiences differently than non-aggressive children.

It is argued herein that the significant association between aggression and classroom perceptions in the prediction of school avoidance provides further support for the person-group similarity theory (Boivin, Dodge, \& Coie, 1995; Stormshak et al., 1999). Within the framework of this theory, it is suggested that the acceptability and status within a group will vary based on group norms. Within the contexts of the current findings, perhaps aggressive children prefer to be in classroom environments that are 
more consistent with their externalizing tendencies. For example, lower perceptions on the WIHIC-R indicate perceptions of low-levels of teacher equity and fairness, a lack of positive relationships among the students, and low levels of personal involvement or participation in class discussions and activities. Therefore, it is argued within the framework of the person-group similarity theory that this type of environment may be more accepting of the typical behaviours of aggressive children.

Shyness. Overall, results indicate that shyness was significantly related to selfreported adjustment difficulties (i.e., loneliness, depressive symptoms, school avoidance), although there are some limitations to these findings. Results indicate that shyness is significantly and negatively related to both peer and school self-concept as well as significantly and positively related to loneliness, depressive symptoms, and school avoidance. These findings are consistent with existing evidence suggesting that shy children are at an increased risk of experiencing adjustment difficulties (Coplan \& Armer, 2007; Gazelle et al., 2005; Rubin \& Coplan, 2004; Rubin, et al., 2009). However, results from the regression analyses indicate that the associations between shyness and aspects of socio-emotional functioning were non-significant. These findings may indicate that when classroom perception variables are entered into the equation, a mediation effect occurs (Tabachnick \& Fidell, 2007). Mediation occurs when the inclusion of a third variable (i.e., classroom perceptions) alters the association between the independent variable (i.e., shyness) and the dependent variables (i.e., adjustment outcomes). In the context of the current research, rather than a direct relation between shyness and adjustment outcomes, perhaps shyness predicts classroom perceptions - which in turn predict socio-emotional functioning. Alternatively, the lack of significance between 
shyness and adjustment outcomes may be due to the strong association between classroom perceptions and adjustment outcomes. Perhaps this strong association is accounting for the large majority of the variance in adjustment outcomes. Nonetheless, the current investigation does provide some evidence for the association between shyness and socio-emotional functioning which is consistent with the literature.

Some gender differences in the association between shyness and socio-emotional adjustment were also found. For example, results indicated that the association between shyness and both depressive symptoms and school avoidance were stronger for boys than for girls. The gender differences reported here are consistent with a large body of evidence that shy boys tend to experience more difficulties than shy girls (i.e., Coplan et al., 2004; Eisenberg et al., 1998; Morison \& Masten, 1991; Rubin et al., 1993; StevensonHinde \& Glover, 1996). Although shy boys and shy girls are both at an increased risk of experiencing adjustment difficulties (i.e., peer exclusion), the associations tend to be stronger for boys (Coplan et al., 2004).

The current study provided some additional support for this assertion. It is often argued that shy boys face particular difficulties due to the societal expectations of boys versus girls in Western societies. For example, boys are often expected to be more boisterous, energetic, and direct, whereas for girls, it is often more socially desirable to be coy, modest, and timid. Nonetheless, although there is some support for gender differences among the association between shyness and adjustment outcomes, results indicate that for the most part this association is the same for boys and girls.

A portion of the current study also explored the potential moderating role of classroom perceptions in the associations between shyness and socio-emotional 
functioning. It is well documented in the literature that shy children are also at risk of experiencing a broad range of adjustment difficulties including loneliness, victimization, depressive symptoms, and social anxiety (Coplan \& Armer, 2007; Gazelle et al., 2005; Rubin \& Coplan, 2004; Rubin, et al., 2009). However, similar to aggressive children, there is heterogeneity among shy children that experience negative social outcomes. In an attempt to explain the heterogeneity in outcomes for shy children, a large body of research has been devoted to exploring environmental factors (i.e., classroom characteristics) that may be contributing to these differences (e.g., Gazelle, 2006; Harms, Clifford, \& Cryer, 1998; Pianta, 1994; Stormshak et al., 1999; Wertahmer-Larsson, Kellam, \& Wheeler, 1991).

Recently in the field of education and psychology, the lens through which social development is understood has broadened to include multiple layers of the child's experience in the prediction of outcomes (i.e., teacher-child relationships, friendship quality, and classroom characteristics). Of particular relevance to the current investigation, a positive classroom climate (based on observations) has been demonstrated to act as a "protective factor" for shy children (Gazelle, 2006). More specifically, as compared to shy children in a negative classroom, shy children with a positive classroom climate are less likely to experience socio-emotional adjustment difficulties. Building upon these findings, a primary objective of the current study was to further explore the role of classroom characteristics by examining the role of classroom perceptions in the association between shyness and socio-emotional functioning. It was predicted that shy children with more positive classroom perceptions would be less likely 
to experience adjustment difficulties than shy children with more negative classroom perceptions.

Findings in the current investigation provided at least some preliminary evidence for classroom perceptions as a moderator in the association between shyness and socioemotional functioning. One significant perception by shyness interaction was found in the prediction of depressive symptoms. Among children with lower classroom perceptions, there was a positive association between shyness and depressive symptoms. However, among children with more positive classroom perceptions, this relation dissipated. These findings suggest that a more positive classroom perception may act as a "buffer" against depressive symptoms for shy children. In other words, shy children that have more positive classroom perceptions are less likely to experience depressive symptoms than shy children with less positive classroom perceptions.

It should be noted that the moderating role of classroom perceptions in the association between shyness and socio-emotional functioning was limited to depressive symptoms. Therefore, although the current findings provided some support for the moderating role of classroom perceptions, this variable does not appear to be significantly related to broader socio-emotional functioning. However, although there does not appear to be support for the moderating role of classroom perceptions between shyness and many of the adjustment outcomes explored in the current investigation, previous research does support the association with depressive symptoms. Gazelle (2006) explored the moderating role of observed classroom climate in the association between shyness and socio-emotional functioning among Grade 1 students. Consistent with the findings presented in the current investigation, Gazelle (2006) also reported that a 
positive classroom climate (based on observations) acts as a moderating variable between shyness and depressive symptoms for girls only.

It is also important to make note of an alternate interpretation of the current findings. It is also possible that shy children who were more depressed were also more likely to interpret their classroom experiences more negatively. Therefore, rather than classroom perceptions contributing to the incidence of depression, depression among shy children may be leading to less positive classroom perceptions. Consistent with the social-cognitive research identify the inherent biases of aggressive (i.e., Dodge $\&$ Price, 1994) and social-withdrawal (Wichmann et al., 2004), processes have been identified for individuals suffering from depressive symptoms (i.e., Dodge, 1993; Quiggle et al., 1992). Osantowski (2001) explored the association between depression and specific aspects of social information processing among adolescent girls. Results indicated that depression significantly predicted a hostile attribution bias (Osantowski, 2001). In other words, adolescent girls that were identified as depressed were more likely to interpret social interaction with hostility. Drawing upon these findings in the context of the current study, it could be argued that children that report depressive symptoms may also be more likely to perceive their classroom less positively. Although, this issue is beyond the scope of the current dissertation, it would be interesting to further explore the nature of the association from a longitudinal perspective.

\section{Limitations and Future Research}

Results from the current study suggest that there is a complex set of interassociations among children's classroom perceptions, behavioural characteristics, and socio-emotional functioning. However, there are a number of caveats that must be 
considered when interpreting these results, which also suggest important directions for future research.

To begin with, because of the correlational nature of the study, inferences about causality and directions of effect cannot be made. For example, findings suggest that children that report lower perceptions of their classroom environment tend to also report socio-emotional adjustment difficulties. However, as mentioned earlier, this finding may also be interpreted that children who experience more socio-emotional difficulties may be more likely to report lower perceptions of their classroom experiences. Thus, these findings should be considered "building blocks" for future research designed to further explore this issue. For example, longitudinal studies could explore the nature of the trajectory for children with early socio-emotional difficulties that have positive and negative classroom perceptions. In order to do this, one could measure the socioemotional functioning of children at the beginning of the school year. Later in the school year, classroom perceptions and socio-emotional functioning could be again measured. By doing so, researchers could better assess the trajectory of adjustment as it relates to classroom perceptions. Further, due to the nested design of the current investigation, it would also be interesting to employ Hierarchical Linear Modeling in an attempt to assess the class-level effects as well.

Further, it would also be interesting to identify early behavioural characteristics (i.e., aggressive and shy) and determine if classroom perceptions moderate the trajectory of experiencing adjustment difficulties for children that are at an increased risk. For example, it would be interesting to identify shy and aggressive children at the beginning of the school year and subsequently explore their classroom perceptions and socio- 
emotional functioning towards the end of the school year. By doing so, inferences could be made with regard to the contribution of classroom perceptions in the prediction of adjustment outcomes. Also, the ability of classroom perceptions to act as a "buffer" for behavioural "at risk" children could also be further examined.

The current study employed self-reported outcome measures of socio-emotional functioning only, which does not allow for an assessment of the "accuracy" of students reports. It would be interesting to also explore the association between self-reported classroom perceptions and observations of global classroom functioning on the same dimensions. For example, perhaps higher classroom perceptions are not resulting from interpretations due to child characteristics; rather these perceptions are an accurate reflection of a positive classroom environment as identified by an unbiased observer. If classroom perceptions are simply an accurate reflection of classroom experiences, it could be argued that the actual classroom climate (rather than classroom perceptions) may be contributing to the prediction of socio-emotional functioning.

In order to address this issue, it would be interesting in future research to also include teacher, parent, and peer reports of social adjustment and classroom climate. With feedback from parents, peers, and teachers, a broader range of socio-emotional functioning could be explored. For example, findings in the current study suggest that aggressive children report very few adjustment difficulties. However, it could be argued that due to the externalizing tendencies of aggressive children, their social functioning may be interpreted quite differently by the teachers and peers. For example, teachers may perceive aggressive children to be quite disruptive in the classroom. Further, peers may tend to report that they reject aggressive children. Therefore, although aggressive 
children in the current study did not report adjustment difficulties, it is argued that a multi-source assessment of outcomes may provide other important information.

It would also be interesting to broaden the outcome measures to other aspects of socio-emotional functioning including friendship quality and teacher-child relationships. As this is the first known study to examine the association between classroom perceptions and socio-emotional functioning, it would be interesting to also explore a broader range of adjustment outcomes that have been linked with global school functioning. For example, for shy children, positive teacher-child relationships and friendships can act as a protective factor against some adjustment difficulties (i.e., Fordham, \& Stevenson-Hinde, 1999; Rubin et al., 2006; Rydell, Bohlin, \& Thorell, 2005). Therefore, it would be interesting to predict whether classroom perceptions are also linked with these variables. It is predicted for example, that shy children with more positive classroom perceptions would be more likely to experience positive relationships with their teachers and high quality friendships. In other words, similar to the findings in the current investigation, positive classroom perceptions would be associated with better social-functioning. Moreover, it would be interesting to also examine externalizing problems and peer-rejection. Similar to the predictions made with regard to shy children, it would be predicted that aggressive children with positive classroom perceptions would be less likely to experience these negative outcomes.

The existing classroom perception literature has largely focused on academic functioning as an outcome variable among adolescent populations. Although the focus of the current study was to explore socio-emotional functioning, it would be interesting to also explore academic functioning among an upper-elementary school sample. Similar to 
existing research employing adolescent samples, it would be predicted that classroom perceptions would be positively associated with academic functioning. In other words, children that report more positive classroom perceptions would be more likely to achieve academically.

Also, the current study limited the behavioural characteristics to shyness and aggression. It would be interesting to broaden these behavioural dimensions to include other characteristics (i.e., ADHD). Although there is a large body of evidence suggesting that aggressive and shy children are at an increased risk of experiencing social adjustment difficulties, these were only moderately demonstrated in the current study. As described earlier, this limited association may be due to the use of self-reported outcomes. To further explore this, it would be interesting in future research to include other behavioural characteristics that have been linked with negative adjustment outcomes. For example, it would be predicted that children identified with ADHD would be at risk of experiencing adjustment difficulties however this relation may be moderated by their classroom perceptions. In other words, children with ADHD will be less likely to experience negative outcomes if they "like" their classroom environment. Moreover, findings in the current study suggest that aggressive children avoid classrooms that were considered to be "positive" according to the definition used in the classroom environment literature. This finding suggests that aggressive children prefer classrooms that are considered "negative" according to this definition. Similar predictions would be made with regard to children identified with ADHD. These predictions lead one to postulate that perhaps the child's preferences of their classroom environment. 
It should also be noted that a large body of research exists exploring the discrepancy between perceived classroom environment and preferred classroom environment (Aldridge \& Fisher, 1998; Aldridge \& Fraser, 2000; Ferguson \& Fraser, 1998; Fraser et al., 1996). For example, a great deal of research attention has been devoted to the discrepancy between perceptions of one's current classroom environment (often referred to as actual environment) and the environment that they would prefer that has received (Aldridge \& Fisher, 1998; Aldridge \& Fraser, 2000; Ferguson \& Fraser, 1998; Fraser et al., 1996). It has been postulated that a child is more likely to succeed in an environment that most closely resembles the type of environment that they prefer. Ratings of both perceived and preferred environments often differ on some composites associated with classroom experiences. Similarly, teachers and students tend to rate their perceived, or actual, and preferred environments differently (Sinclair \& Fraser, 2002). Preferred classroom environment is most often measured as a self-report. In order to assess the discrepancy between the perceived and preferred classroom, participants are asked to report on their 'actual' environment on several dimensions as well as being asked to report on what they would prefer on these same dimensions. The discrepancy is conceptualized as a measure of 'satisfaction' of classroom experience. Gender differences are often reported with girls generally reporting greater satisfaction with their classroom environment than boys (Sinclair \& Fisher, 2002; Byrne et al., 1986).

Further, the current study does not address whether the perceptions of classroom environment are "accurate". If one were to compare classroom climate based on observations and children's perceptions, would the results be the same. As indicated in Gazelle's research, it is suggested that the way in which the shy child perceives their 
classroom does not influence the moderating role of the variable. In other words, regardless of what the child thinks of their environment, if it is observed to be positive, shy children may avoid experiencing depressive symptoms. Whereas, in the current investigation, it is argued that regardless of the observed environment, the way in which a child perceives their environment will predict adjustment outcomes. This issue needs to be further explored by comparing children's perceptions and observed classroom environment.

Finally, it would be useful to further explore to psychometric properties of the WIHIC-R. Although there were several associations with adjustment as predicted, some of the subscales were more strongly associated with the outcomes than others. For example, the Involvement subscale was associated with only a limited number of adjustment outcomes, whereas the associations for Teacher Support and Student Cohesiveness were more strongly related. The differences in these associations among subscales may be indicative of issues with regards to the validity of the measure. Further, these findings may also be due to the revised wording of some of the items. Nonetheless, further validation of the psychometric properties of the WIHIC-R (e.g., test-retest reliability, longer term stability) may be warranted.

\section{Summary}

The theoretical framework guiding the predictions in the current investigation is derived from two separate bodies of research. First, informed by the education literature in which several empirical links between classroom perceptions and academic outcomes (i.e., academic functioning and performance) have been identified, the current investigation employed what is known about classroom perceptions and expanded to also 
include the association with socio-emotional functioning. Second, the current investigation was also largely framed within the lens of the child-environment model in which it is predicted that environmental characteristics play an important role in the social development and functioning.

There is a long tradition of research indicating that children who exhibit shy and aggressive behaviors at school are at risk for social, emotional, and academic difficulties. However, closer inspection of the adjustment of these "high risk" children reveals substantial heterogeneity in their adjustment. Missing from most attempts to explain children's multi-dimensional school adjustment is consideration of the school environment. Yet, modern models of development emphasize that development is a product of dynamic interactions between multiple levels within the child and their environment. Thus, a first step in raising empirical research efforts to match the sophistication of developmental theory is examining the extent to which the relation between individual child behavioral vulnerabilities and adjustment outcomes may be moderated by the quality of classroom environments children encounter as they progress through school. Therefore, guided by a child-by-environment model, the current dissertation explored classrooms factors (i.e., classroom perceptions) as moderators of the multi-dimensional school adjustment of behaviorally "at risk" (e.g., shy and aggressive) children.

Classroom perceptions have been typically assessed among adolescent population. However, it was of particular interest in the current investigation to assess whether the processes of classroom perceptions can be measured in the same way among a younger population. Therefore, the psychometric properties and the construct validity 
of a modified version of a widely used classroom perception measure were examined among children in Grades 3, 4, and 5. Results in the current study provide support for the implementation of classroom perception measures among a younger population.

However, results also indicate that younger children do not differentiate their classrooms in the same way as older samples. Younger children perceive their classrooms in terms of the following three broader dimensions; (1) teacher characteristics - or the extent to which they perceive their teacher to be support and fair to all of themselves and their classmates; (2) student characteristics - or the extent to which the students in the class are friends with each other; and (3) involvement - or the extent to which the child perceives their own involvement in the classroom.

In summary, the current study has been successful in providing initial support for a classroom perceptions measure among an upper-elementary school sample. Further, this study is the first known study to explore the association between classroom perceptions and socio-emotional functioning. Findings provide support for the significant association between the way in which children perceive their classroom experiences and their reports of adjustment. Moreover, the current study has identified significant associations between behavioural characteristics (i.e., aggression and shyness) and perceptions. Findings suggest that aggressive children are more likely to report lower perceptions of teacher support and student cohesiveness whereas shy children are more likely to report less involvement in the classroom. These findings are consistent with the prediction that shy and aggressive children tend to perceive their social environments differently than less shy and less aggressive children. 
Finally, the current study provides some preliminary evidence for classroom perceptions as a moderating variable between behavioural characteristics and socioemotional functioning for children that are already "at risk" of experiencing social adjustment difficulties. For aggressive children, classroom perceptions moderate the association between aggression and school avoidance. For shy children, classroom perceptions moderate the association between shyness and depressive symptoms. Although the moderating role of classroom perceptions was not as broadly associated with outcomes as was originally predicted, the current findings provide some evidence that can be used as "building blocks" for future research. It is hoped that the findings presented in the current study provide preliminary steps that will encourage researchers to continue to ask children about their social experiences when exploring various aspects of development. 


\section{References}

Aiken, L. S., \& West, S. G. (1991). Multiple regression: Testing and interpreting interactions. Newbury Park, CA: Sage.

Aldridge, J., \& Fraser, B. (2000). A cross-cultural study of classroom learning environments in Australia and Taiwan. Learning Environments Research, 3, 101134.

Aldridge, J. M., Fraser, B. J. \& Huang, T. (1999). Investigating classroom environments in Taiwan and Australia with multiple research methods. Journal of Educational Research, 93, 48-57.

Ames, C.A. (1992). Classrooms: Goals, structures, and student motivation. Journal of Educational Psychology, 84, 261-271.

Amir, N., Foa, E. B., \& Coles, M. E. (1998). Negative interpretation bias in social phobia. Behaviour Research and Therapy, 36, 945-957.

Asendorph, J.B. (1991). Development of inhibited children's coping with unfamiliarity. Child Development, 62, 1460-1474.

Bagwell CL, Coie JD, Terry RA, Lochman JE (2000). Peer clique participation and social status in preadolescence. Merrill Palmer Quartly, 46, 280-305.

Bargh, J. A., Lombardi, W. J. \& Higgins, E. T. (1988). Automaticity of chronically accessible constructs in Person $\times$ Situation effects on person perception: It's just a matter of time. Journal of Personality \& Social Psychology, 55, 599-605.

Bandura, A. (1982). Self-efficacy mechanism in human agency. American Psychologist, $37,122-147$. 
Battistich, V., Solomon, D., Kim, D., Watson, M., \& Schaps, E. (1995). Schools as communities, poverty levels of student populations, and students' attitudes, motives, and performance: A multilevel analysis. American Educational Research Journal, 32, 627-658.

Baumeister, R. F., Bushman, B. J. \& Campbell, W. K. (2000). Self-esteem, narcissism, and aggression: Does violence result from low self-esteem or from threatened egotism. Current Directions in Psychological Science, 9, 26-29.

Birch, S. H. \& Ladd, G. W. (1997). The teacher-child relationship and children's early school adjustment. Journal of School Psychology, 35, 61-79.

Boivin, M., Dodge, K. A. \& Coie, J. D. (1995). Individual-group behavioral similarity and peer status in experimental play groups of boys: The social misfit revisited. Journal of Personality and Social Psychology, 69, 269-279.

Boyce, W. T., Frank, E., Jensen, P. S., Kessler, R. C., Nelson, C. A., Steinberg, L. \& the MacArthur Foundation Research Network on Psychopathology and Development. (1998). Social context in developmental psychopathology: Recommendations for future research from the MacArthur Network on Psychopathology and Development. Development \& Psychopathology, 10, 143-164.

Brendgen, M., Bowen, F., Rondeau, N., \& Vitaro, F. (1999). Effects of friends' characteristics on children's social cognitions. Social Development, 8, 41-51.

Bryant, D. M., Clifford, R. M. \& Peisner, E. S. (1991). Best practices for beginners: Developmental appropriateness in kindergarten. American Educational Research Journal, 28, 783-803. Developmental appropriateness in kindergarten. American Educational Research Journal, 28, 783-803. 
Buhs, E. S., \& Ladd, G. W. (2001). Peer rejection as antecedent of young children's school adjustment: An examination of mediating processes. Developmental Psychology, 37, 550-560.

Bukowski, W. M. \& Newcomb, A. F. (1984). Stability and determinants of sociometric status and friendship choice: A longitudinal perspective. Developmental Psychology, 20, 941- 952.

Burchinal, M, Howes, C \& Kontos, S (2002). Structural predictors of child care quality in child care homes. Early Childhood Research Quarterly, 17, 87-105.

Burchinal, M. R., Peisner-Feinberg, E., Pianta, R. C. \& Howes, C. (2002). Development of academic skills from preschool through second grade: Family and classroom predictors of developmental trajectories. Journal of School Psychology, 40, 415436.

Burchinal, M. R., Roberts, J. E., Riggins, R., Zeisel, S. A., Neebe, E. \& Bryant, D. (2000). Relating quality of center-based child care to early cognitive and language development longitudinally. Child Development, 71, 338-357.

Burks, V. S., Dodge, K. A., Price, J. M. \& Laird, R. D. (1999). Internal representational models of peers: Implications for the development of problematic behavior. Developmental Psychology, 35, 802-810.

Bushman, B. \& Baumeister, R. (1998). Threatened egotism, narcissism, self-esteem, and direct and displaced aggression: Does self-love or self-hate lead to violence. Journal of Personality \& Social Psychology, 75, 219-229.

Byrne, D. B., Hattie, J. A. \& Fraser, B. J. (1986). Student perceptions of preferred classroom learning environment. Journal of Educational Research, 80, 10-18. 
Cairns, R. B., Elder, G. H., Jr., \& Costello, E. J. (Eds.). (1996). Developmental science. Cambridge, England: Cambridge University Press.

Cairns, Cairns, Neckerman, Gest, \& Garie (1989). Social networks and aggressive behavior: Peer support or peer rejection? Developmental Psychology, 24, 815823.

Campbell, F. A. \& Ramey, C. T. (1994). Effects of early intervention on intellectual and academic achievement: A follow-up study of children from low-income families. Child Development, 65, 684-698.

Card, N., Stucky, B., Sawalani, G. \& Little, T. (2008). Direct and indirect aggression during childhood and adolescence: A meta-analytic review of gender differences, intercorrelations, and relations to maladjustment. Child Development, 79(5), 1185-1229.

Carlyon, W. D. (1997). Attribution retraining: Implications for its integration into prescriptive social skills training. School Psychology Review, 26(1), 61-73.

Chang, L. (2003). Variable effects of children's social behaviors as functions of teacher beliefs and behaviors. Child Development, 74, 535-548.

Church, M. A., Elliot, A. J. \& Gable, S. L. (2001). Perceptions of classroom environment, achievement goals, and achievement outcomes. Journal of Educational Psychology, 93,43-54.

Cillessen, A. H., Van Ijzendoorn, H. W., Van Lieshout, C. F. \& Hartup, W. W. (1992). Heterogeneity among peer-rejected boys: Subtypes and stabilities. Child Development, 63, 893-905. 
Coie, J. D. \& Dodge, K. A. (1998). Aggression and antisocial behavior. En N. Eisenberg (Ed.),. Social, emotional and personality development, 779-862 New York: Wiley.

Coie, J. D., Dodge, K. A. \& Coppotelli, H. (1982). Dimensions and types of social status: A cross-age perspective. Developmental Psychology, 18, 557-570.

Coie, J., Dodge, K., Kupersmidt, J. (1990). Peer rejection in childhood. In S. Asher (Ed), J. Coie (Ed). Peer rejection in childhood. Cambridge studies in social and emotional development. (pp. 17-59). New York: Cambridge University Press.

Coie, J. D. \& Kupersmidt, J. B. (1983). A behavioral analysis of emerging social status in boys' groups. Child Development, 54, 1400-1416.

Coplan, R.J. \& Arbeau, K. (2008). The stresses of a "brave new world": Shyness and school adjustment in kindergarten. Journal of Research in Childhood Education. 22(4), 377-389.

Coplan, R. J. \& Armer, M. (2005). 'Talking yourself out of being shy': Shyness, expressive vocabulary, and adjustment in preschool. Merrill-Palmer Quarterly, 51, $20-41$.

Coplan, R. J., Girardi, A., Findlay, L. C. \& Frohlick, S. L. (2007). Understanding solitude: Young children's attitudes and responses towards hypothetical sociallywithdrawn peers. Social Development, 16, 390-409.

Coplan, R.J., Prakash, K., O’Neil, K., \& Armer, M. (2004). Do you “want" to play? Distinguishing between conflicted-shyness and social disinterest in early childhood. Developmental Psychology, 40, 244-258. 
Dishion, T. J., Spracklen, K. M., Andrews, D. M. \& Patterson, G. R. (1996). Deviancy training in male adolescent friendships. Behavior Therapy, 27, 373-390.

Dodge, K. A., Coie, J. D. \& Brakke, N. P. (1982). Behavior patterns of socially rejected and neglected preadolescents: The roles of social approach and aggression. Journal of Abnormal Child Psychology, 10, 389-410.

Dodge, K. A. \& Price, J. M. (1994). On the relation between social information processing and socially competent behavior in early school-aged children. Child Development, 65, 1385-1397.

Dorman, J. P. (2003). Cross-national validation of the what is happening in the class? (WIHIC) questionnaire using confirmatory factor analysis. Learning Environments Research, 6,231-245.

Dorman, J., Adams, J., \& Ferguson, J. (2002). Psychosocial environment and student self-handicapping in secondary school mathematics classes: A cross-national study. Educational Psychology, 22, 499-511.

Early, D. M., Bryant, D. M., Pianta, R. C., Clifford, R. M., Burchinal, M. R. \& Ritchie, S. et al. (2006). Are teachers' education, major, and credentials related to classroom quality and children's academic gains in pre-kindergarten. Early Childhood Research Quarterly, 21,174-195.

Eisenberg, N., Shepard, S.A., Fabes, R.A., Murphy, B.C., \& Guthrie, I. (1998). Shyness and children's emotionality, regulation, and coping: Contemporaneous, longitudinal and across-context relations. Child Development, 68, 767-790. 
Engelhard, G., Jr. (2002). Monitoring raters in performance assessments. In G. Tindal \& T. M. Haladyna (Eds.), Large-scale assessment programs for all students (pp. 261-288). Mahwah, NJ: Lawrence Erlbaum.

Entwisle, D. R., \& Hayduk, L. A. (1982). Early schooling. Baltimore: Johns Hopkins University Press.

Estell D, Cairns RB, Farmer T, Cairns BD (2002). Aggression in inner-city early elementary classrooms: Individual and peergroup configurations. Merrill-Palmer Quart, 48, 52-76.

Ferguson, P. D. \& Fraser, B. J. (1998). Changes in learning environment during the transition from primary to secondary school. Learning Environments Research, 1, $369-383$.

Fordham, K. \& Stevenson-Hinde, J. (1999). Shyness, friendship quality, and adjustment during middle childhood. Journal Child Psychology, 40, 757-768.

Franklin, M. E., Huppert, J. D., Langner, R., Leiberg, S., \& Foa, E. B. (2005). Interpretation bias: A comparison of treated social phobics, untreated social phobics, and controls. Cognitive Therapy and Research, 29, 289-300.

Fraser, B.J. (1982). Differences between student and teacher perceptions of actual and preferred classroom learning environment. Educational Evaluation and Policy Analysis, 4, 511-519.

Fraser, B. C. (1986). Child impairment and parent/enfant communication. Child: Care, Health and Development, 12, 141-150. 
Fraser, B.J. (1998a) Science learning environments: Assessments, effects and determinants. In B.J. Fraser (Ed.) \& K.G. Tobin (Ed.), International handbook of science education (pp. 527-564). Dordrecht: Kluwer.

Fraser, B.J. (1998b). Classroom learning environments: Development, validity, and applications. Learning Environments Research, 1, 7-33.

Fraser, B. J., \& Aldridge, J. L. (2001). Junior secondary mathematics student's learning environment and satisfaction in Brunei Darussalam. Paper presented at the Annual Conference of the Australian Association for Research in Education, December 2-6, Fremantle, Western Australia.

Fraser, B. J. \& Fisher, D. L. (1982). Effects of classroom psychosocial environment on student learning. British Journal of Psychology, 52, 374-377.

Fraser, B.J. \& Fisher, D.L. (1983). Validity and use of the classroom environment scale. Educational Research and Policy Analysis, 5, 261-271.

Fraser, B.J., McRobbie, C.J., \& Fisher, D.L. (1996). Development, validation and use of personal and class forms of a new classroom environment instrument. Paper presented at the annual meeting of the American Educational Research Association, New York.

Fraser, B. J. \& Rentoul, A. J. (1980). Person-environment fit in open classrooms. Journal of Educational Research, 1980, 73, 159-167.

Fraser, B. J. \& Wilkinson, D. (1993). Science laboratory climate in British schools and universities,. Research in Science and Technological Education, 11, 49-70. 
Fraser, B., Williamson, J. \& Tobin, K. (1987). Use of classroom and school climate scales in evaluating alternative schools. Teaching and Teacher Education, 3, 219231.

French, D. C. (1990). Heterogeneity of peer-rejected girls. Child Development, 61, 20282031.

French, J. R. P. (1963). The social environment and mental health. Journal of Social Issues, 19, 39-56.

Gazelle, H. (2006). Class climate moderates peer relations and emotional adjustment in children with an early history of anxious solitude: A Child $\times$ Environment Model. Developmental Psychology, 42, 1179-1192.

Gazelle, H. \& Ladd, G. W. (2003). Anxious solitude and peer exclusion: A diathesisstress model of internalizing trajectories in childhood. Child Development, 74, 257-278.

Gazelle, H., Putallaz, M. Li, Y., Grimes, C., Kupersmidt, J. B. \& Coie, J. D. (2005). Anxious solitude across contexts: Girls' interactions with familiar and unfamiliar peers. Child Development, 76, 227-246.

Gazelle, H. \& Rudolph, K. D. (2004). Moving toward and away from the world: Social approach and avoidance trajectories in anxious solitary youth. Child Development, 75,829-849.

Goodenow, C. (1992). Strengthening the links between educational psychology and the study of social contexts. Educational Psychologist, 27, 177-196.

Graue, M. E. (1993). Ready for what? Constructing meanings of readiness for kindergarten. Albany: State University of New York Press. 
Haertel, G., \& Walberg, H (1981). Ability and learning: A theoretical synthesis. Educational Psychology, 3, 241-252

Hamre, B. K. \& Pianta, R. C. (2001). Early teacher-child relationships and the trajectory of children's school outcomes through eighth grade. Child Development, 72, 625638.

Hartup, W. W. (1998). Friendships and developmental significance. In A. Campbell \& S. Muncer(Eds.), The social child. Hove: Psychology Press.

Harms, T., Clifford, R.M. (1980). Early childhood environmental rating. New York: Teacher's College Press.

Harms, T., Clifford, R. M., \& Cryer, D. (1998). The Early Childhood Environment Rating Scale (revised ed.). New York: Teachers College.

Henderson, D., Fisher, D. \& Fraser, B. J. (2000). Interpersonal behavior, laboratory learning environments, and student outcomes in senior biology classes. Journal of Research in Science Teaching, 37, 26-43.

Higgins, E. T. (1990). Personality, social psychology, and person-situation relations: Standards and knowledge activation as a common language. In L. A. Pervin (Ed.), Handbook of personality theory and research (pp. 301-338). New York: Guilford Press.

Higgins, E. T., \& King, G. (1981). Accessibility of social constructs: Information processing consequences of individual and contextual variability. In N. Cantor \& J. F. Kihlstrom (Eds.), Personality, cognition, and social interaction. Hillsdale, N.J.: Erlbaum, 1981. 
Howes, C. (1999). Attachment relationships in the context of multiple caregivers. Handbook of attachment: Theory, research, and clinical applications (pp. pp. 671687). New York: Guilford Press.

Howes, C. (2000). Social-emotional classroom climate in child care, child-teacher relationships and children's second grade peer relations. Social Development, 9, 191-204.

Howes, C. \& Matheson, C. C. (1992). Sequences in the development of competent play with peers: Social and social pretend play. Developmental Psychology, 28, 961974.

Howes, C., Phillipsen, L. C. \& Peisner-Feinberg, E. (2000). The consistency of perceived teacher-child relationships between preschool and kindergarten. Journal of School Psychology, 38, 113-132.

Howes, C., Phillipsen, L. C., \& Whitebook, M. (1992). Thresholds in quality of child care centres and children's social and emotional development. Child Development, 63, $449-460$.

Howes, C. \& Smith, E. (1995a). Relations among child care quality, teacher behavior, children's play activities, emotional security, and cognitive activity in child care. Early Childhood Research Quarterly, 10, 381-404.

Howes, C. \& Smith, E. W. (1995b). Children and their child care caregivers: Profiles of relationships. Social Development, 4, 44-61.

Hudley, C., Britsch, B., Wakefield, W. D., Smith, T., Demorat, M., \& Cho, S. J. (1998). An attribution retraining program to reduce aggression in elementary school students. Psychology in the Schools, 35(3), 271-282. 
Hudley, C., \& Graham, S. (1995). School-based interventions for aggressive AfricaAmerican boys. Applied and Preventive Psychology, 4(3), 185-195.

Hymel, S., Comfort, C., Schonert-Reichl, K., \& McDougall, P. (1996). Academic failure and school dropout: The influence of peers. Social motivation: Understanding children's school adjustment. J, Juvonen (Ed), K. Wentzel (Ed). (pp. 313-345), New York: Cambridge University Press .

Hymel, S., Rubin, K.H., Rowden, L., \& LeMare, L. (1990). Children's peer relationships: Longitudinal predictions of internalizing and externalizing problems from middle to late childhood. Child Development, 61, 2004-2021.

Jackson, M., Barth, J. M., Powell, N. \& Lochman, J. E. (2006). Classroom contextual effects of race on children's peer nominations. Child Development, 77, 13251337.

Johnson, D. W., Johnson, R. \& Anderson, D. (1983). Social interdependence and classroom climate. Journal of Psychology, 114, 135-142.

Juvonen, J., Nishina, A., \& Graham, S. (2000). Peer harassment, psychological adjustment, and school functioning in early adolescence. Journal of Educational Psychology, 92, 349-359.

Kellam, S. G., Ling, X., Merisca, R., Brown, C. H. \& Ialongo, N. (1998). The effect of the level of aggression in the First grade classroom on the course and malleability of aggressive behavior into middle school. Development \& Psychopathology, 10, $165-185$.

Kellam, S. G., Ling, X., Merisca, R., Hendricks, Brown, C. \& Ialongo, N. (2000). Erratum: The effect of the level of aggression in the first grade classroom on the 
course and malleability of aggressive behavior into middle school. Development \& Psychopathology,12, 107.

Kenny, D. T. \& Chekaluk, E. (1993). Early reading performance: A comparison of teacher-based and test-based assessments. Journal of Learning Disabilities, 26, 227-236.

Kochenderfer, B. J., \& Ladd, G. W. (1996a). Peer victimization: Cause or consequence of children's school adjustment difficulties? Child Development, 67, 1293-1305.

Konold, T., Walthall, J. \& Pianta, R. C. (2004). The behavior of child behavior ratings: Measurement structure of the Child Behavior Checklist across time, informants, and child gender. Journal of Behavioral Disorders, 29, 372-383.

Kontos, S., \& Wilcox-Herzog, A. (1997). Teachers' interactions with children: Why are they so important? Young Children, 52(2), 4-12.

Kraemer, H. C., Measelle, J. R., Ablow, J. C., Essex, M. J., Boyce, W. T. \& Kupfer, D. J. (2003). A new approach to integrating data from multiple informants in psychiatric assessment and research: Mixing and matching contexts and perspectives. American Journal of Psychiatry, 160, 1566-1577.

Ladd, G. W. (1990). Having friends, Keeping friends, making friends, and being liked by peers in the classroom: Predictors of children's early school adjustment. Child Development, 61, 1081-1100.

Ladd, G. W. \& Burgess, K. B. (1999). Charting the relationship trajectories of aggressive, withdrawn, and aggressive/withdrawn children during early grade school. Child Development, 70, 910-929 
Ladd, G. W. \& Mize, J. (1983). A cognitive-social learning model of social skill training. Psychological Review, 90, 127-157.

Lamb, M.E. (1998). Nonparental Child Care: Context, Quality, Correlates and Consequences. Handbook of child psychology, 4: Child psychology in practice (5th ed) (pp. 73-133). Hoboken: John Wiley \& Sons.

LaParo, K. M. \& Pianta, R. C. (2000). Predicting children's competence in the early school years: A meta-analytic review. Review of Educational Research, 70, 443484.

La Paro, K. M., Pianta, R. C. \& Stuhlman, M. (2004). The Classroom Assessment Scoring System: Findings from the prekindergarten year. Elementanry School Journal, 104, 409-426.

Luthar SS, \& McMahon, TJ. (1996). Peer reputation among inner-city adolescents: Structure and correlates. J Res Adolescence 6, 581-603.

Maehr, M.L., \& Midgley, C. (1996). Enhancing student motivation: A school-wide approach. Educational Psychologist, 26, 399-427.

Magnusson, D. (1988). Individual development from an interactional perspective: A longitudinal study. Hillsdale, NJ: Erlbaum.

Majeed, A., Fraser, B. J. \& Aldridge, J. L. (2002). Learning environment and its association with student satisfaction among mathematics students in Brunei Darussalam. Learning Environments Research, 5, 203-226.

Mashburn, A., Hamre, B., Downer, J., \& Pianta, R.C. Teacher and classroom characteristics associated with teachers' ratings of prekindergartners' 
relationships and behaviors. (2006). Journal of Psychoeducational Assessment, $24,367-380$.

Mashburn, A. J. \& Henry, G. T. (2004). Assessing school readiness: Validity and bias in preschool and kindergarten teachers' ratings. Educational Measurement: Issues and Practice, 23, 16-30.

McCartney, K. (1984). Effect of quality of day-care environment on children's language development. Developmental Psychology, 20, 244-260.

Meyer, L. A., Wardrop, J. L., Hastings, C. N. \& Linn, R. L. (1993). Effects of ability and settings on kindergarteners' reading performance. Journal of Educational Research, 86, 142-160.

Miell, D., \& MacDonald, R. (2000). Children's creative collaborations: The importance of friendship when working together on a music composition. Social Development, 9(3),348-369.

Moos, R. H. (1979). Evaluating educational environments: Measures, procedures, findings, and policy implications. San Francisco: Jossey-Bass.

Moos, R. H., \& Trickett, E. J. (1974). Classroom environment scale manual. Palo Alto, Calif:: Consulting Psychologists Press.

Morison, P. \& Masten, A. S. (1991). Peer reputation in middle childhood as a predictor of adaptation in adolescence: A seven-year follow-up. Child Development, 62, 9911007.

Murphy, G. L. \& Medin, D. L. (1985). The role of theories in conceptual coherence. Psychological Review, 92, 289-316. 
National Institute of Child Health and Human Development Early Child Care Research Network. (2002). The relation of global first grade classroom environment to structural classroom features, teacher, and student behaviors. Elementary School Journal, 102, 367-387.

National Institute of Child Health and Human Development Early Child Care Research Network. (2002). Early child care and children's development prior to school entry: Results from the NICHD Study of Early Child Care. American Educational Research Journal, 39, 133-164.

National Institute of Child Health and Human Development Early Child Care Research Network. (2001). Nonmaternal care and family factors in early development: An overview of the NICHD SECC. Journal of Applied Developmental Psychology, $22,457-492$.

National Institute of Child Health and Human Development Early Child Care Research Network. (2002). Child care structure process outcome: Direct and indirect effects of child care quality on young children's development. Psychological Science, 13, 199-206.

National Institute of Child Health and Human Development Early Child Care Research Network. (2003). Social functioning in first grade: Associations with earlier home and child care predictors and with current classroom experiences. Child Development, 74, 1639-1662.

National Institute of Child Health and Human Development Early Child Care Research Network. (2004). The relation of first grade classroom environment to structural 
classroom features, teacher, and student behaviors. Elementary School Journal, $102,367-387$.

Newcomb, A. F., Bukowski, W. M. \& Pattee, L. (1993). Children's peer relations: A meta- analytic review of popular, rejected, neglected, controversial and average sociometric status. Psychological Bulletin, 113, 99-128.

Owens, L. \& Barnes, J. (1982). The relationships between cooperative, competitive, and individualized learning preferences and students' perceptions of classroom learning atmosphere. American Educational Research Journal, 19, 182-200.

Owens, L. \& Straton, R. (1980). The development of a cooperative, competitive, and individualized learning preference scale for students. British Journal of Educational Psychology, 50, 147-163.

Pajares, F. (1996). Self-efficacy beliefs and mathematical problem-solving of gifted students. Contemporary Educational Psychology, 21, 325-344.

Parker, J. G. \& Asher, S. R. (1987). Peer relations and later personal adjustment: Are low-accepted children at risk. Psychological Bulletin, 102, 357-389.

Patrick, H., \& Ryan, A. (2005). Identifying Adaptive Classrooms: Dimensions of the Classroom Social Environment. What do children need to flourish: Conceptualizing and measuring indicators of positive development, pp. 271-287, New York: Springer Science + Business Media.

Patrick, H., Ryan, A., \& Kaplan, A. (2007). Early adolescents' perceptions of classroom environment, motivation, and beliefs. Journal of Educational Psychology, 99, 8398. 
Peisner-Feinberg, E. \& Burchinal, M. (1997). Relations between preschool children's child care experiences and concurrent development: The cost, quality, a ad outcomes study. Merrill-Palmer Quarterly, 43, 451-477.

Peisner-Feinberg, E. S., Burchinal, M. R., Clifford, R. M., Culkin, M. L., Howes, C. \& Kagan, S. L. et al. (2001). The relation of preschool child-care quality to children's cognitive and social developmental trajectories through second grade. Child Development, 72, 1534-1553.

Perren, S., Von Wyl, A., Stadelmann, S., Bürgin, D., \& von Klitzing, K. (2006). Associations between behavioral/emotional difficulties in kindergarten children and the quality of their peer relationships. Journal of the American Academy of Child \& Adolescent Psychiatry,45, 867-876.

Pianta, R.C. (1994). Assessing child-teacher relationships. Enhancing relationships between children and teachers (pp. 85-104). Washington: American Psychological Association.

Pianta, R. C. (1999). Enhancing relationships between children and teachers. Washington: American Psychological Association.

Pianta, R., Howes, C., Burchinal, M., Bryant, D., Clifford, R., Early, D., \& Barbarin, O. (2005). Features of pre-kindergarten programs, classrooms, and teachers: Do they predict observed classroom quality and child-teacher interactions. Applied Developmental Science, 9, 144-159.

Pianta, R. C., La Paro, K. M., Payne, C., Cox, M. J. \& Bradley, R. (2002). The relation of kindergarten classroom environment to teacher, family, and school characteristics and child outcomes. Elementary School Journal, 102, 225-238. 
Pianta, R. C., Lopez-Hernandez, C. \& Ferguson, J. E. (1997). Adolescent mothers and their children's early school performance. Early Education \& Development, 8, $377-387$.

Pianta, R. C., Steinberg, M. \& Rollins, K. (1995). The first two years of school: Teacherchild relationships and deflections in children's classroom adjustment.

Development \& Psychopathology, 7, 295-312.

Rodkin, P., Farmer, T., Pearl, R., \& Van Acker, R. (2006). They're cool: social status and peer group supports for aggressive boys and girls. Social Development, 15, 175204.

Roeser, R., Midgley, C. \& Urdan, R. (1996). Perceptions of the school psychological climate and early adolescents' self-appraisals and academic engagement. Journal of Educational Psychology, 88, 408-422.

Rubin, K.H., \& Asendorpf, J.B. (1993). Social-withdrawal, inhibition, and shyness in childhood: Conceptual and definitional issues. In K.H. Rubin \& J.B. Asendorpf (Eds.), Social-withdrawal, inhibition, and shyness in childhood (pp. 3-17). Hillsdale, NJ: Erlbaum.

Rubin, K.H., Bukowski, W.M., \& Parker, J.G. (2006). Peer interactions, relationships, and groups. In N. Eisenberg (Ed.), W. Richard (Series Ed.), Handbook of child psychology: 3. Social, emotional, and personality development (6th ed., pp. 571645). Hoboken: John Wiley \& Sons.

Rubin, K. H., Burgess, K. B. \& Hastings, P. D. (2002). Stability and social-behavioral consequences of toddlers' inhibited temperament and parenting behaviors. Child Development, 73, 483-495. 
Rubin, K.H., Coplan, R.J., \& Bowker, J. (2009). Social withdrawal in childhood. In S.T. Fiske (Ed.) Annual review of psychology, 60. Chippewa Fall, WI: Annual Reviews.

Rubin, K. H., Chen, X., McDougall, P., Bowker, A. \& McKinnon, J. (1995). The Waterloo Longitudinal Project: Predicting internalizing and externalizing problems in adolescence. Development and Psychopathology, 7, 751-764.

Rubin, K. H., Daniels-Beirness, T. \& Hayvren, M. (1982). Social and social-cognitive correlates of sociometric status in preschool and kindergarten children. Canadian Journal of Behavioural Science, 14, 338-348.

Rubin, K. H., Cheah, C. S. L. \& Fox, N. A. (2001). Emotion regulation, parenting, and display of social reticence in preschoolers. Early Education \& Development, 12, $97-115$.

Rubin, K. H., Chen, X., McDougall, P., Bowker, A. \& McKinnon, J. (1995). The Waterloo Longitudinal Project: Predicting internalizing and externalizing problems in adolescence. Development and Psychopathology, 7, 751-764.

Rubin, K. H. \& Mills, R. S. (1988). The many faces of social isolation in childhood. Journal of Consulting and Clinical Psychology, 56, 916-924.

Rubin, K.H., Wojslawowicz, J., Rose-Krasnor, L., Booth-LaForce, K., \& Burgess, K. (2006). The Best Friendships of Shy/Withdrawn Children: Prevalence, Stability, and Relationship Quality. Journal of Abnormal Child Psychology, 34, 143-157.

Ryan, A. M. \& Patrick, H. (2001). The classroom social environment and changes in adolescents' motivation and engagement during middle school. American Educational Research Journal, 38, 437-460. 
Rydell, A. M., Bohlin, G. \& Thorell, L. B. (2005). Representations of attachment to parents and shyness as predictors of children's relationships with teachers and peer competence in preschool. Attachment and Human Development, 7, 187-204.

Sadker, M., \& Sadker, D. (1994). Failing at fairness: How America's schools cheatgirls. New York: Scribner.

Sameroff, A. J. (1993). Models of development and developmental risk. In C. H. J. Zeanah (Ed.), Handbook of infant mental health (pp. 3-13). New York: Guilford Press.

Schreer, G. E. (2002). Narcissism and aggression: is inflated self-esteem related to aggressive driving. North American Journal of Psychology, 4, 333-341.

Schwartz, D., Gorman, A. H., Nakamoto, J., \& Toblin, R. L. (2005). Victimization in the peer group and children's academic functioning. Journal of Educational Psychology, 97, 425-435.

Shafer, E.S., Edgerton, M., \& Aaronson, M. (1987). Classroom Behavior Inventory. Unpublished rating scale. University of North Carolina, Chapel Hill.

Shepardson, D.P., \& Pizzini, E.L. (1994). Gender, achievement, and perception towards science activity. School Science and Mathematics, 94, 188-193.

Shonkoff, J \& Phillips, D.A. (2000). From neurons to neighborhoods: The science of early childhood development. Washington: National Academy Press.

Sinclair, B. B. \& Fraser, B. J. (2002). Changing classroom environments in urban middle schools. Learning Environments Research, 5, 301-328. 
Steinkamp, M. \& Maehr, M. (1984). Gender differences in motivational orientations toward achievement in school science: A quantitative synthesis. American Educational Research Journal, 21, 39-59.

Stevenson-Hinde, J., \& Glover, A. (1996). Shy girls and boys: A new look. Journal of Child Psychology and Psychiatry, 37, 181-187.

Stipek, D. (1996). Motivation and instruction. Handbook of educational psychology (pp. 85-113). New York: Macmillan Library Reference.

Stipek, D., Givvin, K. B., Salmon, J. M. \& MacGyvers, V. L. (1998). Can a teacher intervention improve classroom practices and student motivation in mathematics. The Journal of Experimental Education, 66, 319-337.

Stopa, L., \& Clark, D. M. (2000). Social phobia and interpretation of social events. Behaviour Research and Therapy, 38, 273-283.

Stormshak, E. A., Bierman, K. L., Bruschi, C., Dodge, K. A. \& Coie, J. D. (1999). The relation between behavior problems and peer preference in different classroom contexts. Child Development, 70, 169-182.

Stromquist, V. J. \& Strauman, T. J. (1991). Children's social constructs: Nature, assessment, and association with adaptive versus maladaptive behavior. Social Cognition, 9, 330-358.

Stuhlman, M. W. \& Pianta, R. C. (2002). Teachers' narratives about then-relationships with children: Associations with behavior in classrooms. School Psychology Review, 31, 148-163. 
Teh, G. P. \& Fraser, B. J. (1995). Development and validation of an instrument for assessing the psychosocial environment of computer-assisted learning classrooms. Journal of Educational Computing Research, 12, 177-193.

Trickett, E. J. \& Moos, R. H. (1973). Social environment of junior high and high school classrooms. Journal of Educational Psychology, 1973, 65, 93-102.

Trickett, E. J. \& Moos, R. H. (1974). Personal correlates of contrasting environments: Student satisfactions in high school classrooms. American Journal of Community Psychology, 2, 1-12.

Turner, J. C., Midgley, C., Meyer, D. K., Gheen, M., Anderman, E. M., Kang, Y. \& Patrick, H. (2002). The classroom environment and students' reports of avoidance strategies in mathematics: A multimethod study. Journal of Educational Psychology, 94, 88-106.

Urdan, T. \& Midgley, C. (2003). Changes in the perceived classroom goal structure and patterns of adaptive learning during early adolescence. Contemporary Educational Psychology, 28, 524-551.

Urdan, T., \& Schoenfelder (2006). Classroom effects on student motivation: Goal structures, social relationships, and competence beliefs. Journal of School Psychology, 44, 331-349.

Vaillancourt, T. \& Hymel, S. (2006). Aggression and social status: The moderating roles of sex and peer-valued characteristics. Aggressive Behavior, 32, 396-408.

VanTartwijk, J., Brekelmans, M., Wubbels, T., Fraser, B.J., \& Fisher, D.L. (1998). Students' perception of teacher interpersonal style: The front of the classroom as the teacher's stage. Teaching \& Teacher Education, 14, 607-617. 
Walberg, H.J. (1986). Home environment and school learning: Some quantitative models and research synthesis. Child rearing in the home and school. In R. Giffore (Ed.) \& R. Boger (Ed.), pp.105-120, New York: Plenum Press.

Wentzel, K. R. (1994). Relations of social goal pursuit to social acceptance, classroom behavior, and perceived social support. Journal of Educational Psychology, 86, 173-182.

Werthamer-Larsson, L., Kellam, S. G. \& Wheeler, L. (1991). Effect of first-grade classroom environment on shy behavior, aggressive behavior, and concentration problems. American Journal of Community Psychology, 19, 585-602.

Wichmann, C., Coplan, R. J. \& Daniels, T. (2004). The social cognitions of socially withdrawn children. Social Development, 13, 377-392.

Wojslawowicz, J.C., Rubin, K.H., Rose-Krasnow, L., \& Booth, C. (2003). The "Extended Class Play": A longitudinal study for its factor structure, reliability, and validity. Poster presentation at the Biennial meetings of the Society for Research on Children Development, Tampa, Florida.

Wong, A., \& Fraser, B. (1995). Cross-validation in Singapore of the Science Laboratory Environment Inventory. Psychological Reports, 76, 907-911.

Zajac, R., \& Hartup, W. W. (1997). Friends as coworkers: Research review and classroom implications. Elementary School Journal, 98, 3-13. 
Classroom Perceptions

Appendix A

SCHOOL EXPERIENCES STUDY

Dear Parents,
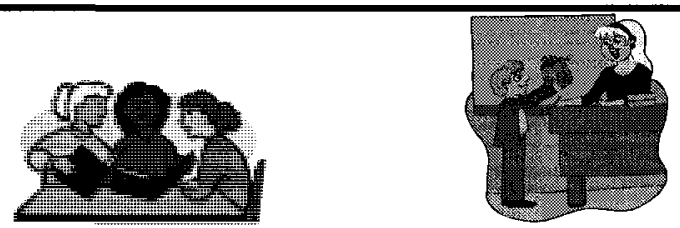

We are writing to ask your permission for your child to participate in a research study that is being conducted at your child's school. One of the most important aspects of children's school experiences is developing satisfying relationships with other children. The purpose of this study is to better understand how children's relationships with other children in their class may be related to how they feel at school. This study is important because it will help us understand why some children enjoy being at school more than other children.

In this study children will be asked to complete questionnaires about their friendships, about how lonely they feel at school, and about how anxious they feel around their classmates. Also, children will be asked what they think about their classroom experiences, how 'liked' they feel they are by their peers, and if they ever feel victimized at school. We will be reading the questions to the kids in a group setting. It is important to us that this process is fun for the children! We will ensure that the children understand that they do not have to answer any questions that they don't want to.

This project has been approved by the Lethbridge School District 51 as well as Carleton University's Ethics Committee for Psychological Research. All information collected from this study is strictly confidential and will only be made available to the principal investigators. If you are interested, we would be happy to provide you with a summary of our findings once all of the data has been collected.

If you have any questions related to this study and/or concerns about your child as a result of participation in this study, please feel free to contact us directly at (613) 520-2600, ext. 1979. Should you have any ethical concerns about this study then please contact Dr. Janet Mantler (Chair, Carleton University Ethics Committee for Psychological Research, (613) 520-2600, ext. 2664). If you have other concerns about this study, feel free to contact Dr. Robert Coplan (Professor, Department of Psychology, (613) 520-2600, ext. 8691) or Dr. Mary Gick (Chair, Department of Psychology, (613) 520-2600, ext. 2648). If you would like to learn more about children's friendships and social adjustment at school, there are numerous websites on the topic (e.g., http://www.cfw.tufts.edu/).

Adrienne DeBow, M.Ed.

Ph.D. Candidate

Department of Psychology

Carleton University
Robert Coplan, Ph.D.

Professor

Department of Psychology

Carleton University 
Appendix B

\section{CONSENT FORM - (for parents)}

The information collected for this project is confidential and protected under the Municipal Freedom of Information and Privacy Act, 1989.

Date:

(name of child - please print)

$\overline{\text { (name of parent or guardian - please print) }}$

Please check one:

I agree to have the Classroom Experiences Study conducted at my school.

I do not agree to have the Classroom Experiences Study conducted at my school.

(signature of parent or guardian)

Please keep the letter (first page) and return the signed consent form and the completed questionnaire to your child's teacher sealed in the enclosed envelope. Please return the consent form as soon as possible even if you are not going to be participating in the study.

If you would like to receive a summary of the findings from this study please indicate an e-mail address or mailing address in which we can send the results: 


\section{THE “CLASSROOM EXPERIENCES" STUDY \\ BACKGROUND INFORMATION}

Child's Name

Child's Birthdate

Child's Age

month day year

Child's Gender: Boy

Girl

Child's Grade

Homeroom Teacher's Name

Mother's formal education completed (check one):

elementary school

high school diploma or

community college or

university degree

graduate school degree
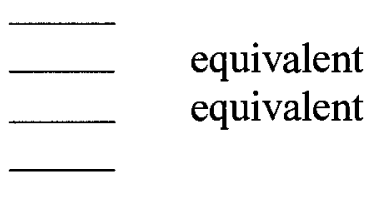

equivalent

Asian

Aboriginal
Black

Other

(optional)

Hispanic

Father's formal education completed (check one):

elementary school

high school diploma or

community college or

university degree

graduate school degree

Father's ethnic group:

Caucasian

(optional)

Hispanic

Asian Aboriginal

Black

Other

Is English the first language spoken in your home? Yes

No 


\section{Appendix D}

What Is Happening In This Class?

These questions tell me about what you THINK about your classroom.

This is NOT a test, just answer each question the best you can.

Circle the answer that you think is the most right for you

\begin{tabular}{|c|c|c|c|c|}
\hline Never & Almost Never & Sometimes & Almost Always & Always \\
\hline \multicolumn{5}{|c|}{ 2. My teacher gives me attention when I need it. } \\
\hline Never & Almost Never & Sometimes & Almost Always & Always \\
\hline \multicolumn{5}{|c|}{ 3. I talk about my ideas in class. } \\
\hline Never & Almost Never & Sometimes & Almost Always & Always \\
\hline \multicolumn{5}{|c|}{ 4. When I work with other kids, there is teamwork. } \\
\hline Never & Almost Never & Sometimes & Almost Always & Always \\
\hline \multicolumn{5}{|c|}{ 5. My teacher listens to me just as much as he/she listens to other kids. } \\
\hline Never & Almost Never & Sometimes & Almost Always & Always \\
\hline \multicolumn{5}{|c|}{ 6. I am friendly to other kids in my class. } \\
\hline Never & Almost Never & Sometimes & Almost Always & Always \\
\hline \multicolumn{5}{|c|}{ 7. My teacher cares about my feelings. } \\
\hline Never & Almost Never & Sometimes & Almost Always & Always \\
\hline \multicolumn{5}{|c|}{ 8. My teacher asks me questions. } \\
\hline Never & Almost Never & Sometimes & Almost Always & Always \\
\hline \multicolumn{5}{|c|}{ 9. I like to do my school work with other kids. } \\
\hline Never & Almost Never & Sometimes & Almost Always & Always \\
\hline \multicolumn{5}{|c|}{ 10. My teacher helps me just as much as he/she helps other kids. } \\
\hline Never & Almost Never & Sometimes & Almost Always & Always \\
\hline \multicolumn{5}{|c|}{ 11. Kids in my class are friends with each other. } \\
\hline Never & Almost Never & Sometimes & Almost Always & Always \\
\hline \multicolumn{5}{|c|}{ 12. My teacher helps me when I need help with my work. } \\
\hline Never & Almost Never & Sometimes & Almost Always & Always \\
\hline
\end{tabular}


13. I ask my teacher questions.

Never Almost Never Sometimes Almost Always Always

14. I like to do my school work by myself.

Never Almost Never $\quad$ Sometimes Almost Always Always

15. My teacher treats me the same as other kids in my class.

$\begin{array}{llll}\text { Never Almost Never } & \text { Sometimes } & \text { Almost Always }\end{array}$

16. I work well with other kids in my class.

$\begin{array}{llll}\text { Never Almost Never } & \text { Sometimes } & \text { Almost Always }\end{array}$

17. My teacher talks to me.

$\begin{array}{llll}\text { Never Almost Never } & \text { Sometimes } & \text { Almost Always }\end{array}$

18. I tell my ideas to other kids in my class.

Never Almost Never Sometimes Almost Always Always

19. I am good at working with other kids.

$\begin{array}{llll}\text { Never } & \text { Almost Never } & \text { Sometimes } & \text { Almost Always }\end{array}$

20. My teacher is fair to all the kids in my class.

$\begin{array}{llll}\text { Never Almost Never } & \text { Sometimes } & \text { Almost Always }\end{array}$

21. Kids in my class like me.

Never Almost Never Sometimes Almost Always Always

22. My teacher cares about my problems.

$\begin{array}{llll}\text { Never Almost Never } & \text { Sometimes } & \text { Almost Always }\end{array}$

23. I answer questions in my class.

$\begin{array}{llll}\text { Never } & \text { Almost Never } & \text { Sometimes } & \text { Almost Always }\end{array}$

24. Kids in my class teach me things.

Never Almost Never Sometimes Almost Always Always

25. My teacher likes all the kids in my class the same.

$\begin{array}{llll}\text { Never Almost Never } & \text { Sometimes } & \text { Almost Always }\end{array}$




\section{Appendix E}

\section{Self-Description Questionnaire I}

This is a chance to look at yourself. It is not a test. There are no right answers and everyone will have different answers. Be sure that your answers show how you feel about yourself. Please circle the number that is the most correct statement about you.

Please do not leave any statements blank. If unsure, please ASK FOR HELP.

$$
\begin{aligned}
& 1=\text { false } \\
& 2=\text { mostly false } \\
& 3=\text { sometimes false, sometimes true } \\
& 4=\text { mostly true } \\
& 5=\text { true }
\end{aligned}
$$

\begin{tabular}{|c|c|c|c|c|c|}
\hline I have lots of friends & 1 & 2 & 3 & 4 & 5 \\
\hline I make friends easily & 1 & 2 & 3 & 4 & 5 \\
\hline $\begin{array}{l}\text { Most kids have more } \\
\text { friends than I do }\end{array}$ & 1 & 2 & 3 & 4 & 5 \\
\hline $\begin{array}{l}\text { I get along with kids } \\
\text { easily }\end{array}$ & 1 & 2 & 3 & 4 & 5 \\
\hline
\end{tabular}

I am easy to like
$\begin{aligned} & \text { Other kids want me to be } \\ & \text { their friend }\end{aligned}$

$\begin{aligned} & \text { I have more friends than } \\ & \text { most other kids }\end{aligned}$
$\begin{aligned} & \text { I am popular with kids of } \\ & \text { my own age }\end{aligned}$
$\begin{aligned} & \text { Most other kids like me } \\ & \text { I am good at all school } \\ & \text { subjects. }\end{aligned}$
$\begin{aligned} & \text { I enjoy doing work in all } \\ & \text { school subjects. }\end{aligned}$




\begin{tabular}{|c|c|c|c|c|c|}
\hline $\begin{array}{l}\text { I get good marks in all } \\
\text { school subjects. }\end{array}$ & 1 & 2 & 3 & 4 & 5 \\
\hline I hate all school subjects. & 1 & 2 & 3 & 4 & 5 \\
\hline $\begin{array}{l}\text { I learn things quickly in } \\
\text { all school subjects. }\end{array}$ & 1 & 2 & 3 & 4 & 5 \\
\hline $\begin{array}{l}\text { I am interested in all } \\
\text { school subjects. }\end{array}$ & 1 & 2 & 3 & 4 & 5 \\
\hline $\begin{array}{l}\text { I am bad in all school } \\
\text { subjects. }\end{array}$ & 1 & 2 & 3 & 4 & 5 \\
\hline $\begin{array}{l}\text { I look forward to all } \\
\text { school subjects. }\end{array}$ & 1 & 2 & 3 & 4 & 5 \\
\hline $\begin{array}{l}\text { Work in all school } \\
\text { subjects is easy for me. }\end{array}$ & 1 & 2 & 3 & 4 & 5 \\
\hline I like all school subjects. & 1 & 2 & 3 & 4 & 5 \\
\hline
\end{tabular}


Appendix F

Loneliness and Social Dissatisfaction Questionnaire

\begin{tabular}{|c|c|c|c|c|c|}
\hline $\begin{array}{l}\text { 1. It's easy for me to } \\
\text { make new friends at } \\
\text { school. }\end{array}$ & $\begin{array}{l}\text { lat's not } \\
\text { ue at all } \\
\text { bout me }\end{array}$ & $\begin{array}{c}\text { that's } \\
\text { hardly } \\
\text { ever true } \\
\text { about me }\end{array}$ & $\begin{array}{c}\text { that's } \\
\text { sometimes } \\
\text { true about } \\
\text { me }\end{array}$ & $\begin{array}{l}\text { that's true } \\
\text { about me } \\
\text { most of } \\
\text { the time }\end{array}$ & $\begin{array}{c}\text { that's } \\
\text { always } \\
\text { true about } \\
\text { me }\end{array}$ \\
\hline 2. I like to read. & $\begin{array}{l}\text { that's not } \\
\text { true at all } \\
\text { about me }\end{array}$ & $\begin{array}{l}\text { that's } \\
\text { hardly } \\
\text { ever true } \\
\text { about me }\end{array}$ & $\begin{array}{l}\text { that's } \\
\text { sometimes } \\
\text { true about } \\
\text { me }\end{array}$ & $\begin{array}{l}\text { that's true } \\
\text { about me } \\
\text { most of } \\
\text { the time }\end{array}$ & $\begin{array}{c}\text { that's } \\
\text { always } \\
\text { true about } \\
\text { me }\end{array}$ \\
\hline $\begin{array}{l}\text { 3. I have nobody to talk } \\
\text { to in class. }\end{array}$ & $\begin{array}{l}\text { that's not } \\
\text { true at all } \\
\text { about me }\end{array}$ & $\begin{array}{l}\text { that's } \\
\text { hardly } \\
\text { ever true } \\
\text { about me }\end{array}$ & $\begin{array}{l}\text { that's } \\
\text { sometimes } \\
\text { true about } \\
\text { me }\end{array}$ & $\begin{array}{l}\text { that's true } \\
\text { about me } \\
\text { most of } \\
\text { the time }\end{array}$ & $\begin{array}{l}\text { that's } \\
\text { always } \\
\text { true about } \\
\text { me }\end{array}$ \\
\hline $\begin{array}{l}\text { 4. I'm good at working } \\
\text { with other children in my } \\
\text { class. }\end{array}$ & $\begin{array}{l}\text { that's not } \\
\text { true at all } \\
\text { about me }\end{array}$ & $\begin{array}{l}\text { that's } \\
\text { hardly } \\
\text { ever true } \\
\text { about me }\end{array}$ & $\begin{array}{c}\text { that's } \\
\text { sometimes } \\
\text { true about } \\
\text { me }\end{array}$ & $\begin{array}{l}\text { that's true } \\
\text { about me } \\
\text { most of } \\
\text { the time }\end{array}$ & $\begin{array}{c}\text { that's } \\
\text { always } \\
\text { true about } \\
\text { me }\end{array}$ \\
\hline 5. I & $\begin{array}{l}\text { that's not } \\
\text { true at all } \\
\text { about me }\end{array}$ & $\begin{array}{l}\text { that's } \\
\text { hardly } \\
\text { ever true } \\
\text { about me }\end{array}$ & $\begin{array}{l}\text { that's } \\
\text { sometimes } \\
\text { true about } \\
\text { me }\end{array}$ & $\begin{array}{l}\text { that's true } \\
\text { about me } \\
\text { most of } \\
\text { the time }\end{array}$ & $\begin{array}{c}\text { that's } \\
\text { always } \\
\text { true about } \\
\text { me }\end{array}$ \\
\hline $\begin{array}{l}\text { 6. It's hard for me to } \\
\text { make friends at school. }\end{array}$ & $\begin{array}{l}\text { that's not } \\
\text { true at all } \\
\text { about me }\end{array}$ & $\begin{array}{l}\text { that's } \\
\text { hardly } \\
\text { ever true } \\
\text { about me }\end{array}$ & $\begin{array}{l}\text { that's } \\
\text { sometimes } \\
\text { true about } \\
\text { me }\end{array}$ & $\begin{array}{l}\text { that's true } \\
\text { about me } \\
\text { most of } \\
\text { the time }\end{array}$ & $\begin{array}{c}\text { that's } \\
\text { always } \\
\text { true about } \\
\text { me }\end{array}$ \\
\hline 7. I like school. & $\begin{array}{l}\text { that's not } \\
\text { true at all } \\
\text { about me }\end{array}$ & $\begin{array}{l}\text { that's } \\
\text { hardly } \\
\text { ever true } \\
\text { about me }\end{array}$ & $\begin{array}{c}\text { that's } \\
\text { sometimes } \\
\text { true about } \\
\text { me }\end{array}$ & $\begin{array}{l}\text { that's true } \\
\text { about me } \\
\text { most of } \\
\text { the time }\end{array}$ & $\begin{array}{c}\text { that's } \\
\text { always } \\
\text { true about } \\
\text { me }\end{array}$ \\
\hline $\begin{array}{l}\text { 8. I have lots of friends } \\
\text { in my class. }\end{array}$ & $\begin{array}{l}\text { that's not } \\
\text { true at all } \\
\text { about me }\end{array}$ & $\begin{array}{l}\text { that's } \\
\text { hardly } \\
\text { ever true } \\
\text { about me }\end{array}$ & $\begin{array}{c}\text { that's } \\
\text { sometimes } \\
\text { true about } \\
\text { me }\end{array}$ & $\begin{array}{l}\text { that's true } \\
\text { about me } \\
\text { most of } \\
\text { the time }\end{array}$ & $\begin{array}{c}\text { that's } \\
\text { always } \\
\text { true about } \\
\text { me }\end{array}$ \\
\hline 9. I feel alone at school. & $\begin{array}{l}\text { that's not } \\
\text { true at all } \\
\text { about me }\end{array}$ & $\begin{array}{l}\text { that's } \\
\text { hardly } \\
\text { ever true } \\
\text { about me }\end{array}$ & $\begin{array}{c}\text { that's } \\
\text { sometimes } \\
\text { true about } \\
\text { me }\end{array}$ & $\begin{array}{l}\text { that's true } \\
\text { about me } \\
\text { most of } \\
\text { the time }\end{array}$ & $\begin{array}{l}\text { that's } \\
\text { always } \\
\text { true about } \\
\text { me }\end{array}$ \\
\hline $\begin{array}{l}10 . I \text { can find a friend in } \\
\text { my class when I need } \\
\text { one. }\end{array}$ & $\begin{array}{l}\text { that's not } \\
\text { true at all } \\
\text { about me }\end{array}$ & $\begin{array}{l}\text { that's } \\
\text { hardly } \\
\text { ever true } \\
\text { about me }\end{array}$ & $\begin{array}{l}\text { that's } \\
\text { sometimes } \\
\text { true about } \\
\text { me }\end{array}$ & $\begin{array}{l}\text { that's true } \\
\text { about me } \\
\text { most of } \\
\text { the time }\end{array}$ & $\begin{array}{c}\text { that's } \\
\text { always } \\
\text { true about } \\
\text { me }\end{array}$ \\
\hline
\end{tabular}


Classroom Perceptions

\begin{tabular}{|c|c|c|c|c|c|}
\hline 11. I play sports a lot. & $\begin{array}{l}\text { that's not } \\
\text { true at all } \\
\text { about me }\end{array}$ & $\begin{array}{l}\text { that's } \\
\text { hardly } \\
\text { ever true } \\
\text { about me }\end{array}$ & $\begin{array}{c}\text { that's } \\
\text { sometimes } \\
\text { true about } \\
\text { me }\end{array}$ & $\begin{array}{l}\text { that's true } \\
\text { about me } \\
\text { most of } \\
\text { the time }\end{array}$ & $\begin{array}{c}\text { that's } \\
\text { always } \\
\text { true about } \\
\text { me }\end{array}$ \\
\hline $\begin{array}{l}\text { 12. It's hard to get kids } \\
\text { in school to like me. }\end{array}$ & $\begin{array}{l}\text { that's not } \\
\text { true at all } \\
\text { about me }\end{array}$ & $\begin{array}{l}\text { that's } \\
\text { hardly } \\
\text { ever true } \\
\text { about me }\end{array}$ & $\begin{array}{c}\text { that's } \\
\text { sometimes } \\
\text { true about } \\
\text { me }\end{array}$ & $\begin{array}{l}\text { that's true } \\
\text { about me } \\
\text { most of } \\
\text { the time }\end{array}$ & $\begin{array}{c}\text { that's } \\
\text { always } \\
\text { true about } \\
\text { me }\end{array}$ \\
\hline 13. I like science. & $\begin{array}{l}\text { that's not } \\
\text { true at all } \\
\text { about me }\end{array}$ & $\begin{array}{l}\text { that's } \\
\text { hardly } \\
\text { ever true } \\
\text { about me }\end{array}$ & $\begin{array}{l}\text { that's } \\
\text { sometimes } \\
\text { true about } \\
\text { me }\end{array}$ & $\begin{array}{l}\text { that's true } \\
\text { about me } \\
\text { most of } \\
\text { the time }\end{array}$ & $\begin{array}{c}\text { that's } \\
\text { always } \\
\text { true about } \\
\text { me }\end{array}$ \\
\hline $\begin{array}{l}\text { 14. I don't have anyone } \\
\text { to play with at school. }\end{array}$ & $\begin{array}{l}\text { that's not } \\
\text { true at all } \\
\text { about me }\end{array}$ & $\begin{array}{l}\text { that's } \\
\text { hardly } \\
\text { ever true } \\
\text { about me }\end{array}$ & $\begin{array}{c}\text { that's } \\
\text { sometimes } \\
\text { true about } \\
\text { me }\end{array}$ & $\begin{array}{l}\text { that's true } \\
\text { about me } \\
\text { most of } \\
\text { the time }\end{array}$ & $\begin{array}{l}\text { that's } \\
\text { always } \\
\text { true about } \\
\text { me }\end{array}$ \\
\hline 15. I like music. & $\begin{array}{l}\text { that's not } \\
\text { true at all } \\
\text { about me }\end{array}$ & $\begin{array}{l}\text { that's } \\
\text { hardly } \\
\text { ever true } \\
\text { about me }\end{array}$ & $\begin{array}{l}\text { that's } \\
\text { sometimes } \\
\text { true about } \\
\text { me }\end{array}$ & $\begin{array}{l}\text { that's true } \\
\text { about me } \\
\text { most of } \\
\text { the time }\end{array}$ & $\begin{array}{c}\text { that's } \\
\text { always } \\
\text { true about } \\
\text { me }\end{array}$ \\
\hline $\begin{array}{l}\text { 16. I get along with my } \\
\text { classmates. }\end{array}$ & $\begin{array}{l}\text { that's not } \\
\text { true at all } \\
\text { about me }\end{array}$ & $\begin{array}{l}\text { that's } \\
\text { hardly } \\
\text { ever true } \\
\text { about me }\end{array}$ & $\begin{array}{c}\text { that's } \\
\text { sometimes } \\
\text { true about } \\
\text { me }\end{array}$ & $\begin{array}{l}\text { that's true } \\
\text { about me } \\
\text { most of } \\
\text { the time }\end{array}$ & $\begin{array}{l}\text { that's } \\
\text { always } \\
\text { true about } \\
\text { me }\end{array}$ \\
\hline $\begin{array}{l}\text { 17. I feel left out of } \\
\text { things at school. }\end{array}$ & $\begin{array}{l}\text { that's not } \\
\text { true at all } \\
\text { about me }\end{array}$ & $\begin{array}{l}\text { that's } \\
\text { hardly } \\
\text { ever true } \\
\text { about me }\end{array}$ & $\begin{array}{l}\text { that's } \\
\text { sometimes } \\
\text { true about } \\
\text { me }\end{array}$ & $\begin{array}{l}\text { that's true } \\
\text { about me } \\
\text { most of } \\
\text { the time }\end{array}$ & $\begin{array}{l}\text { that's } \\
\text { always } \\
\text { true about } \\
\text { me }\end{array}$ \\
\hline $\begin{array}{l}\text { 18. There are no other } \\
\text { kids I can go to when I } \\
\text { need help in school. }\end{array}$ & $\begin{array}{l}\text { that's not } \\
\text { true at all } \\
\text { about me }\end{array}$ & $\begin{array}{l}\text { that's } \\
\text { hardly } \\
\text { ever true } \\
\text { about me }\end{array}$ & $\begin{array}{c}\text { that's } \\
\text { sometimes } \\
\text { true about } \\
\text { me }\end{array}$ & $\begin{array}{l}\text { that's true } \\
\text { about me } \\
\text { most of } \\
\text { the time }\end{array}$ & $\begin{array}{c}\text { that's } \\
\text { always } \\
\text { true about } \\
\text { me }\end{array}$ \\
\hline $\begin{array}{l}\text { 19. I like to paint and } \\
\text { draw. }\end{array}$ & $\begin{array}{l}\text { that's not } \\
\text { true at all } \\
\text { about me }\end{array}$ & $\begin{array}{l}\text { that's } \\
\text { hardly } \\
\text { ever true } \\
\text { about me }\end{array}$ & $\begin{array}{l}\text { that's } \\
\text { sometimes } \\
\text { true about } \\
\text { me }\end{array}$ & $\begin{array}{l}\text { that's true } \\
\text { about me } \\
\text { most of } \\
\text { the time }\end{array}$ & $\begin{array}{c}\text { that's } \\
\text { always } \\
\text { true about } \\
\text { me }\end{array}$ \\
\hline $\begin{array}{l}\text { 20. I don't get along with } \\
\text { other children in school. }\end{array}$ & $\begin{array}{l}\text { that's not } \\
\text { true at all } \\
\text { about me }\end{array}$ & $\begin{array}{l}\text { that's } \\
\text { hardly } \\
\text { ever true } \\
\text { about me }\end{array}$ & $\begin{array}{c}\text { that's } \\
\text { sometimes } \\
\text { true about }\end{array}$ & $\begin{array}{l}\text { that's true } \\
\text { about me } \\
\text { most of } \\
\text { the time }\end{array}$ & $\begin{array}{c}\text { that's } \\
\text { always } \\
\text { true about } \\
\text { me }\end{array}$ \\
\hline 21.1 & $\begin{array}{l}\text { that's not } \\
\text { true at all } \\
\text { about me }\end{array}$ & $\begin{array}{l}\text { that's } \\
\text { hardly } \\
\text { ever true } \\
\text { about me }\end{array}$ & $\begin{array}{c}\text { that's } \\
\text { sometimes } \\
\text { true about } \\
\text { me }\end{array}$ & $\begin{array}{l}\text { that's true } \\
\text { about me } \\
\text { most of } \\
\text { the time }\end{array}$ & $\begin{array}{c}\text { that's } \\
\text { always } \\
\text { true about } \\
\text { me }\end{array}$ \\
\hline
\end{tabular}


Classroom Perceptions

\begin{tabular}{|c|c|c|c|c|c|}
\hline $\begin{array}{l}\text { 22. I am well liked by } \\
\text { the kids in my class. }\end{array}$ & $\begin{array}{l}\text { that's not } \\
\text { true at all } \\
\text { about me }\end{array}$ & $\begin{array}{l}\text { that's } \\
\text { hardly } \\
\text { ever true } \\
\text { about me }\end{array}$ & $\begin{array}{c}\text { that's } \\
\text { sometimes } \\
\text { true about } \\
\text { me }\end{array}$ & $\begin{array}{l}\text { that's true } \\
\text { about me } \\
\text { most of } \\
\text { the time }\end{array}$ & $\begin{array}{l}\text { that's } \\
\text { always } \\
\text { true about } \\
\text { me }\end{array}$ \\
\hline aying board & $\begin{array}{l}\text { that's not } \\
\text { true at all } \\
\text { about me }\end{array}$ & $\begin{array}{l}\text { that's } \\
\text { hardly } \\
\text { ever true } \\
\text { about me }\end{array}$ & $\begin{array}{l}\text { that's } \\
\text { sometimes } \\
\text { true about } \\
\text { me }\end{array}$ & $\begin{array}{l}\text { that's true } \\
\text { about me } \\
\text { most of } \\
\text { the time }\end{array}$ & $\begin{array}{c}\text { that's } \\
\text { always } \\
\text { true about } \\
\text { me }\end{array}$ \\
\hline $\begin{array}{l}24 . \text { I don' } \\
\text { friends in }\end{array}$ & $\begin{array}{l}\text { that's not } \\
\text { true at all } \\
\text { about me }\end{array}$ & $\begin{array}{l}\text { that's } \\
\text { hardly } \\
\text { ever true } \\
\text { about me }\end{array}$ & $\begin{array}{c}\text { that's } \\
\text { sometimes } \\
\text { true about } \\
\text { me }\end{array}$ & $\begin{array}{l}\text { that's true } \\
\text { about me } \\
\text { most of } \\
\text { the time }\end{array}$ & $\begin{array}{l}\text { that's } \\
\text { always } \\
\text { true about } \\
\text { me }\end{array}$ \\
\hline
\end{tabular}

Filler items: 2, 5, 7, 11, 13, 15, 19, 23 
Appendix G

Self-Report Victimization Scale

\begin{tabular}{|l|c|c|c|c|}
\multicolumn{1}{|c|}{ Items } & Never & or & Sometimes & A lot \\
\hline $\begin{array}{l}\text { (Training Items) ARE THERE TIMES } \\
\text { WHEN YOU: }\end{array}$ & & & & \\
\hline Have ice cream for dessert? & 1 & & 2 & 3 \\
\hline Ride the bus to school? & 1 & & 2 & 3 \\
\hline Eat breakfast at night-time? & 1 & & 2 & 3 \\
\hline
\end{tabular}

\begin{tabular}{|c|c|c|c|c|}
\hline $\begin{array}{l}\text { WHEN IN SCHOOL, DOES ANYONE IN } \\
\text { YOUR CLASS: }\end{array}$ & Never & or & Sometimes & A lot \\
\hline 1. Pick on you at school? & 1 & & 2 & 3 \\
\hline 2. Play games with you? & 1 & & 2 & 3 \\
\hline 3. Tell you you're good at doing things? & 1 & & 2 & 3 \\
\hline $\begin{array}{l}\text { 4. Make you feel better if you are having a bad } \\
\text { day? }\end{array}$ & 1 & & 2 & 3 \\
\hline 5. Let you play with them? & 1 & & 2 & 3 \\
\hline 6. Say mean things to you? & 1 & & 2 & 3 \\
\hline 7. Say bad things about you to other kids? & 1 & & 2 & 3 \\
\hline $\begin{array}{l}\text { 8. Share things like stickers, toys, and games } \\
\text { with you? }\end{array}$ & 1 & & 2 & 3 \\
\hline 9. Hit or kick you? & 1 & & 2 & 3 \\
\hline 10. Miss you if you weren't in school? & 1 & & 2 & 3 \\
\hline 11. Cheer you up if you feel sad? & 1 & & 2 & 3 \\
\hline 12. Help you if kids are being mean to you? & 1 & & 2 & 3 \\
\hline
\end{tabular}

Victimization items: 1, 6, 7,9 (the remainder of items are filler items) 


\section{Appendix $\mathrm{H}$}

Social Anxiety Scale for Children - Revised

1. I worry about doing something new in front of not at all hardly sometimes ever most of all the the time time other kids.

\begin{tabular}{lccccc} 
2. I like to read. & not at all & $\begin{array}{c}\text { hardly } \\
\text { ever }\end{array}$ & sometimes & $\begin{array}{r}\text { most of } \\
\text { the time }\end{array}$ & $\begin{array}{c}\text { all the } \\
\text { time }\end{array}$ \\
\hline $\begin{array}{l}\text { 3. I worry about } \\
\text { being teased. }\end{array}$ & not at all & $\begin{array}{c}\text { hardly } \\
\text { ever }\end{array}$ & sometimes & $\begin{array}{r}\text { most of } \\
\text { the time }\end{array}$ & $\begin{array}{c}\text { all the } \\
\text { time }\end{array}$ \\
\hline $\begin{array}{l}\text { 4. I feel shy } \\
\text { around kids I } \\
\text { don't know. }\end{array}$ & not at all & $\begin{array}{c}\text { hardly } \\
\text { ever }\end{array}$ & sometimes & $\begin{array}{r}\text { most of } \\
\text { the time }\end{array}$ & $\begin{array}{c}\text { all the } \\
\text { time }\end{array}$ \\
$\begin{array}{l}\text { 5. I feel that other } \\
\text { kids talk about } \\
\text { me behind my } \\
\text { back. }\end{array}$ & not at all & $\begin{array}{c}\text { hardly } \\
\text { ever }\end{array}$ & sometimes & $\begin{array}{c}\text { most of } \\
\text { the time }\end{array}$ & $\begin{array}{c}\text { all the } \\
\text { time }\end{array}$ \\
\hline
\end{tabular}

6. I only talk to kids I know really not at all hardly sometimes most of all the well.

not at all

7. I like to play not at all hardly

sometimes the time time with other kids. ever most of all the the time time

8. I worry about what other kids think of me.

$$
\text { not at all hardly sometimes }
$$
ever most of all the time

9. I'm afraid that other kids will not like me. not at all hardly sometimes most of the time

all the ever the time time

10. I get nervous when I talk to not at all hardly sometimes ever

most of the time

all the kids I don't know very well. 


$\begin{aligned} & \text { 11. I like to play not at all hardly sometimes } \\ & \text { sports. }\end{aligned}$
ever

12. I worry about

what other children say

not at all hardly sometimes

most of all the ever the time time about me.

13. I get nervous when I talk to not at all hardly sometimes most of all the new kids. ever the time time

14. I worry that other kids don't like me. not at all hardly sometimes most of all the the time time

15. I am quiet when I'm with group of kids. ever the time

\begin{tabular}{|c|c|c|c|c|c|}
\hline $\begin{array}{l}\text { 16. I like to play } \\
\text { by myself. }\end{array}$ & not at all & $\begin{array}{c}\text { hardly } \\
\text { ever }\end{array}$ & sometimes & $\begin{array}{l}\text { most of } \\
\text { the time }\end{array}$ & $\begin{array}{l}\text { all the } \\
\text { time }\end{array}$ \\
\hline $\begin{array}{l}\text { 17. I feel that kids } \\
\text { are making fun of } \\
\text { me. }\end{array}$ & not at all & $\begin{array}{l}\text { hardly } \\
\text { ever }\end{array}$ & sometimes & $\begin{array}{l}\text { most of } \\
\text { the time }\end{array}$ & $\begin{array}{l}\text { all the } \\
\text { time }\end{array}$ \\
\hline $\begin{array}{l}\text { 18. If I get into an } \\
\text { argument with } \\
\text { another kid, I } \\
\text { worry that he or } \\
\text { she won't like } \\
\text { me. }\end{array}$ & not at all & $\begin{array}{l}\text { hardly } \\
\text { ever }\end{array}$ & sometimes & $\begin{array}{l}\text { most of } \\
\text { the time }\end{array}$ & $\begin{array}{l}\text { all the } \\
\text { time }\end{array}$ \\
\hline
\end{tabular}

19. I'm afraid to invite others to my house because not at all hardly sometimes most of all the ever the time time they might say no.

20. I feel nervous when I'm around certain kids. not at all hardly sometimes most of the time time

21. I feel shy even with kids I not at all hardly sometimes most of all the 
22. It's hard for me to ask other kids to play with $\begin{array}{cccc}\text { not at all } & \text { sometimes } & \begin{array}{c}\text { most of } \\ \text { the time }\end{array} & \begin{array}{c}\text { all the } \\ \text { time }\end{array}\end{array}$ me.

Fear of Negative Evaluation (FNE) items: $3,5,8,9,12,14,17,18$

Social Avoidance and Distress-Specific to New Peers or Situations (SAD-New) items: 1, $4,6,10,13,20$

Generalized Social Avoidance and Distress (SAD-General) items: 15, 19, 21, 22

Filler items: 2, 7, 11, 16 
Classroom Perceptions

Appendix I

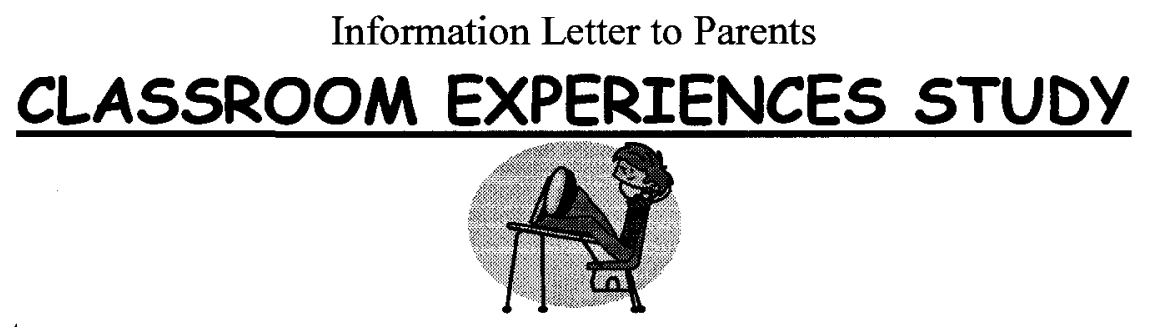

Dear Parents,

Last year we collected information from 350 students in your child's school as well as several other schools around Lethbridge. We asked students what they think about their experiences at school and in their classroom. If you participated last year, thank you for your time and assistance with our project! This year we are continuing our project and are writing to ask your permission for your child to participate in a continuing research study that is being conducted at your child's school. We would be happy to have children that participated last year, as well as new children who have not yet participated.

One of the most important aspects of children's school experiences is developing confidence through learning, and developing satisfying relationships with other children and with teachers. The purpose of this study is to better understand how children perceive these classroom experiences and how this may be related to how they feel at school and with their friends. We believe that this study is important because it will help us understand why some children enjoy being at school more than other children.

In this study children will be asked to complete questionnaires about their friendships, about how lonely they feel at school, and about how anxious they feel around their classmates. Also, children will be asked what they think about their classroom experiences, how 'liked' they feel they are by their peers, and if they ever feel victimized at school. We will be reading the questions to the kids in a group setting. It is important to us that this process is fun for the children! We will ensure that the children understand that they do not have to answer any questions that they don't want to.

This project has been approved by the Lethbridge School District 51 as well as Carleton University's Ethics Committee for Psychological Research. All information collected from this study is strictly confidential and will only be made available to the principal investigators. If you are interested, we would be happy to provide you with a summary of our findings once all of the data has been collected.

If you have any questions related to this study and/or concerns about your child as a result of participation in this study, please feel free to contact us directly at (613) 520-2600, ext. 1979. Should you have any ethical concerns about this study then please contact Dr. Avi Parush (Chair, Carleton University Ethics Committee for Psychological Research, (613) 520-2600, ext. 6026). If you have other concerns about this study, feel free to contact Dr. Robert Coplan (Professor, Department of Psychology, (613) 520-2600, ext. 8691) or Dr. Anne Bowker (Chair, Department of Psychology, (613) 520-2600, ext. 8218). If you 
would like to learn more about children's friendships and social adjustment at school, there are numerous websites on the topic (e.g., http://www.cfw.tufts.edu/).

Adrienne DeBow, M.Ed.

Ph.D. Candidate

Department of Psychology

Carleton University
Robert Coplan, Ph.D.

Professor

Department of Psychology

Carleton University 
Appendix $\mathbf{J}$

Extended Class Play

Now what we want you to do is pretend that you are a director of a play starring the students in this classroom. The director of a play has to do many things but the most important job is to select the right people to act in the play. So, your job is to choose the students who could play each part or role best. Try to pick the students who seem to fit each part in real life.

From the list below, choose 1 boy and 1 girl in your class who would be a good actor for each of the roles in the play. You may pick the same person in your class for more than one part in the play, but do not pick yourself for any of the roles.

\section{Roles in the Play}

1. Interrupts others

Boy:

Girl:

2. Very shy

Boy:

Girl:

3. Good ideas

Boy:

Girl:

4. Mean things said to them

Boy:

Girl:

5. Many friends

Boy:

Girl:

6. Loses temper easily

Boy:

Girl:

7. Talks quietly or rarely

Boy:

Girl:

8. Trustworthy

Boy:

Girl:

9. Fights

Boy:

Girl:

10. Waits for their turn

Boy:

Girl:

11. Feelings hurt easily

Boy:

Girl:

12. Trouble making friends

Boy:

Girl:

13. Plays fair

Boy:

Girl:

14. Rarely starts

Boy:

Girl: 
15. Everyone listens to Boy: Bo Girl:

16. Spreads rumors

Boy:

Girl:

17. Can't get others to listen

Boy:

Girl:

18. Gets picked on

Boy:

Girl:

19. Makes new friends

Boy:

Girl: easily

20. Too bossy

Boy:

Girl:

21. Often left out

Boy:

Girl:

22. Helps others

Boy:

Girl:

23. Usually sad

Boy:

Girl:

24. Everyone likes

Boy:

Girl:

25. Teases others

Boy:

Girl:

26. Hit or kicked by others

Boy:

Girl:

27. Likes to play with others

Boy:

Girl:

28. Nervous about class

Boy:

Girl:

29. Picks on others

Boy:

Girl:

30. Polite

Boy:

Girl: 
Appendix $\mathrm{K}$

Child Depression Inventory Short-Form

I am sad once in awhile

I am sad many times for me

I am sad all the time

I do most things O.K

I do many things wrong

I do everything wrong

I feel like crying everyday

I feel like crying many days

I feel like crying once in a while

I look O.K.

There are some bad things about my looks

I look ugly

I have plenty of friends

I have some friends but I wish I had more

I do not have any friends
Nothing will ever work out for me

I am not sure if things will work out

Things will work out for me O.K.

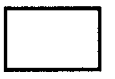

I hate myself

I do not like myself

I like myself

Things bother me all the time

Things bother me many times

Things bother me once in a while

I do not feel alone

I feel alone many times

I feel alone all the time

Nobody really loves me

I am not sure if anybody loves me

I am sure that somebody loves me 
Appendix L

School Liking and School Avoidance Scale

We are interested in how kids feel about school. For each of the questions below circle a "never", "hardly ever", "sometimes", "most of the time", or "all the time".

1. Is school fun? never hardly sometimes most all ever of the the time time

2. Does school make you feel like crying? never hardly sometimes most all ever of the the time time

3. Do you wish you didn't have to go to school?

never hardly sometimes ever most all scho

4. Are you happy when you're at school? never hardly sometimes ever of the the time time most all

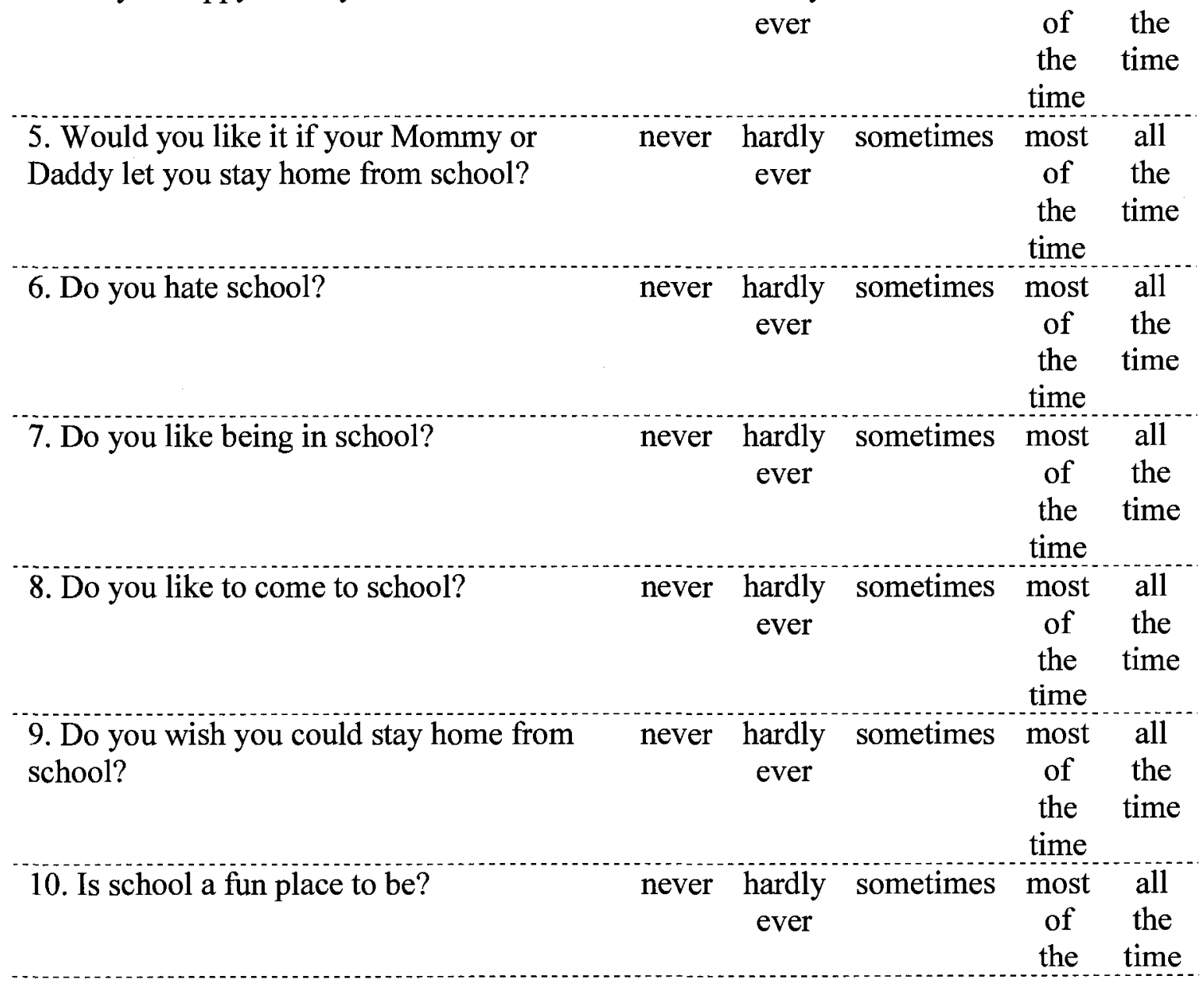




\begin{tabular}{|c|c|c|c|c|c|}
\hline & & & \multicolumn{3}{|c|}{ time } \\
\hline $\begin{array}{l}\text { 11. When you get up in the morning, do you } \\
\text { feel happy about going to school? }\end{array}$ & never & $\begin{array}{l}\text { hardly } \\
\text { ever }\end{array}$ & sometimes & $\begin{array}{l}\text { most } \\
\text { of } \\
\text { the } \\
\text { time }\end{array}$ & $\begin{array}{l}\text { all } \\
\text { the } \\
\text { time }\end{array}$ \\
\hline 12. Is school awful? & never & $\begin{array}{l}\text { hardly } \\
\text { ever }\end{array}$ & sometimes & $\begin{array}{l}\text { most } \\
\text { of } \\
\text { the } \\
\text { time }\end{array}$ & $\begin{array}{l}\text { all } \\
\text { the } \\
\text { time }\end{array}$ \\
\hline $\begin{array}{l}\text { 13. Do you feel happy when it's time to go } \\
\text { home from school? }\end{array}$ & never & $\begin{array}{l}\text { hardly } \\
\text { ever }\end{array}$ & sometimes & $\begin{array}{l}\text { most } \\
\text { of } \\
\text { the } \\
\text { time }\end{array}$ & $\begin{array}{c}\text { all } \\
\text { the } \\
\text { time }\end{array}$ \\
\hline $\begin{array}{l}\text { 14. Do you ask your Mommy or Daddy to } \\
\text { let you stay home from school? }\end{array}$ & never & $\begin{array}{l}\text { hardly } \\
\text { ever }\end{array}$ & sometimes & $\begin{array}{l}\text { most } \\
\text { of } \\
\text { the } \\
\text { time }\end{array}$ & $\begin{array}{l}\text { all } \\
\text { the } \\
\text { time }\end{array}$ \\
\hline
\end{tabular}

